\title{
Towards strategies to stimulate first time trial of unfamiliar healthful food products
}

Citation for published version (APA):

Schickenberg, B. A. (2010). Towards strategies to stimulate first time trial of unfamiliar healthful food products. [Doctoral Thesis, Maastricht University]. Universiteit Maastricht. https://doi.org/10.26481/dis.20101126bs

Document status and date:

Published: 01/01/2010

DOI:

10.26481/dis.20101126bs

Document Version:

Publisher's PDF, also known as Version of record

\section{Please check the document version of this publication:}

- A submitted manuscript is the version of the article upon submission and before peer-review. There can be important differences between the submitted version and the official published version of record.

People interested in the research are advised to contact the author for the final version of the publication, or visit the DOI to the publisher's website.

- The final author version and the galley proof are versions of the publication after peer review.

- The final published version features the final layout of the paper including the volume, issue and page numbers.

Link to publication

\footnotetext{
General rights rights.

- You may freely distribute the URL identifying the publication in the public portal. please follow below link for the End User Agreement:

www.umlib.nl/taverne-license

Take down policy

If you believe that this document breaches copyright please contact us at:

repository@maastrichtuniversity.nl

providing details and we will investigate your claim.
}

Copyright and moral rights for the publications made accessible in the public portal are retained by the authors and/or other copyright owners and it is a condition of accessing publications that users recognise and abide by the legal requirements associated with these

- Users may download and print one copy of any publication from the public portal for the purpose of private study or research.

- You may not further distribute the material or use it for any profit-making activity or commercial gain

If the publication is distributed under the terms of Article $25 \mathrm{fa}$ of the Dutch Copyright Act, indicated by the "Taverne" license above, 


\title{
Towards strategies to stimulate first time trial of unfamiliar healthful food products
}

\author{
Proefschrift \\ ter verkrijging van de graad van doctor \\ aan de Universiteit Maastricht, \\ op gezag van de Rector Magnificus, Prof. Mr. G.P.M.F. Mols, \\ volgens het besluit van het College van Decanen, \\ in het openbaar te verdedigen \\ op vrijdag 26 november 2010 om 14:00 uur \\ door
}

Bilbo Alexander Schickenberg 
The work presented in this thesis was performed at the NUTRIM School for Nutrition, Toxicology and Metabolism, funded by grant number 40050012 of ZonMw, the Netherlands Organization for Health Research and Development

Layout: Bilbo Schickenberg

Cover: Bilbo Schickenberg

Printed by: Ipskamp Drukkers, Enschede

Copyright Bilbo Schickenberg, 2010. All rights reserved. No part of this thesis may be reproduced or transmitted in any form or by any means, electronic or mechanical, including photocopying, recording, or any information storage or retrieval system without permission in writing from the author, or, when appropriate, from the publishers of the publications. 


\section{Promotores:}

Prof. dr. N.K. de Vries

Prof. dr. ir. J. Brug (EMGO instituut VU Medisch Centrum)
Copromotor:
Dr. P. van Assema

Beoordelingscommissie:

Prof. dr. H. de Vries (voorzitter)

Prof. dr. F. Brouns

Prof. dr. G. J. Kok

Prof. dr. L. Lechner (Open Universiteit Nederland)

Dr. I.H.M. Steenhuis (Vrije Universiteit Amsterdam) 



\section{Content}

CHAPTER 1:

INTRODUCTION

CHAPTER 2:

REPLACING FOODS HIGH IN SATURATED FAT BY LOW

SATURATED FAT ALTERNATIVES - A COMPUTER

SIMULATION OF THE POTENTIAL EFFECTS ON REDUCTION OF SATURATED FAT CONSUMPTION

CHAPTER 3:

A QUALITATIVE STUDY OF FACTORS ASSOCIATED WITH FIRST TIME TRIAL OF UNFAMILIAR HEALTHFUL FOODS

CHAPTER 4:

ARE THE DUTCH ACQUAINTED WITH AND WILLING TO TRY HEALTHFUL FOOD PRODUCTS: THE ROLE OF FOOD NEOPHOBIA

CHAPTER 5:

INFORMATION ABOUT THE TASTE STIMULATES CHOICE OF UNFAMILIAR HEALTHFUL FOOD PRODUCTS

CHAPTER 6:

PRODUCT SAMPLES STIMULATE CHOICE OF UNFAMILIAR HEALTHFUL FOOD PRODUCTS

CHAPTER 7:

$\begin{array}{ll}\text { GENERAL DISCUSSION } & 105\end{array}$

$\begin{array}{ll}\text { REFERENCES } & 117\end{array}$

$\begin{array}{ll}\text { SUMMARY } & 127\end{array}$

$\begin{array}{ll}\text { SAMENVATTING } & 131\end{array}$

$\begin{array}{ll}\text { ZUSAMMENFASSUNG } & 135\end{array}$

$\begin{array}{ll}\text { CURRICULUM VITAE } & 139\end{array}$

$\begin{array}{ll}\text { DANKWOORD } & 141\end{array}$ 
Chapter 1:

Introduction 
The goal of the research project described in this thesis was to gain insight into what may encourage people to try unfamiliar food products that may contribute to a more healthful diet. Ultimately, the research aims to contribute to the development of strategies to promote more healthful eating, especially a lower intake of saturated fat and an increase in fruit and vegetables (F\&V) consumption. The project consisted of five different studies. This introductory chapter describes the rationale for the project and provides short descriptions of the five studies.

Earlier studies have indicated that nutrition is important for the prevention of chronic diseases. For example, high serum cholesterol levels, and especially elevated Low-Density Lipoprotein (LDL) cholesterol and low levels of High-Density Lipoprotein (HDL) cholesterol, are associated with an increased risk of cardiovascular diseases (World Health Organization, 2003). The consumption of saturated fatty acids contributes to a higher level of LDL cholesterol (Clarke, Frost, Collins, Appleby, \& Peto, 1997; Howell, McNamara, Tosca, Smith, \& Gaines, 1997; Mensink \& Katan, 1992). In contrast, higher intakes of unsaturated fatty acids are associated with higher levels of HDL cholesterol, and with lower risk of coronary heart diseases (Gordon, Castelli, Hjortland, Kannel, \& Dawber, 1977). Furthermore, through the energy density of high-fat foods the consumption of (saturated) fat contributes to an increased risk of higher body weight and thus of overweight and obesity. Obesity is an independent risk factor for a wide range of diseases including type 2 diabetes, several forms of cancer and respiratory problems (Haslam \& James, 2005).

Consumption of ample amounts of fresh $F \& V$ has been shown to have various positive effects on health. It is still inconclusive exactly which nutrients in $F \& V$ are responsible for these protective effects. Over the last ten years a change has taken place in the judgement of the protective effects of the consumption of $F \& V$ against various forms of cancer. First these effects were judged to be convincing (Riboli \& Norat, 2003; World Cancer Research Fund, 1997); results of more recent cohort studies have lead to a reconsideration judging them to be probable (World Cancer Research Fund, 2007). There is a convincing protective effect of the consumption of $F \& V$ on the risk for cardiovascular diseases (World Health Organization, 2003).

The current understanding of the relation between nutrition and health has led most countries and organisations such as the World Health Organization to issuing dietary guidelines, in which it is recommended to decrease the intake of saturated fat and 
increase the intake of $F \& V$ products. In the Netherlands, currently a maximum daily intake of saturated fat of not more than $10 \%$ of total energy intake (en\%) is recommended for adults with a normal and stable weight and it is recommended to consume at least two servings of fruit ${ }^{1}$ and 150-200 $\mathrm{g}$ of vegetables per day (Health Council of the Netherlands, 2006).

To study the degree to which the Dutch comply with these recommendations five national food consumption studies, assessing the participants' daily food intakes, have been conducted between 1987 and 2006 (Hulshof et al., 2004; Ministerie van Welzijn Volksgezondheid en Cultuur en het Ministerie van Landbouw en Visserij, 1988; Ocké et al., 2008; Voedingscentrum, 1998; Voorlichtingsbureau voor de Voeding, 1993). In these national surveys the mean intake of total fat, saturated fat and trans fat has been shown to decrease; e.g. saturated fat intake went down from 14.8 en $\%$ in 1987 to 12.1 en\% in 2003 (Hulshof et al., 2004; Ministerie van Welzijn Volksgezondheid en Cultuur en het Ministerie van Landbouw en Visserij, 1988). Regarding the consumption of F\&V an unfavourable trend has been observed. Mean intake of vegetables dropped from 151 $\mathrm{g}$ per day in 1987 to $100 \mathrm{~g}$ in 2003; mean consumption of fruit dropped from $130 \mathrm{~g}$ in 1987 to $98 \mathrm{~g}$ in 2003 (Hulshof et al., 2004; Ministerie van Welzijn Volksgezondheid en Cultuur en het Ministerie van Landbouw en Visserij, 1988). The diet of most Dutch is thereby not in agreement with dietary recommendations regarding the consumption of $\mathrm{F} \& \mathrm{~V}$ and saturated fat (Hulshof et al., 2004). The most recent national food consumption survey among young adults in 2003 showed that only $6 \%$ of female and $11 \%$ of male participants consumed saturated fat at or below the recommended level (Hulshof et al., 2004). Only 4.1\% (4.7\% of males and 3.4\% of females) of the participants met the recommendation to eat at least 2 'pieces' of fruit including fruit juice (200-300 g) and $200 \mathrm{~g}$ of vegetables a day (Hulshof et al., 2004).

In a study issued by the Netherlands National Institute for Public Health and the Environment, based on the food consumption data from 2003, it was estimated that about 1000 deaths of coronary heart diseases per year are directly attributable to the overconsumption of saturated fats. An additional 5500 deaths per year through coronary heart diseases were attributed to the deficient consumption of fruit (3500) and

\footnotetext{
${ }^{1}$ One serving of fruit equals about $100-150 \mathrm{~g}$ of fruit.
} 
vegetables (2000). The report further gives an indication that about 2000 cancer deaths per year are attributable to the low consumption of fruits (ca. 1500) and vegetables (ca. 700) (RIVM, 2004). So, changing consumption of both saturated fat and F\&V to the recommended levels is expected to yield substantial health benefits (Ammerman, Lindquist, Lohr, \& Hersey, 2002; Hooper et al., 2001; Hulshof et al., 2004; Mokdad et al., 2001)

To explore ways to reach the recommended levels of intake of saturated fat, in this thesis we focussed on product groups that highly contribute to the consumption of saturated fat in the Dutch diet. The product groups of dairy products (including cheese), meat and meat products, fats, and bakery goods (including biscuits) were identified to strongly contribute to the consumption of saturated fat (Hulshof et al., 2004). In the last decades, the food industry has introduced alternative food products with reduced fat contents in all these product groups, e.g. low-fat milk, lean cheese, meat substitutes, and 'diet' margarine. Alternatives for fresh F\&V have also been introduced, such as juices with pulp or chunks. These products are offered in a ready to consume state which might be more easily accepted than fresh $F \& V$ due to improved convenience (Pollard, Kirk, \& Cade, 2002).

The basic idea of the project was that significant reductions in the intake of saturated fat might be achieved by stimulating people to replace some traditional products by healthful alternative food products low in saturated fat, and that significant increases in the intake of $\mathrm{F} \& \mathrm{~V}$ might be achieved by stimulating additional consumption of alternative $F \& V$ products. Some earlier studies found that replacement of high-fat products by low-fat products resulted in a considerable reduction in total fat intake (Gatenby, Aaron, Jack, \& Mela, 1997; Gatenby, Aaron, Morton, \& Mela, 1995; Kistemaker, 1991), even if only a limited number of products was replaced (Morgan et al., 1997). To our knowledge no earlier studies were conducted focussing on the addition of convenient alternatives for $F \& V$ products with the aim of increasing the intake of $F \& V$.

The first aim of the research project was to determine whether the replacement of a small number of traditional products by healthful alternatives might theoretically result in significant reductions in saturated fat intake in the Dutch diet. A simulation study was conducted using the data of 750 participants from the Dutch national food consumption survey of 2003. For each participant, those three products that 
contributed most to their saturated fat intake were sequentially 'replaced' by lower saturated fat alternatives available in Dutch supermarkets. Mean en $\%$ from saturated fat and energy intake in $\mathrm{kJ}$ per day were calculated before and after each of the three simulated replacements. The simulation study is reported in Chapter two.

Although availability of healthful alternatives has increased, most consumers do not include these products in their daily diet in real life yet. In the process of integrating new food products in the (daily) diet, first time trial of a previously unfamiliar taste or product is crucial. Many studies have indicated that a product's taste is one of the most important determinants of product acceptance (Rozin, 1988). If the taste is disliked, and certainly if the product is considered awful or nauseating, food aversion is likely to develop. A single trial of a food product can then be sufficient for not wanting to consume the product (ever) again in the future. The speed with which such an aversion is developed can be explained by its evolutionary function of preventing consumption of harmful foods (Capaldi, 1996; Shepherd \& Raats, 2006). A single trial of a food product followed by a positive evaluation of the taste, however, is not enough to develop a preference for that specific food product or taste, although it has been shown that liking for a taste is likely to increase with repeated exposure to that taste and, eventually, a preference for that taste might develop (Capaldi, 1996). Preferred foods are more likely to be integrated in the daily diet.

So, individuals can learn to like unfamiliar foods, starting with first time trial of such foods. But how can we stimulate people to try unfamiliar products for a first time? To answer this question we need to know what influences the decision of people to try such products. The second aim of the research project was to identify factors that are related to first time trial of healthful alternative products. Earlier research has not specifically addressed this. First, a preliminary conceptual model was developed by reviewing the literature in related research fields, i.e. taste research, marketing research, research into novel foods, and research into determinants of food choice in general. The preliminary model includes three main components that were expected to determine whether or not people will try an unfamiliar product.

The first component consists of product-related variables, such as retail price, bestby date, brand, product taste, degree of convenience, sensory appeal, colour and quality in general, ingredients and similarity to familiar products (Capaldi, 1996; Grunert, 2006; Hill, Knox, Hamilton, Parr, \& Stringer, 2002; Martins \& Pliner, 1998; Steptoe, Pollard, 
\& Wardle, 1995). The second component includes person-related variables in food choice, such as the personality trait of food neophobia (defined as "the avoidance of or reluctance to ingest novel foods" (Birch \& Marlin, 1982), subjective norms and attitudes, recall of previous experiences, the tendency to comply with other peoples' food choices, taste preferences and previous experiences with unfamiliar foods (Birch, 1999; Birch \& Fisher, 1996; Birch \& Marlin, 1982; Contento, 2007; Hobden \& Pliner, 1995). Finally, the third component includes situation-related variables, such as the effort needed to obtain food, direct or indirect influence of others, e.g. the presence of others acting as role models for trying unfamiliar foods, the influence of different contexts and time (of day) in which food choices have to be made, the attractiveness and safety of the food choice environment, previous exposure to marketing activities for the new foods, previous forced exposure to unfamiliar foods, and mood (Meiselman, 2006; Meiselman, Johnson, Reeve, \& Crouch, 2000; Pliner, Eng, \& Krishnan, 1995; Pliner, Pelchat, \& Grabski, 1993; Steptoe, Pollard, \& Wardle, 1995). Using the preliminary model, a focus group study was conducted to assess which person-, product-, and situation-related factors Dutch consumers think might be related to their decision to try an unfamiliar healthful (low-fat or F\&V) product for the first time. The focus group study is reported in Chapter 3.

As mentioned above, one of the factors assumed to determine first time trial of healthful alternatives is the personality trait of food neophobia. Food neophobia has been explained in the context of the omnivore dilemma (Rozin, 1984). This dilemma, between needing a balanced and varied diet on the one hand, and being concerned about safety of foods on the other hand, is described as an evolutionary mechanism of survival, since unfamiliar foods could negatively influence one's health after consumption. For ethnical foods (food products that are known in other cultures than one's own) the trait has been identified to determine one's willingness to try such products. Persons high in food neophobia were found to be more reluctant to try these novel foods, compared to low neophobics (Arvola, Lähteenmäki, \& Tuorila, 1999; Hobden \& Pliner, 1995; Hursti \& Sjödén, 1997; Pliner, Eng, \& Krishnan, 1995; Pliner \& Hobden, 1992; Raudenbush \& Frank, 1999; Raudenbush, Schroth, Reilley, \& Frank, 1998; Tuorila, Lähteenmäki, Pohjalainen, \& Lotti, 2001; Tuorila, Meiselman, Bell, Cardello, \& Johnson, 1994). We expected healthful low-fat and F\&V alternatives to appear as less novel than the ethnical food products used in the previously mentioned 
studies. Nevertheless, as such healthful alternative products are still unfamiliar it is likely that one's level of food neophobia is related to one's willingness to try healthful alternative products for a first time. The third aim of the project was to assess the influence of food neophobia on people's acquaintance with and willingness to try healthful alternative food products, and to assess possible differences among subgroups. Furthermore, we aimed to assess the reliability of an adapted Dutch version of a ten-item food neophobia scale (Pliner \& Hobden, 1992). A cross-sectional study was conducted using a web-based questionnaire, including a retest of the food neophobia scale one week later. Additional measures included acquaintance with and willingness to try fifteen healthful food alternatives, level of education, gender and age. The results of this study are reported in Chapter 4.

The fourth aim of the project was to use the results of the first three studies within this project to develop strategies that stimulate people to try healthful alternative products for a first time, and to assess the effectiveness of the strategies. All strategies were designed to be tested in a restaurant setting where participants were asked to make actual food choices from a lunch buffet with the intention to consume the products offered. We strived to create a testing situation that closely mimicked a natural food choice environment. Per participant one out of four different healthful alternatives products was offered alongside their respective traditional counterparts. Participants had to choose either the traditional product or the healthful alternative. In one condition, a lean alternative for cheese was presented next to a full fat cheese popular in the Dutch diet. The other three healthful alternative products were a lean bread spread as an alternative for butter or margarine products, and either a fruit juice or a $F \& V$ juice as more convenient alternatives for fresh $\mathrm{F} \& \mathrm{~V}$.

Five strategies were developed, including all materials and protocols needed for conducting experimental studies on the effectiveness of those strategies. The first strategy resulted from the finding that participants were only willing to try a healthful alternative product if they had access to information about the taste of that unfamiliar product, and if they think that they would like the product's taste. The strategy consisted of an information poster providing taste information and information about the mouthfeel of the offered healthful alternative. Furthermore, a comparison was made between the taste of the offered healthful alternative and a generally familiar product which was expected to be liked by participants. 
The second strategy was based on the result that participants indicated to be unwilling to take risks with trying a healthful alternative product. Participants specifically indicated not to be willing to pay too much for a product which they perhaps do not like, or to have to buy or choose an unfamiliar product in a large quantity. The strategy was to provide participants with the possibility to try a small biteor sip-sized quantity of a healthful alternative product prior to having to make a choice between the offered healthful alternative and its traditional counterpart.

Participants indicated to be more willing to try a healthful alternative product if they were previously familiarized with the product by having been exposed to the product through an advertisement or otherwise having heard of the product. The resulting third strategy was to expose future participants one week prior to their participation in the experimental study to a print advertisement in which the healthful alternative product was pictured and its name was given.

The fourth strategy resulted from the finding that participants' reluctance to try an unfamiliar food product may decrease if they were somehow tricked or 'forced' to try an unfamiliar food product, e.g. by circumstances in which avoidance of the food was not possible or appropriate, and that exposure was not followed by negative consequences. The strategy was to ask participants prior to their participation in the experimental study to sample a small quantity of another new food product and to evaluate that product's taste.

The fifth strategy resulted from the finding that participants' willingness to ingest unfamiliar foods increased after observing others doing the same, without experiencing negative consequences. The strategy was to let a confederate of the experimenter choose the healthful alternative first in the presence of the participant and to openly express his/her enthusiasm for this product.

Due to problems with recruiting the necessary number of participants only the first and second strategy were tested in two experimental studies. Chapter 5 describes an experimental study to assess the effectiveness of taste information in stimulating people to choose the healthful alternative. Chapter 6 describes an experimental study about the effectiveness of offering a bite/sip-sized sample of the healthful alternatives. Both studies were conducted among participants aged 18-25, using a 2 (condition) by 4 (product) between subjects design with a pre- and post-experiment questionnaire. 
Chapter 7 includes an integrated discussion of the results of the five studies, a detailed description of study limitations and their implications, and concluding recommendations for healthy diet promotion practice and further research. 


\section{Chapter 2:}

\section{Replacing foods high in saturated fat by low saturated fat alternatives - A computer simulation of the potential effects on reduction of saturated fat consumption}

Published as:

Schickenberg, B., van Assema, P., Verkaik-Kloosterman, J., Ocké, M. C., Brug, J., \& de Vries, N. K. (2009). Replacing foods high in saturated fat by low saturated fat alternatives - A computer simulation of the potential effects on reduction of saturated fat consumption. British Journal of Nutrition, 102, 478-483. 


\begin{abstract}
This simulation study aimed to assess the change in saturated fat intake achieved by replacing one to three of the products contributing most to individual saturated fat intake by alternative products low in saturated fat. Food consumption data of 750 participants (aged 19-30 years) from a recent Dutch food consumption survey were used. For each participant, the three products (from different product groups) were ranked in order of diminishing contribution to their saturated fat intake. These products were sequentially replaced by lower saturated fat alternatives that were available in Dutch supermarkets. Mean percentage energy (en\%) from saturated fat and energy intake in $\mathrm{kJ}$ per day were calculated before and after each of the three replacements. Dutch cheese, meat (for dinner) and milk were the main contributors to saturated fat intake for most participants. Starting at a mean en $\%$ from saturated fat of 12.4 , the three replacements together resulted in a mean reduction of $4.9 \mathrm{en} \%$ from saturated fat. The percentage of participants meeting the recommendation for saturated fat $(<10$ en $\%)$ increased from $23.3 \%$ to $86.0 \%$. We conclude that the replacement of relatively few important highsaturated fat products by available lower-saturated fat alternatives can significantly reduce saturated fat intake and increase the proportion of individuals complying with recommended intake levels.
\end{abstract}




\section{Introduction}

In many countries, including the Netherlands, dietary recommendations for the public have been issued. The recommendations focus on the intake of various nutrients (i.e. fibre, saturated fatty acids, mono trans-fatty acids easily fermentable sugars, salt) and foods (i.e. fruit, vegetables, whole-grain cereal products, fish) (Health Council of the Netherlands, 2006). The most recent Dutch food consumption survey among young adults (19-30 years) indicated that it is particularly the intake of saturated fats that is higher than recommended (Hulshof et al., 2004). Whereas the guidelines recommend the consumption of less than $10 \%$ of total energy intake (en $\%$ ) from saturated fat (Health Council of the Netherlands, 2006), the usual intake of no more than an estimated $6 \%$ of the female and $11 \%$ of male participants met this recommendation in 2003 (Hulshof et al., 2004).

High intake of saturated fat has been linked to increased risk of cardiovascular diseases (World Health Organization, 2003), and reducing consumption of saturated fat intake to the recommended levels is expected to yield substantial health benefits (RIVM, 2006; World Health Organization, 2003).

Several product groups are responsible for a high intake of saturated fat in the daily diet of the Dutch population. These product groups include dairy products (including cheese), meat and meat products, fats, bakery goods and biscuits, grain and grain products, sweets, and sauces (Hulshof et al., 2004). In the last few decades, the food industry has introduced alternative food products with reduced (saturated) fat contents for virtually every product group, for example, low-fat milk, lean cheese, meat substitutes, and 'diet' margarine. Because nutrition is a complex behaviour, individuals might think that it would take great effort for them to meet the dietary recommendations. Morgan et al., however, suggest that the replacement of only a limited number of products might already result in a considerable change in macronutrient intake (Morgan et al., 1997). The aim of the present study was therefore to assess the change in intake of saturated fat that can theoretically be achieved by replacing one to three of the products that contribute most to an individual's saturated fat intake by food products that contain less saturated fat available on the Dutch food market. 
In a simulation study by Kistemaker using data from the 1987-8 Dutch national food consumption survey, high-fat products (cheese, milk, meat, and fat spreads) were substituted by lean alternatives (Kistemaker, 1991). Simultaneous total replacement in all four product groups led to a mean reduction of $11.7 \mathrm{en} \%$ from fat in their population. Using data of men aged 22-49 year from the same dataset, Kistemaker et al. (1991) also compared the percentage energy intake from fat in men solely using lean products within a product group and in users of higher-fat products within the same product group (Kistemaker, Löwik, Wedel, \& Hulshof, 1991). Solely using lean products in a specific product group was associated with a higher en $\%$ from fat from other product groups. However, despite this compensation behaviour, the use of lean products caused an overall reduction in energy intake from fat. Morgan et al. analysed the theoretical effect of fat reduction strategies within single and across multiple product groups on the macronutrient profile of a typical American diet (Morgan et al., 1997). Based on Third National Health and Nutrition Examination Survey (NHANESIII) data, three-day menus were created for both men and women, designed to fit the parameters of total energy consumption and en $\%$ from fat (34 en $\%$ for both). While mean total energy content of the meals was left unchanged, replacement of more products and more extreme replacements (e.g. fat-free replacement for full-fat products) resulted in greater reductions in intake of en $\%$ from fat. In a small field experiment conducted in the UK, participants in the experimental group were instructed to consume reduced-fat foods ad libitum instead of the traditionally high-fat counterparts they usually consumed, whereas controls were given no special instructions. The unrestricted use of reduced-fat products resulted in a reduction of fat intake to the recommended levels. Total energy intake did not differ significantly between the two groups due to compensation of energy intake from other macronutrients (carbohydrates and protein) (Gatenby, Aaron, Morton, \& Mela, 1995). The $1 \%$ or less campaign in the USA aimed to reduce the total and saturated fat consumption of communities by encouraging adults and children to switch from drinking whole or $2 \%$ milk to $1 \%$ or skimmed milk. The basic idea is that if the average whole-milk drinker switches to skimmed milk, his/her saturated fat intake drops from 12 to $10 \mathrm{en} \%$. The percentage of participants reporting switching from high- to low-fat milk ranged from 13-38\% in four different communities (Wootan, Reger-Nash, BoothButterfield, \& Cooper, 2005). Finally, a Dutch field experiment found that participants 
who had the opportunity to choose ad libitum from fourty-four reduced-fat foods for a period of 6 month significantly reduced their total fat intake as compared to participants who chose from fourty-four full-fat products (Weststrate et al., 1998).

In contrast to these earlier studies, the present study focused on reducing the intake of saturated fat instead of total fat recognising that total en $\%$ from fat is a less important public health target. Furthermore, only the three highest suppliers of saturated fat intake for each individual are replaced, while earlier studies either simulated replacement of all consumed products within one or more product groups (Kistemaker, 1991; Kistemaker, Löwik, Wedel, \& Hulshof, 1991; Morgan et al., 1997), or offered participants ad libitum use reduced-fat products (Gatenby, Aaron, Morton, \& Mela, 1995; Weststrate et al., 1998) without reporting the number of products participants actually replaced in their diet.

The specific research questions of the present study were:

1. What reduction in en $\%$ saturated fat can theoretically be achieved by the replacement of up to three products from three different product groups in individuals' diets by alternatives with lower levels of saturated fatty acids?

2. What percentage of participants meets the recommendation for saturated fat intake after these replacements?

3. What is the effect of the replacements on total energy intake?

\section{Methods}

\section{Sample, design and procedure}

Data of the 2003 Dutch food consumption survey among young adults were used (Hulshof et al., 2004). Participants, aged 19-30 years, were members of consumer panels. Response was $42 \%$. The participants were considered representative of Dutch young adults in terms of sex, age, level of education, and region of residence. Food consumption data were collected by trained dieticians using two $24 \mathrm{~h}$ dietary recalls, using a computer-assisted interview created with EPIC-SOFT software (IARC, Lyon, France) (Slimani et al., 1999). The period to which the questions referred was from getting up the day before the interview until getting up the day of the interview. A 7-14 day time interval was set between the first and the second interview. The second 
interview was conducted on a different day of the week than the first. Participants were also asked to fill in a questionnaire on their demographics and other background variables.

The mean quantities (over the two recall days) of all products consumed were calculated for each participant. Information on energy $(\mathrm{kJ})$ and saturated fat $(\mathrm{g})$ content per $100 \mathrm{~g}$ of each product was based on the 2001 Netherlands food composition table (NEVO-Table, 2001). This information was used to calculate energy and macronutrient intakes for each participant.

\section{Defining of product groups}

All products consumed were classified into product groups, each of which was defined as a set of products that are comparable in several respects, such as form and function, including aspects on when (time of day) and how (preparation) a product is supposed to be used (for example meat for main course or as cold cuts for sandwiches). The classification of products into product groups was based for the most part on the classification of products in the 2001 Dutch food composition table (NEVO-Table, 2001). If products within one product group differed too much from each other, making it impossible to replace these products by one single alternative product, subgroups were defined. For example, instead of replacing all consumed cheeses by a single alternative product, the cheeses were subdivided into four subgroups (Dutch hard cheeses, Dutch soft cheeses, non-Dutch hard and non-Dutch soft cheeses) and a healthful alternative was selected for each of those subgroups. Other subgroups were formed in the product groups of meats, pastry goods, milk and milk products, nuts and snacks, soup, candy, and fats (Table 2.1).

\section{Selection of healthful alternatives}

One single healthful alternative was selected for each product group. The selection of healthful alternatives aimed to include food products that resemble the products originally consumed as closely as possible in appearance and function. Alternatives had to contain less saturated fat than the traditionally consumed products and had to be available in Dutch supermarkets at the time of the study. If multiple alternatives were available for a product group, the product with the lowest saturated fat content per 100 
g product was chosen. Suitability of the selected healthful alternatives to represent the products in each product group given was evaluated by the authors. Information on saturated fat $(\mathrm{g})$ and energy $(\mathrm{kJ})$ per $100 \mathrm{~g}$ of all alternative products was included in the data file. Whenever available, the product information was acquired from the 2001 Dutch food composition table. Information on the nutrient composition of alternatives not included in the 2001 table were retrieved from the 2006 table, nutrition label information on the packages, or directly from the producers (NEVO-Table, 2001, 2006). For the product group of chocolate, no suitable alternative product was available that featured lower levels of saturated fat, without differing in other product characteristics and purpose. Therefore, we selected an alternative product that offered the same volume but less weight per portion. All alternative products that we selected are listed in Table 2.1.

\section{Data analysis}

We started by calculating the mean intake of saturated fat from each product consumed for each participant, by multiplying the amount consumed by the saturated fat content of the product $(\mathrm{g} / 100 \mathrm{~g})$. The three products that contributed most to the intake of saturated fat were ranked in order of diminishing contribution for each participant. If more than one of those three products belonged to the same product group, the least consumed product was removed and replaced by the next product in line, until three products belonging to different product groups were left. This procedure was chosen for to prevent replacement of multiple products by one single alternative product, which would reduce food variety. In eighty-nine cases it turned out to be necessary to shift to the next-highest supplier of saturated fat.

The three products were consecutively replaced by their corresponding alternative products. Mean en $\%$ from saturated fat and total energy intake $(\mathrm{kJ})$ per day, as well as the percentage of participants meeting the recommendation for saturated fat intake were calculated before and after each additional replacement.

For all but one product group, replacement was based on the quantity of product originally consumed, i.e. the consumed amount (in $\mathrm{g}$ ) of the original product consumed was replaced by exactly the same amount of the alternative product. For the product group of chocolate, however, replacement was based on standard product portion. 
The difference in fat content between the original products and the alternative was assessed by computing mean saturated fat content per $100 \mathrm{~g}$ for each product group. Data were analysed using the SPSS 13.0 statistical package (SPSS Inc., Chicago, IL, USA).

\section{Results}

\section{Response and sample characteristics}

The 2003 Dutch food consumption survey was conducted among 750 (response rate $42 \%$ ) participants aged 19-30 (mean 25.0; SD 3.6); 53.1\% were females. Of the participants $24.7 \%$ had a low level of education (none, primary school or lower vocational school), 46.7\% a medium level (senior secondary vocational school or university preparatory education) and $28.7 \%$ a high level (higher professional education or university degree). The sample characteristics and results of the survey have been thoroughly described elsewhere (Hulshof et al., 2004).

\section{Products, product groups and alternatives low in saturated fat}

A total of 231 different products were identified to be in the participants' top-three suppliers of saturated fat. Sixteen of the top-three products were omitted from the analysis. In seven cases, this was because no suitable alternative was found: eggs (4 participants), coconut bread (2 participants), bread (16 participants), pancakes (4 participants), muesli (2 participants), prawn crackers ( 2 participants), and bread/pizza dough (6 participants).

In another nine cases: i.e. coconut, porridge, oatmeal, buttermilk, semolina, drinking breakfast, chocolate (truffles), chicken nuggets and granola bars, the reason for omitting them was a combination of two factors. On the one hand, their distinctive taste or product properties made it impossible to include these products in other, existing, product groups. On the other hand, each of these products was included only in a single participants' top-three suppliers of saturated fat.

The omitted products were part of the top-three ranking of forty-five participants. The remaining products were divided into forty product groups, with a single alternative for each group (Table 2.1). 
A total of $42.0 \%$ of all replacements that we implemented related to the product groups of Dutch cheese, meats, and milks (Table 2.1). For most product groups, including the three most frequently replaced groups, alternatives were found that differed substantially in saturated fat content. In other, less frequently replaced product groups, for example whipped cream, the difference between the weighted mean saturated fat content of the originally consumed products and the saturated fat content of the alternative was less substantial (Table 2.1). 


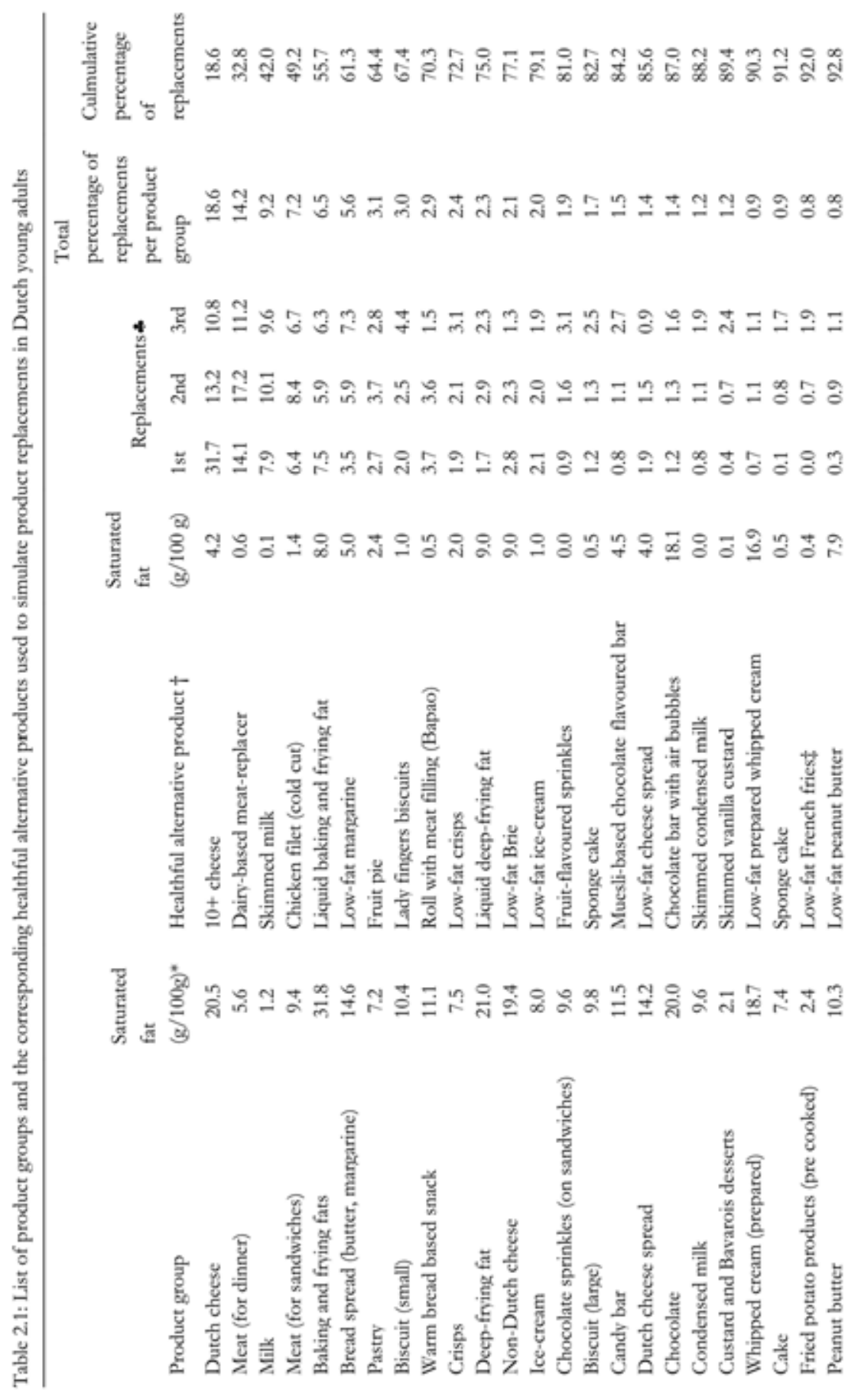




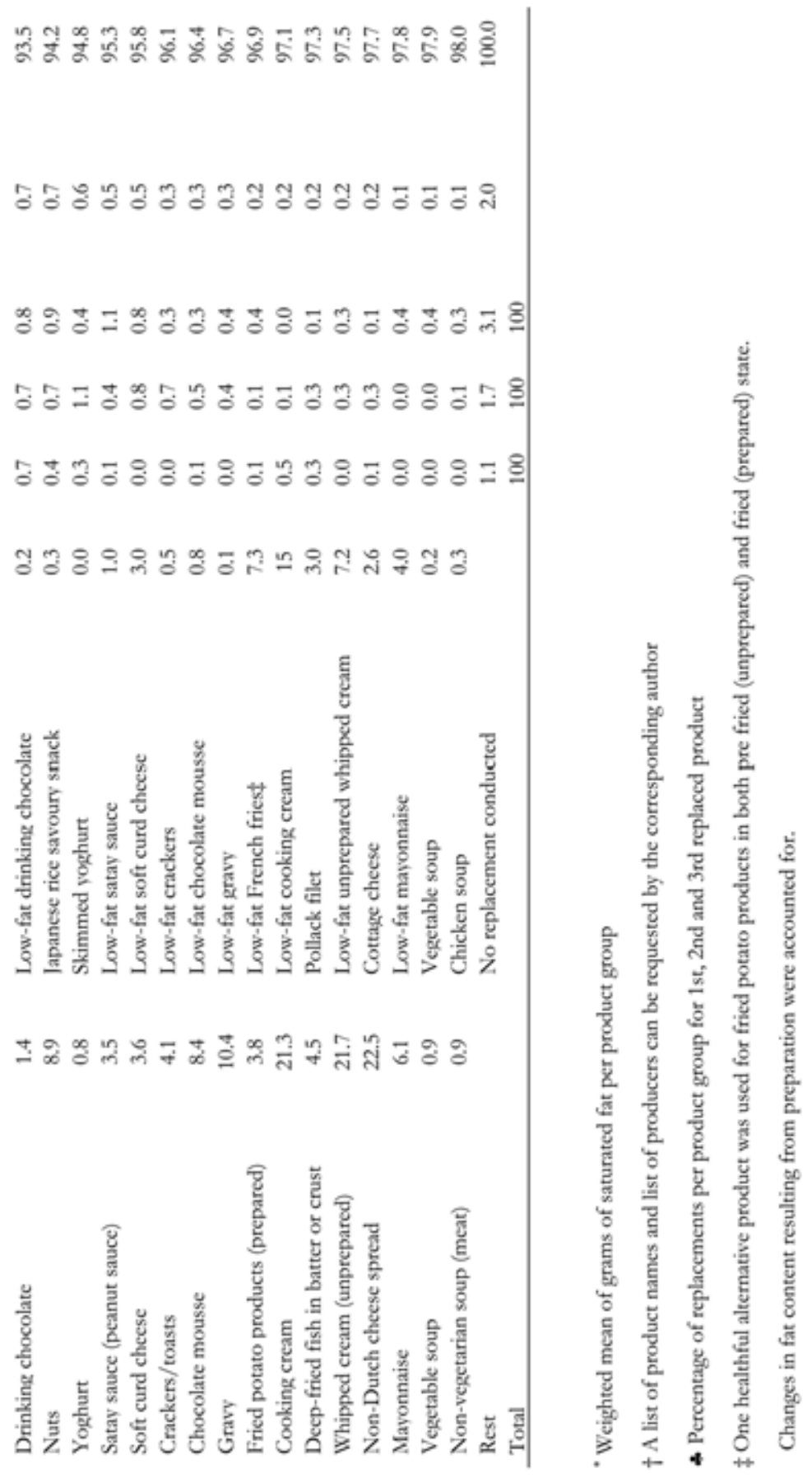




\section{Results of replacement}

Table 2.2 shows that $23.3 \%$ of the participants already met the recommended level of saturated fat intake of less than $10 \mathrm{en} \%$ on the two recalled days. Replacement of only the highest ranked product resulted in a mean reduction of $2.4 \mathrm{en} \%$ from saturated fat and in an additional $27.3 \%$ of the participants meeting the recommendation regarding saturated fat. The second replacement resulted in an additional mean reduction of 1.5 en $\%$ from saturated fat and an additional $21.8 \%$ of the participants meeting the recommendations. The third replacement resulted in an average additional reduction of $1.1 \mathrm{en} \%$ from saturated fat and in an additional $13.0 \%$ of the participants meeting the recommendations.

The three product replacements together resulted in a mean reduction of $13.4 \mathrm{~g}$ saturated fat or $5.0 \mathrm{en} \%$ from saturated fat and in an additional $63.2 \%$ of the participants meeting the recommendation $(<10 \mathrm{en} \%$ from saturated fat), bringing the total percentage of participants meeting the recommendation in this simulation to $86 \%$.

The intake of total energy was on average reduced by $156 \mathrm{~kJ}$ after the first replacement, while the replacement of the second highest ranked supplier of saturated fat yielded a mean reduction of $76 \mathrm{~kJ}$ and the replacement of the third highest supplier yielded an additional reduction of $78 \mathrm{~kJ}$. In sum, the mean reduction in total energy intake after all three replacements was $310 \mathrm{~kJ}$. 


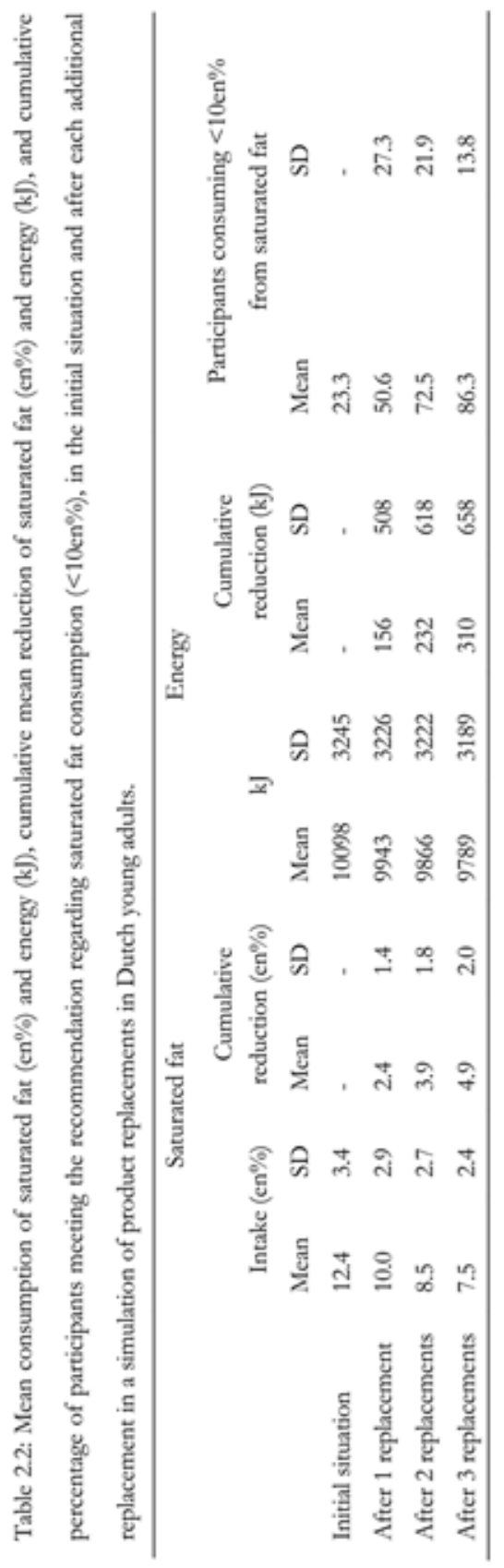




\section{Discussion}

The present study simulated the replacement by alternatives of up to three products contributing most to saturated fat intake in the daily diet, and assessed the effect of this strategy on the intake of saturated fat and total energy. Results showed that even one replacement (only the product ranked first in the list of suppliers of saturated fats) led to a considerable decline in saturated fat intake. After replacement of three products, the percentage of participants that met the saturated fat recommendation inclined from $23.3 \%$ to a vast majority of $86 \%$. (The reported percentage of participants meeting the recommendation of saturated fat intake deviates from data from the original report on the Dutch food consumption survey (1), because that report estimated usual population intake distribution by correction for within-individual variation.) These effects are very large, and would have a substantial public health impact. They might, for instance, contribute to lower serum cholesterol levels and to a lesser degree also to lower obesity rates, due to a reduced total energy intake. The present study indicates that a relatively small number of changes in the diet could theoretically lead to substantial favourable changes in macronutrient and energy intake, and is therefore in line with earlier findings concerning total fat reduction through product replacements.

Corroborating findings from other studies, we showed that consumption of products from three product groups had a high impact on the consumption of saturated fat. For $42 \%$ of the sample, the top three suppliers of saturated fat came from three product groups, namely Dutch hard cheese, meats, and milk. Therefore, a targeted intervention that takes account of inter-personal differences is expected to have more effect than a generic approach that only aims at replacements in these three product groups, because the remaining $58 \%$ of the replacements came form thirtyseven different product groups.

Another useful finding was that alternatives for products high in saturated fat were available in the Netherlands for almost all product groups, but most importantly for the most frequently consumed product groups that are high in saturated fat content.

Although these simulation results are promising, field studies are needed to test the feasibility and impact of the proclaimed strategy in real life. The type of data we used, as well as the simulation character of the present study, the type of healthful alternatives used for the calculations, and the specific research population we studied imply some 
threats to the external validity of the present results. First of all, real-life replacements might differ from our simulation as subjects might not always manage to choose the alternative, or they might even completely relapse into their old habits. In addition, compensatory behaviour might occur. Individuals might consume larger quantities of the healthful alternatives than of the original products or might start eating other products from the same or other product groups in addition to the alternatives, for instance due to the reduction in total energy intake that we found after the replacements. Although this reduction is favourable from the perspective of overweight prevention, it might be preferable to select and recommend alternatives with reduced saturated fat, but comparable energy, to prevent individuals from eliminating the effect on saturated fat intake by compensatory behaviour. Compensatory behaviour across product groups might also occur to compensate the loss in taste. On the other hand, in an earlier study, the usage of solely lean products in one product group was only partially compensated by the increase in consumption of products from other product groups (Kistemaker, Löwik, Wedel, \& Hulshof, 1991). Similar results were found in the field experiments by Gatenby et al., and Weststrate et al., where participants were found to show increased consumption of other macronutrients, while nevertheless consolidating the reduction in energy intake from fat over time (Gatenby, Aaron, Morton, \& Mela, 1995; Weststrate et al., 1998).

Another threat to external validity of the proposed strategy is that we selected rather extreme alternatives (although available in Dutch supermarkets), effecting the largest possible reduction in saturated fat content. We did not take aspects of product acceptability into consideration. For example, in the category of Dutch hard cheeses, a product containing $6.2 \%$ total fat $(4.2 \%$ saturated) was selected to replace a full-fat cheese (Goudse 48+) containing 31.2\% total fat (19.8\% saturated). This difference in fat content between the cheeses is large and may not be acceptable at all because of large differences in taste. Selection of less extreme alternative products such as a $30+$ cheese, a product containing $17.6 \%$ total fat (11.2 saturated) or a $20+$ cheese with $11.9 \%$ total fat $(7.6 \%$ saturated) would yield a smaller reduction in saturated fat intake, but might be a more acceptable alternative. Another aspect that we did not take into account was the overall healthfulness of the alternative products. We only considered energy intake and did not measure the effects on the intake of other nutrients. That would be a relevant and challenging extension of the present study, and link up with the 
current shift from nutrient-specific recommendations to food- and food patternoriented recommendations, resulting from the fact that nutrition-related health problems are nowadays more strongly related to foods and food patterns than to nutrients (Bere \& Brug, 2009).

Another limitation of the present study that needs to be addressed is that the study was conducted among young adults only. We cannot generalize our results beyond this group, because eating habits are known to differ between different age groups (Hulshof et al., 2004). Finally, the simulation was not conducted using a measure of usual intake, but with the average consumption measured on two recall days. The present study thus only allows us to learn about the potential effects on reduction of saturated fat intake for the two recall days, and not about the potential effects on usual intake.

We conclude that replacing a few influential high-saturated fat products by available lower-fat alternatives can significantly reduce saturated fat intake and increase the proportion of individuals complying with recommended intake levels. Findings in this simulation study are promising enough to proceed with field experiments to assess the feasibility and impact of the replacement strategy in 'real life'.

Acknowledgments:

The authors are thankful for Janneke van den Bergh's contribution to the preparation of this study and the selection of alternatives low in saturated fat. 


\title{
Chapter 3:
}

\author{
A qualitative study of factors associated with \\ first time trial of unfamiliar healthful foods
}




\section{Abstract:}

Objective: exploration of factors influencing first time trial of unfamiliar healthful low-fat or fruit and vegetable products.

Design: Content-analysis of eight focus group interviews using Nvivo 2.0 ( $\mathrm{N}=66$; aged 16-56). The interview guide was based on a preliminary conceptual model including product-, personand situation-related factors.

Results: Product-related factors mentioned to influence decision to try unfamiliar healthful products were: expected taste, purpose-related information, ingredients and what product group it belonged to; perceived convenience and safety; price and whether it was a 'light' product. Person-related factors discussed were the participant's level of food neophobia, taste preferences, health status, weight control behaviour, trust in personal food preparation skills and habit strength. Situation-related factors mentioned were social influences, no-choice situations, supermarket and restaurant visits, free promotion samples, weekends versus weekdays, appetite and mood.

Conclusion: First time trial of unfamiliar healthful products is influenced by a broad range of product-, person- and situation-related factors. Several starting points for interventions addressing the integration of such products in the daily diet emerged. However, research on underlying psychological processes, the relative importance of the identified factors and the strength of the relationships between the factors is recommended. 


\section{Introduction}

During the last 10 years or so, there has been a vast increase in the number of alternative food products in Dutch supermarkets that claim to be more healthful. This phenomenon has followed the increased public, policy and corporate attention to nutrition and health, (Ministerie van Volksgezondheid Welzijn en Sport, 2006; World Health Organization, 2003), which has resulted in a growing market for what are presumed to be health foods.

In the Netherlands, as elsewhere, a major public health priority concerns the failure to meet national nutrition recommendations regarding the intake of saturated fat, fruit and vegetables (F\&V) (Hulshof et al., 2004; Voedingscentrum, 1998). There thus is a need for effective means of changing eating habits. In the latest Dutch national food consumption survey among younger adults (aged 19-30), only $8.1 \%$ of the participants met the recommendation to consume less than $10 \%$ of total energy intake (en $\%$ ) from saturated fat. Only $4.1 \%$ of the participants (4.7\% of men and $3.4 \%$ of women) met the recommendation to eat at least 2 'pieces' of fruit (200-300 g) and $200 \mathrm{~g}$ of vegetables a day (Hulshof et al., 2004).

Within the product groups that predominantly contribute to the consumption of saturated fat in the Netherlands (i.e., dairy products, meat and meat products, added fats and oils), manufacturers have introduced alternatives such as fat-free milk, low-fat cheese, meat substitutes and reduced-fat margarines. As regards fresh $F \& V$, new alternatives aim mostly at increased convenience - e.g. fruit juices in ready-to-carry portion-sized containers with a relatively long shelf-life.

Both simulation and field studies have found that replacing traditional products by leaner alternatives may have positive effects on people's diets (Gatenby, Aaron, Jack, \& Mela, 1997; Kistemaker, 1991; Morgan et al., 1997; Schickenberg et al., 2009). This suggests that the introduction of new, more healthful alternatives for food products can contribute to public health. However, a precondition of course is that consumers do indeed decide to use these new foods. The aim of the present study was to explore factors that influence the decision to try unfamiliar healthful food products, such as the low-fat or $\mathrm{F} \& \mathrm{~V}$ products that have been introduced on the market in recent years. Exposure to unfamiliar foods has been shown to be a way to develop preferences for new food products (Rozin, 2006). If a product is tasted without negative consequences, 
liking for the food increases (Capaldi, 1996). Liking a food precedes preference for that food, and preference for foods is an important determinant of food intake (Rozin, 2006).

Research has not specifically addressed factors related to the first time trial of healthful alternative food products. To develop a preliminary conceptual model for the present study, we reviewed the literature in related research fields, i.e. taste research, marketing research, research into novel foods and research into determinants of food choice in general.

Our preliminary model included three main components that were expected to determine whether or not people will try an unfamiliar product. The first component consisted of product-related variables, such as retail price, best-by date, brand, product taste, degree of convenience, sensory appeal, colour and quality in general, ingredients and similarity to familiar products (Capaldi, 1996; Glanz, Basil, Maibach, Goldberg, \& Snyder, 1998; Grunert, 2006; Martins \& Pliner, 1998; Steptoe, Pollard, \& Wardle, 1995). The second component included person-related variables related to food choice, such as the personality trait of food neophobia ('the reluctance to ingest unfamiliar food products'), subjective norms and attitudes, recall of previous experiences related to food consumption, the tendency to comply with other peoples' food choices, taste preferences and previous experiences with unfamiliar foods (Birch, 1999; Birch \& Fisher, 1996; Birch \& Marlin, 1982; Contento, 2007; Hobden \& Pliner, 1995). Finally, the third component included situation-related variables, such as the effort needed to obtain food, the influence of others, the influence of different contexts and time, the presence of others who may act as role models for trying unfamiliar foods, the attractiveness and safety of the food choice environment, previous exposure to marketing activities for the new foods, previous forced exposure to unfamiliar foods and mood (Meiselman, 2006; Meiselman, Johnson, Reeve, \& Crouch, 2000; Pliner, Eng, \& Krishnan, 1995; Pliner, Pelchat, \& Grabski, 1993; Steptoe, Pollard, \& Wardle, 1995). The research question in the present study was which person-, product-, and situationrelated factors consumers think might affect the decision to try an unfamiliar healthful (low-fat or F\&V) product for the first time. 


\section{Methods}

\section{Data collection method}

The study used focus group interviews as these are considered a useful means of exploratory data collection when relatively little is known about the phenomenon of interest. Participants are stimulated to discuss a particular problem or phenomenon amongst themselves and thereby react to remarks made by other group members. The recommended group size is 4-12 persons (Krueger \& Casey, 2000).

\section{Participants}

We included men and women aged 18-50 years with all levels of education. After collecting initial information about their size and composition, convenience groups were recruited at various institutions, such as sports clubs, businesses, the local welfare institution and musical societies, in the medium-sized town of Maastricht, the Netherlands. Eight focus group interviews were conducted with a total of 66 participants, 30 women and 36 men. The smallest group consisted of three, the largest of twelve participants. Participants' mean age was 34 years, ranging from 16 to 56 years. Participants of all levels of education were included (36\% low, 35\% intermediate, $29 \%$ high). All but two subjects were Caucasian. Most participants were acquainted with the other members of their group. Participants were informed that the researchers wanted to talk about nutrition in general, without mentioning the focus on unfamiliar healthful food products prior to the group meeting. Participants received $€ 10$ for their participation.

\section{Focus group interview guide}

All focus group interviews were conducted in a semi-structured manner, using an interview guide (Table 3.1). Questions were designed to evoke discussion amongst the participants, and participants were explicitly asked to respond to comments made by other group members. The questions in the guide were based on the preliminary conceptual model and thus addressed all three main components, i.e. product-, person-, and situation-related factors affecting the choice of unfamiliar healthful food products. Throughout the interview, however, participants were actively encouraged to 
spontaneously discuss all factors they considered relevant. Due to the open character of the focus group method, the sequence of the topics discussed varied across the interviews.

To further facilitate and focus the discussion, we used a display of fifty-one example products, arranged by product group (e.g. F\&V products, bread spreads, dairy products, desserts and meat substitutes). Most products were available in Dutch supermarkets. For each product group, participants were asked to indicate whether there were any products on the display that were unfamiliar to them. If products were unfamiliar, participants were asked to explain why they would or would not be willing to try the product, and other group members were encouraged to comment on the responses made.

Table 3.1: Interview guide.

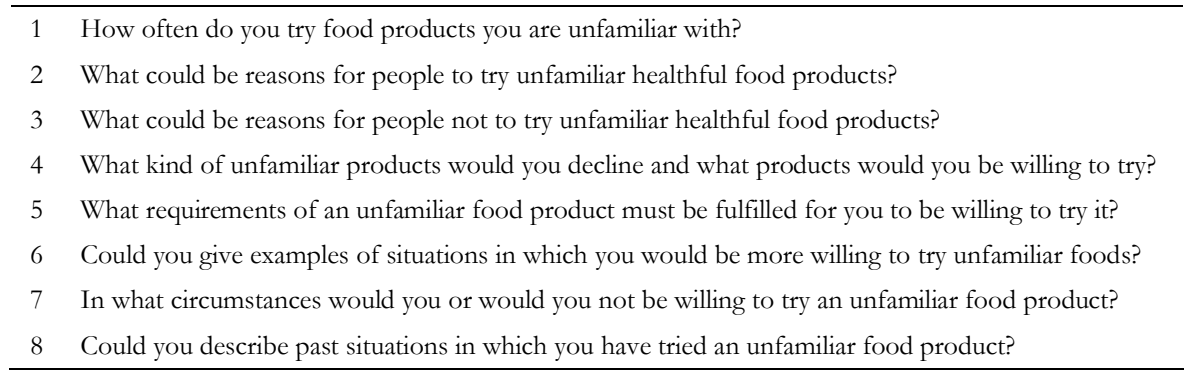

\section{Procedure}

The interviews lasted about 90 minutes and were conducted in locations and at times that suited the respective groups best, such as the work-place, rehearsal rooms etc. Each focus group interview was audio taped, with the consent of all participants. All interviews were led by the same two researchers, a moderator and an assistant, as suggested by Krueger and Casey (Krueger \& Casey, 2000). The role of the moderator was to lead the discussion, while the assistant took notes on non-verbal reactions of participants, and supervised the recording process.

The interviews started with a word of welcome and a brief introduction to the specific topic of healthful alternatives. Halfway through the meeting, there was a short 
break. At the end of the interview, the participants were reimbursed and were asked to complete a short questionnaire on their demographics.

\section{Data analysis}

We used the transcript-based method of analysis as it is the most rigorous way of analyzing focus group content (Krueger \& Casey, 2000). All recordings of the interviews were transcribed verbatim, and the assistants' observations were added to the text. The transcripts were thematically analyzed for content using the Nvivo 2.0 (QSR International) program for the analysis of qualitative data.

All text related to the first time trial of unfamiliar products was preliminarily structured by coding all statements as referring to one of the three main factors from the preliminary model. In a second step, subfactors were identified and coded until all relevant text from all interviews had been coded. If remarks were judged to refer to more than one factor, multiple labels were applied. In the third step of the analysis, the resulting structure of codes was simplified by grouping or renaming codes that had substantial overlap. All coded text was then summarized by subfactor.

As a check on the quality and completeness of the coding process, two other researchers checked the codes in the transcripts independently, using detailed definitions of the codes, which were provided by the first researcher. Across all interviews, 1237 passages were coded. Disagreement between the three analysts arose in 14 cases $(1.13 \%)$. In most instances, the disagreement involved one of the three researchers having missed a piece of text that the other two had found to be worth coding. The discrepancies were resolved in a group meeting with these three researchers.

\section{Results}

\section{PRODUCT-RELATED FACTORS}

When asked to explain why they would or would not try unfamiliar products, participants in all interviews spontaneously started mentioning product-related factors that influenced their decision to try unfamiliar healthful products (Table 3.2). 


\section{Expected taste of the product}

The factor most frequently mentioned by participants was that they needed to expect a pleasant taste if they were to try the unfamiliar product. Participants agreed that they would not be willing to eat any unfamiliar product if they expected it to have a bad taste. The need for information on a product differed greatly between participants. While some participants expressed a willingness to try a product without being provided with information, others preferred to be extensively informed on which taste to expect. The most frequently mentioned type of information in this respect was printed information on the packaging, e.g. the name or ingredient information. Participants also mentioned that they based their taste expectations on a product's general appearance, its perceived freshness, its colour, smell and surface structure, and the language used on the packaging. Some participants indicated that they were less willing to try a food if the information provided on the packaging was in an unfamiliar language. Participants also indicated that they estimated an unfamiliar product's taste on the basis of their prior experience with comparable products, i.e. products within the same product group, of the same brand, or other 'light' products.

\section{Information about purpose}

Many participants expressed a need for information on an unfamiliar product's purpose and/or its function. Several participants stated that they would be less willing to try a product if they lacked information on the way the product has to be prepared or about the appropriate moment to consume it.

\section{Information about product ingredients}

In addition to creating a taste expectation, product ingredient information was used by several participants due to their allergy status or because they were on a special diet. In both instances, participants indicated the desire to check unfamiliar products for the presence or absence of certain ingredients (e.g. nuts in a muesli bar). Some others explicitly said that information on ingredients was of less or no importance to them. 


\section{Product group}

Some participants expressed greater willingness to try unfamiliar products from some product groups than from others. They were especially inclined to try new products from product groups frequently used in the typical Dutch diet, such as dairy and bakery products, cereals and jam.

\section{Convenience of the product}

Several participants reported that they would be more willing to try an unfamiliar product when they believed it to offer advantages in terms of e.g. reduced preparation time, easier preparation or better quality retention (e.g. fresh milk with longer best-by period).

\section{Perceived safety of the products}

Many participants expressed a general belief that all products available in stores were safe. If they were in doubt regarding a product's safety, some participants indicated that they would first judge a product based on the completeness and comprehensibility of the ingredient information, the country of origin and the length of the 'best-before' period before they would be willing to try it. Some participants stated or agreed that if they perceived an unfamiliar product's 'best before' period to be too long, they would become suspicious and unwilling to try such a product, as they would doubt its freshness and authenticity (e.g. milk). Several participants expressed hesitations about trying products that had been genetically modified. Participants did not discuss the techniques of genetic modification in detail but made it clear that they favoured 'natural' products.

\section{Product price}

Many participants indicated that a price reduction of the unfamiliar product compared to the familiar product often cued them to try it. Some participants, however, indicated that the discrepancy in price between two otherwise comparable products (based on product group and function) must not be too large, as this would raise their concern 
about the quality and taste of the product (e.g. commenting on too-good-to-be-true offers at a food discounter).

\section{Light products}

Several participants expressed a negative attitude towards products labelled as 'light' or 'diet', and indicated that they would be categorically unwilling to try such unfamiliar products. These participants explained their negative attitude by referring to negative taste experiences in the past and by referring to more general concerns about the ingredients used in such products.

Some other participants indicated that they tended to be interested in trying a light version of a product especially if it concerned a product that they eat regularly, as a possible way to control weight or reduce the intake of certain ingredients because of health issues.

\section{PERSON-RELATED FACTORS}

\section{Level of food neophobia}

Many participants could tell about themselves and about important others whether they were generally attracted to trying unfamiliar food products or were repelled by such products. Participants expressed that this was a general attitude towards unfamiliar products, which was a stable factor in their lives. Many participants tried to explain their reluctance to try unfamiliar foods by exposure to unfamiliar food products during their youth. Some participants said that their parents had made them try such products even though they did not wish to do so, and that such experiences might at least partly explain their current negative attitude towards unfamiliar foods.

\section{Taste preference}

Many participants mentioned their personal taste preferences as an important factor in their willingness to try unfamiliar foods. If they expected the taste of an unfamiliar product not to match their taste preferences, these participants would decline to try the product. 


\section{Health and weight control issues}

Some participants who said that they were allergic to specific nutrients indicated that they were more reluctant to try unfamiliar foods for this reason. Other participants stressed that they were attracted to trying unfamiliar healthful foods because of concerns about their weight, other health-related concerns or intentions to improve the quality of their nutrition (e.g. low-fat desserts).

\section{Trust in personal food preparation skills}

If an unfamiliar product needs to be prepared, several participants indicated that they would be more willing to try it if the food was prepared by someone with the right skills, as these participants reported that they lacked the necessary food preparation skills. These people would be more willing to try unfamiliar foods at restaurants, or at supermarkets when bite-size ready-to-eat products are offered.

\section{Dietary habits}

Several participants indicated that pursuing a particular dietary habit restrained them from trying new products. They indicated that they were happy to stick to their usual food choices because these take less effort, and that they saw no reason to change them. Older participants more commonly referred to their persistence in eating habits than younger ones. Health or weight problems were mentioned as cues to change food habits.

\section{SITUATION-RELATED FACTORS}

\section{Social influence}

Having heard about favourable characteristics of an unfamiliar product, either through advertisements or from significant others (word-of-mouth), was reported to make products seem less unfamiliar, thus increasing participants' willingness to try such products. Some participants also said that seeing someone else enjoying the product increased their willingness to try it. First time trials were said by some participants to occur mostly in public eating situations, such as supermarkets where samples are being 
offered, in restaurants and at parties. Living together with someone, e.g. children, someone who is allergic, or otherwise in need of a special diet, was reported to influence participants' shopping and cooking behaviour. Some participants said that they were unwilling to cook different meals tailored to each family member's personal needs, so they would make more conservative choices in relation to food, to be able to cook one meal that they supposed would suit everybody.

\section{No-choice social situations}

Several participants mentioned that they had tried unfamiliar products in social situations where they felt to have no other choice than to eat the specific food product. Situations described by participants were, for example, within the family when a parent told them to eat a particular product, and at social occasions such as a dinner or party with friends, where unfamiliar foods were presented and had to be eaten to satisfy one's appetite and/or for reasons of social desirability. Some participants indicated that such 'forced' exposure to unfamiliar food products resulted in that they now easily approach such foods, while other participants reported that such exposure let to a negative attitude towards unfamiliar foods, as was also mentioned for the person-related factor of food neophobia.

\section{Supermarket}

The place where participants said they were most likely to be exposed to unfamiliar food products was the supermarket. Participants indicated that unfamiliar products were sometimes placed on the shelves where they used to find familiar products. This sometimes encouraged them to try the unfamiliar product. Several participants described in-store preparation and giving away free samples of unfamiliar foods as being moments when they would be more willing to try a product (see free promotion).

Participants also expressed greater willingness to try unfamiliar products when familiar products were no longer available. Other participants indicated they were not willing to buy new products in supermarkets but would be willing to try such products if they were bought by someone else and available at home. 


\section{Restaurant}

A small group of participants indicated that they were more willing to try unfamiliar foods in a restaurant because they trusted the chef's cooking skills more than their own (see Trust in personal food preparation skills). Other participants would not try unfamiliar foods in restaurants, due to the apparent risk that they might not like the product and would still have to pay for it and perhaps go away hungry.

\section{Free promotion}

Several participants expressed their willingness to try such products if a product is offered in samples in stores or elsewhere free of charge. In such situations, participants reported to be influenced by several of the factors described above, such as the product being free, seeing other people try the product and, if the product is being prepared on the spot, the smell of the product and the environment. Several participants also mentioned, however, that they would only try the foods if both the food products and the cooking situation appeared hygienic. Being able to taste a bite-sized portion of an unfamiliar food product was labelled by participants as a 'no-risk' situation. If it turned out that they disliked the product, they would suffer no monetary loss by having tried it. Participants also indicated that they would be less willing to try a healthful product if it was offered in large amounts, as they would consider it a waste if it turned out they did not like the product after all.

Some participants mentioned that the product being offered had to fit the time of day. Offering an unfamiliar dessert product early in the morning, for example, would make these participants decide not to try it, even though it might be free.

Some participants opposed such product presentations in supermarkets and claimed to never try such samples. They motivated their statements by comparing the offering of free food samples to the distribution of free food to the poor and needy.

\section{Moment}

Several participants said to be more willing to try preparing unfamiliar products in weekends. Participants expressed a concern that the first time preparation of unfamiliar 
foods would take more time than preparing familiar ones. During weekends or holidays, they would have more time to experiment with new foods or recipes.

\section{Appetite and mood}

Several participants agreed that their level of appetite influenced their willingness to eat unfamiliar foods. When hungry, most participants claimed they would stick to familiar foods rather than experiment with unfamiliar foods or tastes. Several participants explained this behaviour from the risk of remaining hungry after having chosen to try an unfamiliar food product they turned out to dislike. An exception to this rule seems to be deep-fried foods available at snack bars throughout the Netherlands. Some participants mentioned that they would be willing to try a snack they had not had before even when being hungry, referring to previous positive experiences with deepfried snacks.

Several participants stated that they were more willing to try unfamiliar foods when in a happy mood, whereas many participants agreed they would not be open to experiments with unfamiliar foods when they felt down. 
Table 3.2: Examples of statements on various issues associated with the $1^{\text {st }}$ time trial of healthful alternatives

\section{Product-related factors}

Expected taste of the product

'It's all about taste; if I expect a product to have a bad taste, why would I want to try it?

I wouldn't try this product because it looks cheap; ... I'm not going to try it if the product looks disgusting.

I know how another product by the same brand tastes and I like that product, so I might try the new one as well.

I knew the product (juice) with a different flavour (orange) and then I saw it with a lemon flavour. So I thought I'd try something different for a change, and it tasted good, too.

Information about purpose

I need to know what it's good for and how I have to prepare it, otherwise I won't try it.

Information about products ingredients

I look at the nutrition information and (if that ingredient is in the product) I won't try it.

Product group

You sometimes get fed up with products and you want to try something else. But I've noticed that I tend to try desserts more easily than different sorts of cheese or bread for example.

Convenience of the product

With milk for example, I was glad to see that they brought out milk with a longer best-before period. Since I don't drink that much milk, it always used to turned sour after some days. Now I buy milk you can keep in the fridge longer and it keeps well.

Perceived safety of the products

I don't care about what's in a product. I have to eat it anyway. You won't die from eating it; otherwise they'd not be allowed to sell it in stores.

With meat, I look at where it comes from, what with that mad cow disease thing...

That product over there with the spines on the surface. I have never had that. I think because it's foreign.

I don't always trust new products. If milk is supposed to keep for three months, I question what has happened to that product. That can't be healthy, can it?

Product price

I tend to try [new] products when there's an introduction offer.

I think that everyone tries things more easily when they come in a small-sized package than when a new product comes in a big container. [If it turns out that] you don't like the product, you are stuck with a large amount of a product you don't like.

Light products

I wouldn't try this product, as it is a light product. I consistently reject light products. Fanta-Light for example tastes worse than the original Fanta. I think everything labelled as 'light' tastes less good than the original.

...'Light' products such as diet-cola are all chemical stuff, isn't it?

Then they put in other stuff instead of sugar, which is unnatural... that can't possibly be healthy.

For example, if there was a new mustard sauce with less calories I'd try it

Whipped cream light? That is not whipped cream at all! I wouldn't try that. I only use cream sparsely throughout the year and when I do I want to have the real thing. 
Table 3.2: continued

\section{Person-related factors}

Level of food neophobia

I try everything, like everything and eat everything

I like everything and I will try anything new. Except sushi; I won't try that. It's just the idea...

Imagining trying something new makes me feel bad. Some things you don't like, even without trying.

Taste preference

I think a lot of people have certain things they don't like. For example, fish or cheese. There are specific products that stop them from trying the unfamiliar.

Health status/weight control

My mother is allergic to lactose and won't try anything new that doesn't fit in with her diet. Therefore, I have to read the nutrition information when considering to buy unfamiliar products at the shop.

...My mother is overweight and she often scans the store for new light products and brings them home.

Trust in personal food preparation skills

If you buy new products in stores, then you have to prepare them yourself. If you don't know how to do that, you have to experiment... at the same time if you go to a restaurant you know that the cook prepares that food probably several times a day and knows what he or she is doing.

Dietary habits

It's strange. You tend to go on eating what you're used to.

I think it's laziness. If you know how to prepare things and you have a strict dietary habit, staying with those products is easier and takes less thinking. 


\section{Situation-related factors}

Social influence

I saw that others tried the product and liked it, so I tried it myself

Someone said that it's a good product

I (sometimes try new products), but only if I come across the products in the stores and think 'Oh yes, I could try that for a change'. But I have to admit that I'm sensitive to commercials. If they are advertising something and I see it in the store, then I often try it.

I remember having eaten a salad with something in it I didn't know. I just ate the salad with those white cubes and then I asked one of the others on what this product was. They said it was Feta and that I should try it, because it tasted good. So I did.

...I must admit that I try products more easily if $\mathrm{I}$ have seen them in a commercial

No-choice social situations

We went out to dinner with friends and they had already ordered the meal for us. It included snails and I'd never had snails before. My friends have them frequently and it was a nice evening so I tried them. I thought I couldn't chicken out now, so I tried the snails.

\section{Supermarket}

If you are looking for a product you want to buy and you go to its usual spot in the store and find a new product there... then I sometimes see people take that new product instead.

It matters to me what the store looks like. If the store looks nice and clean I'm more willing to try something new as compared to a store that appears unhygienic with dust on boxes and products just sitting in boxes without being unpacked...that doesn't go well with food.

If there is a product sampling in a store I'd try the product then, but I would not fetch it from the shelf myself.

\section{Restaurant}

In a restaurant I'm more willing to try something new, as I expect the cook to be more experienced in preparing the food than I would be.

Not in restaurants, cause then I'm hungry and I'm afraid that I won't like the food and that I'll still be hungry. I do try things in supermarkets, but almost never in restaurants.

Free promotion

If someone offers samples of unfamiliar foods in stores I will try them and then I'll ask about the price.

I'd never have tried the product had they not handed out free bottles of it.

If I'm in a supermarket in the morning and someone offers fried snacks, then I won't try those products. On the other hand, later in the day you see that more and more people try such products.

I not only find it intrusive, those samplings at supermarkets but also very cheap. All those people cuing up for a free sausage...

\section{Moment}

During the week when I have to cook I don't have too much time. Therefore, I rely on fixed food habits. ... at the weekend, with more time at hand I'm more willing to try and prepare something new.

Appetite and mood

If I'm hungry I usually don't try new foods. If I find out that I don't like the food, I'd still be hungry afterwards.

If I'm hungry while at the shop I'm susceptible to trying new products, but usually only snacks.

I think it's the mood you're in... if I don't feel good I don't eat much. On the other hand, at parties, when I'm feeling good, I'm willing to try something new if it is being served. 


\section{Discussion}

The aim of the present study was to explore factors involved in the process of trying unfamiliar healthful (low-fat or F\&V) food products for the first time. The proposed subdivision into product-, person- and situation-related factors used to develop the interview guide was generally corroborated by the study's findings. Within each of these three general categories, multiple factors were identified. Influential factors varied between persons, with decisional factors for individual persons particularly seeming to depend on the specific product and its perceived characteristics, but also on situational factors. Often, multiple factors seemed to act simultaneously. For instance, the value of greater convenience of an unfamiliar product compared to that of a familiar one was often judged in combination with the price difference between the products, and the influence of participants' food preferences was smaller when others chose the food for them.

Our study thus revealed several factors involved in the choice of healthful alternative food products. It was not the aim of the current study to rank all these factors according to their importance, as the research method we used is not suitable for this. Nevertheless, the results of the present study suggest that the expected taste of an unfamiliar product and the degree of food neophobia are of importance for participants' expressed willingness to try unfamiliar foods such as those discussed in this study. The importance of taste expectations in relation to taste preferences in the process of food choice confirms the findings of other studies (Glanz, Basil, Maibach, Goldberg, \& Snyder, 1998; Steptoe, Pollard, \& Wardle, 1995; Story, Neumark-Sztainer, \& French, 2002; Woodward et al., 1996). Food neophobia has been found to influence food choice and product acceptance in previous studies using ethnic food products as stimuli (Birch \& Marlin, 1982; Feunekes, de Graaf, Meyboom, \& van Staveren, 1998; Pliner \& Melo, 1996; Tuorila, Lähteenmäki, Pohjalainen, \& Lotti, 2001). Studies into associations between level of food neophobia and willingness to try products comparable to those discussed in the present study, for instance studies including lowfat margarine, found no associations or only weak ones (Tuorila, Lähteenmäki, Pohjalainen, \& Lotti, 2001). In a quantitative internet study we conducted, a relationship emerged between participants' level of food neophobia and their willingness to try healthful food stuffs (Schickenberg, van Assema, Brug, \& de Vries, 2008). Studies including food products that were assumed to be familiar to the 
participants (e.g. smoked ham, tuna fish, meat balls) usually found no or weak associations between the level of food neophobia and the willingness to try these products (Pliner, Lähteenmaki, \& Tuorila, 1998; Tuorila, Lähteenmäki, Pohjalainen, \& Lotti, 2001).

Other factors that came up in the present study have also been mentioned in previous research as determinants of food choice, viz. product ingredient information (Lewis \& Hollingsworth, 1992), product convenience (Glanz, Basil, Maibach, Goldberg, \& Snyder, 1998; Martins \& Pliner, 1998; Steptoe, Pollard, \& Wardle, 1995; Story, Neumark-Sztainer, \& French, 2002; Woodward et al., 1996), product safety (Birch, McPhee, Shoba, Pirok, \& Steinberg, 1987), product price (Cardello, Maller, Bloom Masor, Dubose, \& Edelman, 1985; Glanz, Basil, Maibach, Goldberg, \& Snyder, 1998; Kristensen, Ostergaard, \& Juhl, 1998; Steptoe, Pollard, \& Wardle, 1995; Story, Neumark-Sztainer, \& French, 2002), perceived health status or interest in weight control (Contento, Michela, \& Williams, 1995; Furst, Connors, Bisgogni, Sobal, \& Winter Falk, 1996; Mela, 2001; Steptoe, Pollard, \& Wardle, 1995), habits (Furst, Connors, Bisgogni, Sobal, \& Winter Falk, 1996), hunger and mood (Furst, Connors, Bisgogni, Sobal, \& Winter Falk, 1996), and social influence (Furst, Connors, Bisgogni, Sobal, \& Winter Falk, 1996; Hobden \& Pliner, 1995). The other factors identified in the present study might be characteristic of decisions on the type of unfamiliar healthful products our study focused on.

Limitations of the study include the research method and its reliance on introspection, the danger that not all relevant factors were identified, the limited opportunities for generalizations from the results and the lack of opportunities to discuss differences between participants. The focus group method relies strongly on participants actively describing their thoughts and considerations about trying unfamiliar food products. Since it is likely that some factors are more accessible to introspection than others, the interview guide addressed a wide variety of questions to elicit factors that people might not come up with spontaneously. Although we succeeded in identifying some factors that are considered to reflect unconscious factors in food choice (e.g. mood and hunger), the method we used might lend itself mostly to revealing conscious determinants of food choice. During the interviews we asked the participants to focus on their considerations regarding unfamiliar healthful food 
products, but we cannot rule out that other factors, e.g. regarding unfamiliar foods in general, were also mentioned.

We conducted eight group discussions; after the sixth interview a point of saturation was reached, and no new information surfaced in the last two interviews. Nevertheless, the possibility remains that not all relevant factors were identified. Furthermore, the questions included in the interview guide might also have influenced our findings. Perhaps these questions left some topics unaddressed that could have triggered new information. Although participants were actively encouraged to say anything they wanted during the interviews, timidity and the desire not to say things considered irrelevant by other group members may have prevented them from speaking freely.

The qualitative method used for our analysis restricts the generalizability of the results. The number of participants in the present study was small compared to numbers usually required in quantitative studies. The participants were not representative of the general Dutch population in several respects, e.g. level of education, ethnic status, age (we only included persons aged roughly 18-50 years) and region (all participants were from the area around the town of Maastricht).

Finally, our use of audio recordings of the group discussions limited the possibility to link demographic characteristics of participants (e.g. gender and sometimes age and level of education) to their remarks during the interview.

The study has helped to identify several factors that possibly influence participants' expressed willingness to try unfamiliar healthful food products for the first time. The method we used does not permit conclusions about the relative importance of the factors identified or the degree to which these factors are interrelated. Several of these factors were already known to influence participants' willingness to try unfamiliar foods in general, and this study supports their influence for unfamiliar healthful alternative food products. For some of the factors, e.g. provision of information that a novel food tastes good, there is evidence that willingness to try novel foods is most likely to be achieved by increasing participants' taste expectations towards the food being offered (Pelchat \& Pliner, 1995). For most factors, however, the exact processes and mechanisms that underlie participants' willingness to try unfamiliar foods still need to be studied to determine the best ways of putting the acquired knowledge into practice. Nevertheless, the identification of these factors has allowed us to generate ideas for 
health promotion interventions to stimulate replacement of traditional products in the daily diet by healthful alternatives even without being able to pronounce upon the relative importance of underlying mechanisms of the factors. We suggest the following strategies. Changes in product locations in supermarkets could be all that is needed to stimulate some consumers to try a different product than the one usually placed at the familiar spot. Offering taste information about healthful alternatives to consumers, in which comparisons are being made between the taste of the healthful alternative product and presumably familiar and preferred products is likely to decrease the perceived novelty of the healthful alternatives and thereby increase consumers' willingness to try them. Offering bite- or sip-sized samples of healthful alternatives for free would target two barriers to first time trial of unfamiliar foods discussed in the focus group study: (1) the economic barrier of a monetary investment and (2) the fear of having to waste the remains of a product if, after tasting, it turns out one does not like it. Using advertisements to expose potential consumers to the name and possibly other characteristics of a healthful alternative could lead to product recognition and thereby decrease the perceived novelty of a product when it is encountered in e.g. a supermarket. Using social modelling, where the example of the behaviour of choosing a healthful alternative is given by another person one can relate to, could also increase one's willingness to try the healthful alternative product. However, before such strategies can be implemented, research is needed into their effectiveness in representative samples. It would also be desirable to study the relative importance of the identified factors and the relation between them in representative samples, to be able to focus behavioural change interventions on the most promising factors for specific target groups. 


\section{Chapter 4:}

\section{Are the Dutch acquainted with and willing to try healthful food products: The role of food neophobia}

Published as:

Schickenberg, B., van Assema, P., Brug, J., \& de Vries, N. K. (2008). Are the Dutch acquainted with and willing to try healthful food products? The role of food neophobia. Public Health Nutrition, 11, 493-500. 


\section{Abstract}

Objective: To assess participants' acquaintance with and willingness to try healthful food alternatives, and to test the psychometric properties of an adapted Dutch version of the Food Neophobia Scale (FNS) in order to study the role of food neophobia in this context.

Design: A cross-sectional study incorporating two web-based questionnaires, including a retest of the FNS one week later. Measures included acquaintance with and willingness to try 15 healthful food alternatives, level of food neophobia, level of education, gender and age. Multiple linear regression analyses were used to study associations between demographics and level of food neophobia as well as associations between level of food neophobia and acquaintance with and willingness to try the healthful alternatives.

Setting: The study was conducted in the Netherlands using a representative internet panel.

Participants: A total of 326 participants aged 18-50.

Results: Internal consistency and test-retest reliability of the used FNS version were sufficient. On average participants were acquainted with 7.9 of the products and modestly willing to try the products. Lowly educated participants had significantly higher FNS scores than highly educated participants $(\beta=-0.23, \mathrm{p}<0.01)$. FNS score was significantly associated with acquaintance with $(\beta=-0.21, \mathrm{p}<0.001)$ and willingness to try the healthful alternatives $(\beta=-0.26, \mathrm{p}<0.001)$.

Conclusion: Further research into the role of food neophobia is warranted, when wanting to stimulate the integration of healthful alternative products to the daily diet, especially among the low educated. 


\section{Introduction}

High intakes of saturated fat and low intakes of fruit and vegetables (F\&V) have been linked to increased risk for cardiovascular diseases (Fung, Willett, Stampfer, Manson, \& $\mathrm{Hu}, 2001$; Hooper et al., 2001; Hu et al., 2000) various forms of cancer (Fung, Willett, Stampfer, Manson, \& Hu, 2001) and obesity (Alavanja, Brown, Swanson, \& Brownson, 1993; Steinmetz \& Potter, 1996; Willett, 1995). In the Netherlands, as in most Western countries, dietary recommendations have been issued indicating maximum recommended quantities of daily fat intake and minimal recommended intakes of $F \& V$ (Health Council of the Netherlands, 2001). National food consumption surveys in the Netherlands have shown that the average consumption of saturated fat and F\&V is not in accordance with these recommendations (Hulshof et al., 2004). Changing consumption of both fat and $F \& V$ to the recommended levels is expected to yield substantial health benefits (Ammerman, Lindquist, Lohr, \& Hersey, 2002; Hooper et al., 2001; Hulshof et al., 2004; Mokdad et al., 2001).

The present study aimed to assess to what degree the Dutch are acquainted with and willing to try several healthful alternatives for food products. These healthful alternatives could contribute to a decrease of saturated fat intake and an increase of $\mathrm{F} \& \mathrm{~V}$ consumption if used on a regular daily basis. More specifically, the role of food neophobia in this context was studied as one's level of food neophobia has been shown to affect both the quality and the variety of foods in the diet (Falciglia, Couch, Gribble, Pabst, \& Frank, 2000).

Margarine, full-fat cheese, butter, milk, pork meat, bakery goods, and minced meat are examples of product groups contributing highly to the intake of saturated fat in the regular Dutch diet (van den Brandt, van de Crommert, \& Mordant, 1990). In the last decades, the food industry has introduced alternatives with reduced fat contents for products in virtually every product group, e.g. meat substitutes, low-fat milk products, diet margarine, and lean cheese.

In a simulation study it was shown that for most people the replacement of just a few daily used products high in saturated fat by healthful alternatives would help to reduce saturated fat intake in the daily diet to the recommended levels (Morgan et al., 1997). Moreover, in another such study (Kistemaker, Löwik, Wedel, \& Hulshof, 1991) it was shown that participants using solely lean products in a certain product group 
were found to only partly compensate the reduction of energy intake through fat by increasing consumption of products from other product groups. In a field experiment, Gatenby et al. compared groups of female participants who consumed fat-reduced foods for a period of ten weeks with a control group that consumed full-fat traditional products (Gatenby, Aaron, Morton, \& Mela, 1995). Results indicated that this method had short-term effects on energy balance by reducing intake of fat.

Low consumption of $\mathrm{F} \& \mathrm{~V}$ in the Dutch has been shown to be related to low perceived convenience of fresh F\&V products (Brug, Lechner, \& de Vries, 1995). Therefore, fresh $\mathrm{F} \& \mathrm{~V}$ product alternatives with higher convenience have been introduced, e.g. F\&V juice with a prolonged shelf-life in comparison to fresh $F \& V$ that contains a considerable percentage of the daily recommended amounts of $F \& V$ and is packaged in an easy-to-transport ready-to-use container.

A crucial step in the process of incorporating new products into daily eating routines is that the new product needs to be tried a first time. For this to happen several situational and product-related prerequisites have to be met, such as the product must be available (Mela, 1999) and appropriate for the time of day, meal or situation (Furst, Connors, Bisgogni, Sobal, \& Winter Falk, 1996) and the person must be willing to try the product.

A first testing and a first exposure to a product's taste, is crucial for product acceptance and potential continuous use. Earlier studies on human food choice behaviour concluded that the personality trait of food neophobia may be a crucial determinant of people's willingness to try a new product (Arvola, Lähteenmäki, \& Tuorila, 1999; Hobden \& Pliner, 1995; Hursti \& Sjödén, 1997; Pliner, Eng, \& Krishnan, 1995; Pliner \& Hobden, 1992; Raudenbush \& Frank, 1999; Raudenbush, Schroth, Reilley, \& Frank, 1998; Tuorila, Lähteenmäki, Pohjalainen, \& Lotti, 2001; Tuorila, Meiselman, Bell, Cardello, \& Johnson, 1994). Food neophobia has been defined as "the avoidance of or reluctance to approach novel foods" (Birch \& Marlin, 1982). Pliner \& Hobden developed a 10 item self-administered questionnaire called the Food Neophobia Scale (FNS) to reliably measure the degree of food neophobia and differentiate between food neophilics and neophobics, scoring at the lower or higher end of the spectrum, respectively (Pliner \& Hobden, 1992). The FNS was developed in Canada and has since been used in a number of studies in various western countries such as the USA (Pliner \& Hobden, 1992), Sweden (Koivisto \& Sjödén, 1996, 1997), 
Finland (Arvola, Lähteenmäki, \& Tuorila, 1999), Australia (Flight, Leppard, \& Cox, 2003), Belgium (Eertmans, Victoir, Vansant, \& van den Bergh, 2005), and France (Nicklaus, Boggio, Chabanet, \& Issanchou, 2005). The personality variable is associated with reluctance to try new foods and is negatively correlated to familiarity ratings of food products.

Tuorila has proposed a distinction between five different categories of unfamiliar foods, i.e. functional foods, genetically modified foods, nutritionally modified foods, organic foods, and ethnic foods (Bäckström, Pirttilä-Backman, \& Tuorila, 2003; Tuorila, 2001). Pliner, referring to this categorization, has argued that research does show that FNS predicts willingness to try ethnical products, but not much evidence is available on products from other categories (Pliner, 2002).

In scientific databases no data was available on how acquainted the Dutch are with healthful alternatives for products typical for the Dutch diet and how willing they are to try these products. Moreover, the level of food neophobia in the Dutch population and the relationship between food neophobia and acquaintance with and willingness to try these kinds of products has not been studied before. Therefore, it is unknown whether participants' level of food neophobia has to be taken into account as a barrier in the process of stimulating the use of healthful alternative products.

The first purpose of the present study was to assess acquaintance with and willingness to try several products that can be used as more healthful or more convenient alternatives for regular food products, among Dutch adults. Secondly, we aimed to test the psychometric properties of a Dutch version of the FNS, and to assess respondents' level of food neophobia and possible sub-group differences. A third aim was to assess the association between level of participants' food neophobia and acquaintance with and willingness to try several healthful alternatives for traditional Dutch foods.

\section{Methods}

\section{Sample, design and procedure}

Respondents were members of a research panel of a Dutch Internet research agency (Flycatcher B.V.) consisting of about 12000 members. The panel is representative for the Dutch society except for a slight over-representation of people from the province 
of Limburg (in the South of the Netherlands) and women. From this panel a stratified sample of 543 respondents was selected. We controlled for the variables gender, age (18-50 years), level of education and province of residence. The variable education was included in the regression analysis as a dummy variable. These persons were invited to participate in a study on food products and emailed the web address of an electronic questionnaire. Participants were reimbursed by the agency after completion of the questionnaire. A cross-sectional design was used, with the exception of the retest measure of the FNS for which participants were invited one week after completion of the first questionnaire. Respondents could not save their answers on their personal computer, nor was it possible to complete the questionnaire more than once. Respondents' answers were automatically saved on the central server into a data file. Participants were given a one-week deadline; it was not possible for respondents to enter the questionnaire after that date.

\section{Measures}

The first questionnaire included an adapted Dutch version of the FNS (Pliner \& Hobden, 1992) (Table 4.1). The FNS was translated to the Dutch language by a research group of Wageningen University. For the present study we introduced two changes in wording in response to comprehension problems encountered in an earlier unpublished study. FNS items were answered using a 7-point Likert scale format with answers ranging from 'I totally disagree' (1) to 'I totally agree' (7). Respondents' food neophobia score was computed by summing the answers of the ten items, after reversing the scores of items 1, 4, 6, 9, and 10 (theoretical range 10-70). 
Table 4.1: The items of the Food Neophobia Scale

\begin{tabular}{|c|c|c|}
\hline & Item & Statement \\
\hline \multirow[t]{3}{*}{ (R) } & 1. & I am constantly sampling new and different foods \\
\hline & 2. & I don't trust new foods \\
\hline & 3. & If I don't know what a food is, I won't try it \\
\hline \multirow[t]{2}{*}{ ( ) } & 4. & I like foods from different cultures \\
\hline & 5. & Ethnic food looks too weird to eat \\
\hline \multirow[t]{3}{*}{ (R) } & 6. & At dinner parties, I will try new foods \\
\hline & 7. & I am afraid to eat things I have never had before \\
\hline & 8. & I am very particular about the foods I eat \\
\hline ( & 9. & I will eat almost anything \\
\hline (B) & 10. & I like to try new ethnic restaurants. \\
\hline
\end{tabular}

${ }^{\circledR}=$ scores were reversed for these items

In addition, respondents' acquaintance with and willingness to try 15 healthful alternatives was measured. The healthful alternatives (Table 4.2) consisted of 12 products containing less saturated fat than their traditionally used counterparts. These products included alternatives for meat products, full-fat cheese, solid frying fat, butter, sauce, snacks and dairy products, as these products categories highly contribute to the intake of saturated fat in the Dutch diet. Three products were included in the study as more convenient alternatives for no or low intake of fresh $F \& V$. These products included a fruit-based breakfast product, a fruit juice and a juice based on $F \& V$ juice.

Two of the 15 products were selected based on the fact that they were not (yet) available in the Netherlands. The remaining 13 products were purposefully selected from a wider selection of 51 products within the chosen product categories gathered during visits to several supermarket chains. Only products that could indeed be considered more healthful were selected, so products that e.g. over-compensated the decrease of fat with another unhealthful ingredient were excluded. The final selection included the products most unfamiliar to 64 participants of a pilot study. If products were more or less equally unfamiliar, the product lowest in saturated fat content was chosen. At least one product per product category was selected. One of the remaining two products was available in Dutch supermarkets one week after conducting the study, the last product was a lean chocolate bar available in Australia which was imported for 
this study. A pilot study among 64 participants indicated that the products were unfamiliar to most participants.

Front side photographs of each product, as well as the product's name, were presented to participants alongside all questions. Acquaintance was measured with a single item per product ('I have seen the product before'; Yes/No). Willingness to try was measured by the item 'I would be willing to try the product' (5-point Likert scale from disagree (-2) to agree $(+2)$ ). Both items were used in an earlier study of Tuorila et al. (Tuorila, Lähteenmäki, Pohjalainen, \& Lotti, 2001). A separate answering category was included for past consumption of the products. If participants indicated to have already tried a product their willingness to try the product was not measured and automatically set to the maximum $(+2)$, as past consumption was interpreted as evidence of willingness to try. An acquaintance sum score was calculated by summing the acquaintance scores of the 13 healthful alternatives available in Dutch supermarkets (range 0-13). Similarly, a willingness to try sum score was calculated by the mean of the individual scores of the 15 products (range -2 to 2 ).

Finally, the first questionnaire measured age, gender, country of origin, and level of education. Due to differences in routing depending on the respondents' answers, the length of the questionnaire was maximally 96 items, but varied between respondents. The second questionnaire consisted merely of the 10 FNS items. 
Table 4.2: Overview of the healthful alternative products used in the study

\begin{tabular}{|c|c|c|}
\hline Traditionally products in the Dutch diet & Healthful alternative & Product description \\
\hline Full-fat (Goudse) cheese & Uniekaas Zonnezuivel & $\begin{array}{l}\text { Cheese-like product from milk and } \\
\text { sunflower-oil which compared to full- } \\
\text { fat 'Goudse' cheese has } 40 \% \text { less total } \\
\text { fat and } 50 \% \text { less saturated fat. }\end{array}$ \\
\hline Whole or semi-skimmed milk & Campina $0 \%$ vet melk & Fat free 'skimmed' milk \\
\hline Coffee milk & Friesche Vlag Balance & Fat free 'skimmed' coffee milk \\
\hline Yoghurt & Becel pro active & $\begin{array}{l}\text { Fat free yoghurt that helps lowering } \\
\text { cholesterol }\end{array}$ \\
\hline Spread & $\begin{array}{l}\text { Van-Dijk Food } \\
\text { products Twenty four } \\
\text { ultralight }\end{array}$ & $\begin{array}{l}\text { Diet margarine with } 20 \% \text { fat thereof } \\
\text { only } 6 \% \text { is saturated. }\end{array}$ \\
\hline Butter & Blue band culinesse & $\begin{array}{l}\text { Lean liquid frying fat with } 82 \% \text {, thereof } \\
30 \% \text { saturated }\end{array}$ \\
\hline Mayonnaise & Remia frites lijn & $\begin{array}{l}\text { Mayonnaise-like product with } 5.3 \% \\
\text { total fat, thereof } 0.8 \% \text { saturated }\end{array}$ \\
\hline Meat & Quorn & Meat substitute based on soy beans \\
\hline Meat & Campina valess & $\begin{array}{l}\text { Meat substitute based on milk, protein } \\
\text { \& seaweed }\end{array}$ \\
\hline Crisps/potato chips & Snack-a-jack & Puffed rice \\
\hline Biscuit & $\begin{array}{l}\text { Bolletje zachte } \\
\text { fruitkoek }\end{array}$ & $\begin{array}{l}\text { Soft biscuit with } 41 \% \text { fruit } 9 \% \text { total fat, } \\
\text { thereof } 4 \% \text { saturated. }\end{array}$ \\
\hline Fresh fruit & Hero Fruitontbijt & $\begin{array}{l}\text { Drinkable breakfast based on fruit and } \\
\text { fibers }\end{array}$ \\
\hline Fresh fruit & Hero Fruit 2 day & $\begin{array}{l}\text { The equivalent of two pieces of fruit } \\
\text { (juice and fiber) in a bottle }\end{array}$ \\
\hline Fresh fruit and vegetables & Knorr Vie Fruit shot & $\begin{array}{l}\mathrm{F} \& \mathrm{~V} \text { pulp including banana, pumpkin } \\
\text { and kiwi }\end{array}$ \\
\hline Chocolate bar & Mars lite & $\begin{array}{l}\text { Mars chocolate bar with } 30 \% \text { less fat } \\
\text { than an original Mars chocolate bar } \\
\text { (import from Australia, not available in } \\
\text { the Netherlands) }\end{array}$ \\
\hline
\end{tabular}




\section{Data analysis}

Data were analyzed using the SPSS 13.0 statistical package (SPSS Inc., Chicago, IL, USA). Possible selective dropout between (1) the invitation phase and actual enrolment in the study and (2) the two measurements was assessed using logistic regression analyses with dropout as dependent and age, sex, and level of education as independent variables (as well as food neophobia score in the second dropout analysis).

The internal consistency of the adapted version of the Dutch FNS was assessed using Cronbach's $\alpha$ on both measurements; test-retest reliability was assessed with the Pearson correlation coefficient. Possible subgroup differences in level of food neophobia were analyzed using linear regression analysis with level of food neophobia as dependent and the demographic variables (age, gender and level of education) as independent variables.

To assess associations with level of food neophobia, stepwise linear regression analyses were conducted with the acquaintance or willingness to try scores as dependent variables. To control for the possible influence of age, gender and level of education, these variables were included as independent variables in step 1 . In step 2 level of food neophobia was included as independent variable.

\section{Results}

\section{Response and sample characteristics}

Of the 543 panel members that were invited for this study 326 completed the first questionnaire $(60.0 \%$ response). No selective dropout occurred between the invitation phase and enrolment in the study. Participants' mean age was 32.8 years (SD 8.7) and $56.4 \%$ were female. Of the participants $19.9 \%$ had a low level of education (none, primary school or lower vocational school), 38.3\% a medium level (secondary vocational school or high school degree) and $41.7 \%$ a high level (college or university degree). Of these 326 participants 274 completed the second questionnaire as well (84.1\% response). Between the two measurements also no selective dropout occurred. 


\section{Acquaintance with and willingness to try healthful alternatives}

The acquaintance sum score was 7.9 (SD 2.4), indicating that the participants on average had seen 7.9 of the 13 products before. The average willingness to try score across the fifteen products was 0.79 (range -2 to 2 , SD 0.78). For the individual products that were available in Dutch supermarkets at the time of the study, percentage acquaintance varied from $14.1 \%$ (alternative for butter) to $94.5 \%$ (convenient alternative for fresh fruit at breakfast), and mean willingness to try score from -0.13 (low-fat alternative for full-fat coffee milk) to 1.35 (frying fat with reduced levels of saturated fat) (Table 4.3).

\section{Psychometric analysis of adapted version of Dutch FNS}

The internal consistency of the FNS was almost the same for the two measurements, i.e., $\alpha=0.81$ and 0.85 , respectively. The Pearson correlation coefficient for the FNSscore between the two measurements was 0.81 . Due to the comparable results of the two measurements and the larger sample it was decided to use the first measurement of the FNS for the remainder of the analyses.

\section{Level of food neophobia and subgroup differences}

The mean food neophobia score was 30.1 (range 11-63, SD 9.5). Low educated participants had a significantly higher food neophobia score (mean 32.5, SD 9.7) compared to participants with a high level of education (mean 28.2, SD 9.3) $(\beta=-0.23$, $\mathrm{p}<0.01)$. No other significant differences in level of food neophobia for the tested demographic variables were found.

Association between level of food neophobia and acquaintance with and willingness to try healthful alternatives

Gender was significantly associated with the acquaintance with the healthful alternatives $(\beta=-0.27, p<0.001)$; women had seen more of the healthful alternatives than men. Furthermore, food neophobia score was inversely associated with acquaintance $(\beta=$ $0.21, \mathrm{p}<0.001)$. Gender $(\beta=-0.12, \mathrm{p}<0.05)$ and food neophobia score $(\beta=-0.26, \mathrm{p}$ 
CHAPTER 4

$<0.001)$ were also significantly associated with mean willingness to try the products. For the individual products significant associations were found between participants' level of food neophobia and their acquaintance with three and their willingness to try eight products (Table 4.3). 


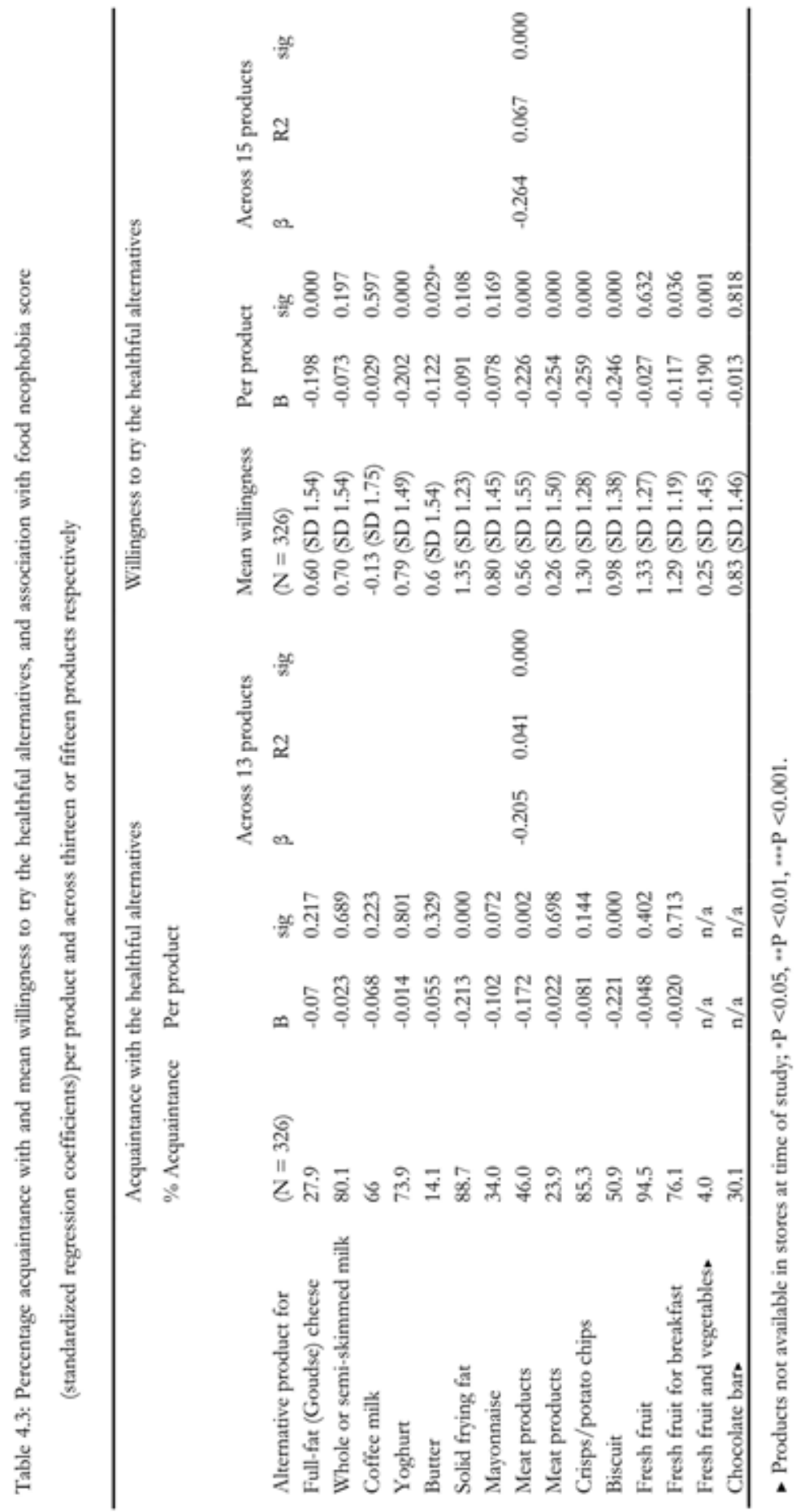




\section{Conclusions and discussion}

In the present study it was shown that on average participants were acquainted with the majority of a range of food products that can be regarded as healthful alternatives for regular products. On average, respondents were also rather willing to try these potentially healthful alternatives.

Acquaintance ratings of the healthful alternatives as well as mean willingness to try scores appeared higher than in comparable studies, which, however, mainly used different kinds of products than the present study. The majority of studies on the relationship between level of food neophobia and behaviour towards unfamiliar food products have used ethnical foods (McFarlane \& Pliner, 1997; Meiselman \& Schutz, 2003; Pelchat \& Pliner, 1995; Pliner \& Martins, 2002; Tuorila, Lähteenmäki, Pohjalainen, \& Lotti, 2001). The fact alone that we used products from frequently used product groups might explain the higher acquaintance ratings. Furthermore, we presented participants with unaltered information about the products depicting real product names and in most cases brand names as well. Some other studies have used fake product names or product descriptions to decrease familiarity (Martins, Pelchat, \& Pliner, 1997; Pliner \& Hobden, 1992; Pliner, Pelchat, \& Grabski, 1993; Potts \& Wardle, 1998; Tuorila, Lähteenmäki, Pohjalainen, \& Lotti, 2001) or presented stimuli in plastic cups instead of their original packaging (Arvola, Lähteenmäki, \& Tuorila, 1999; Martins $\&$ Pliner, 2005). The internet format of the present study might be another explanation for the comparably high willingness to try scores as the study did not include (the risk of) actual tasting of the products which was included in other studies (Arvola, Lähteenmäki, \& Tuorila, 1999; Martins, Pelchat, \& Pliner, 1997; Martins \& Pliner, 2005; Pliner \& Pelchat, 1991). The surprisingly high reported acquaintance with one of the products not available might be due to high similarity of the package with the original Mars chocolate bar available in the Netherlands in colour, font and proportions. The psychometrical qualities of the adapted Dutch version of the FNS were sufficient (Nunnally \& Bernstein, 1994; Spector, 1992) and comparable to other studies reporting internal consistency and/or test-retest correlation of translations of the original scale (Eertmans, Victoir, Vansant, \& van den Bergh, 2005; Tuorila, Lähteenmäki, Pohjalainen, \& Lotti, 2001). In the present study we did not validate the FNS against neophobia measures in the laboratory as had been done in Pliner and Hobdens' original 
work (Tuorila, Lähteenmäki, Pohjalainen, \& Lotti, 2001), therefore we cannot say anything about the true validity of the adapted Dutch version of the FNS.

Mean level of food neophobia in the sample seems comparable to results of earlier studies in participants of roughly comparable ages (Tuorila, Lähteenmäki, Pohjalainen, \& Lotti, 2001). However, Ritchey et al. warn against cross-nationally comparing results acquired with the FNS before it has been ultimately proven that this scale is transnational, thus reliably measuring the same concepts in different languages/cultures (Ritchey, Frank, Koivisto Hursti, \& Tuorila, 2003). In the present study we did not find significant gender or age differences in level of food neophobia. Differences between level of food neophobia in men and women have been reported in three studies from Scandinavia where men were found to score higher (Bäckström, Pirttilä-Backman, \& Tuorila, 2003; Hursti \& Sjödén, 1997; Tuorila, Lähteenmäki, Pohjalainen, \& Lotti, 2001). Other studies did not report such differences between men and women (Falciglia, Couch, Gribble, Pabst, \& Frank, 2000; Hobden \& Pliner, 1995; Koivisto \& Sjödén, 1996; Pliner, 1994; Pliner \& Hobden, 1992; Rigal et al., 2006; Wardle, Carnell, \& Cooke, 2005). Several studies report age differences in level of food neophobia (Cooke, Wardle, \& Gibson, 2003; Hursti \& Sjödén, 1997; Koivisto \& Sjödén, 1996; McFarlane \& Pliner, 1997; Pliner \& Loewen, 1997; Raudenbush, Schroth, Reilley, \& Frank, 1998; Tuorila, Lähteenmäki, Pohjalainen, \& Lotti, 2001), whereas others do not (Addessi, Galloway, Visalberghi, \& Birch, 2005; Falciglia, Couch, Gribble, Pabst, \& Frank, 2000). Many studies support the notion that one's level of food neophobia decreases as age increases (Tuorila, Lähteenmäki, Pohjalainen, \& Lotti, 2001). As Cooke et al. put it: 'Food neophobia appears to be minimal in infancy, raising rapidly at age two and gradually tailing off thereafter' (Cooke, Wardle, \& Gibson, 2003). The absence of an effect of age on level of food neophobia in the present study might therefore be explained by the chosen age range in the study sample (18 to 50 years), omitting the very young and the elderly. To our knowledge two earlier studies looked into the relationship between socio economical status (SES) and level of food neophobia. Our finding of a significant relationship between level of education and food neophobia scores replicates results of a study in Finland (Tuorila, Lähteenmäki, Pohjalainen, \& Lotti, 2001) which used participants' level of education as a proxy for SES. Flight et al., however, were not able to show significant relationships between their proxies for SES (two household indexes) and food neophobia scores (Flight, Leppard, \& Cox, 2003). 
As in related studies, we were able to show significant, though small, negative associations between level of food neophobia and both acquaintance with and willingness to try the presented food products. In the present study, however, for the first time these findings were replicated using only products from, in Tuorila's terms, the category of nutritionally modified foods and for $F \& V$ products with improved convenience (Tuorila, 2001). Women were significantly more acquainted with and willing to try the healthful alternatives. These results are consistent with findings of Tuorila et al., (Tuorila, Lähteenmäki, Pohjalainen, \& Lotti, 2001) and are likely to be resulting from differences in exposure to food products through food preparation (Hursti \& Sjödén, 1997).

In interpreting our findings, it should be kept in mind that the items used to measure acquaintance with and willingness to try were based on items used in other studies, but information on the reliability and validity of these items is lacking, and both concepts were measured using only a single item for each concept. Face validity of the acquaintance item is judged to be high as participants were asked to remember whether they had seen a product before on the basis of the product name and a picture of each product. Another factor that might have influenced the results of the present study is the selection of the 15 products from the broader range of available products of interest, i.e. healthful alternatives for traditional foods in the Dutch diet. We do not know how much this influenced the results, as we do not know whether the role of food neophobia differs for each product or each product category (or even broader categories), because the study only included one or two products per product category. Furthermore, we did not control for possible confounders that could have influenced the association between food neophobia and both acquaintance with and willingness to try the products. It therefore is possible that the found associations might be attributed to third variables, for instance a personality characteristic, and might be overestimated. Finally, since this study was conducted in a sample of 18-50 year olds results are not to be generalized to other groups in the Dutch society.

To overcome some of the limitations of the present study, further research it should try to include some possible confounders in the design and also include actual tasting of the unfamiliar food products as an outcome variable.

Despite the study limitations and the modest associations that we found, we conclude that our study results indicate that a person's level of food neophobia might 
be a factor worth accounting for when wanting to introduce foods in the diet one is not acquainted with. This seems to hold especially true for the low educated group, because this group has the greatest need for behavioural change with respect to diet (van der Lucht \& Picavet, 2006), on the one hand, and has been shown to be affected most by food neophobia, on the other. Literature suggests a number of strategies to reduce level of food neophobia to alter food choice behaviour regarding unfamiliar foods, for example taste-information (Martins, Pelchat, \& Pliner, 1997; McFarlane \& Pliner, 1997; Pelchat \& Pliner, 1995; Tuorila, Meiselman, Bell, Cardello, \& Johnson, 1994), repeated exposure (Tuorila, Meiselman, Bell, Cardello, \& Johnson, 1994), and social modelling (Hobden \& Pliner, 1995). At the least our study warrants further study into the role of food neophobia, to explore whether the use of such strategies in health education interventions focussing on integration of healthful alternatives in the daily diet is indeed promising to accomplish health gain.

\footnotetext{
Acknowledgments:

We thank Annet Hoek and Kees de Graaf of Wageningen University for giving their permission to let us use and alter their Dutch translation of the food neophobia scale for this study.
} 


\section{Chapter 5:}

Information about the taste stimulates choice of unfamiliar healthful food products 


\section{Abstract}

Background. The purpose of this study was to assess whether product information about unfamiliar low-fat and fruit and vegetable products leads to more positive taste expectations and stimulates choice for these products. The impact of level of food neophobia on such effects was studied.

Method. The study had a 2 (condition) by 4 (product) between subjects design with a pre- and post-experiment questionnaire and was conducted in a restaurant room in a university building among a convenience sample of 396 university students. A poster providing detailed information on the taste of the offered target product was provided as an intervention. The effect measures included taste expectations and product choice. Other measures included level of food neophobia, appetite level, mood states, usual intake of fruit, vegetables and fat, and demographics.

Results. Product information did not result in more positive taste expectations, but did stimulate the choice of unfamiliar healthful products. These effects were unrelated to level of food neophobia.

Conclusion. Offering detailed taste information on unfamiliar healthful products seems to be a promising strategy to increase first time trial of such products, independent of participants' level of food neophobia. 


\section{Introduction}

High intakes of saturated fat and low intakes of fruits and vegetables (F\&V) have been linked to increased risk for cardiovascular diseases, various forms of cancer, and obesity (World Cancer Research Fund, 2007). Therefore, dietary recommendations have been issued indicating maximum recommended quantities of daily saturated fat intake (in the Netherlands: less than 10 percent of total energy intake) and minimum recommended daily intakes of $F \& V$ (in the Netherlands: 2 pieces of fruit and $200 \mathrm{~g}$ of vegetables) (Health Council of the Netherlands, 2006). In the Netherlands, a majority of the population does not comply with the recommendations (Hulshof et al., 2004), despite many efforts to encourage people to do so, e.g. in school settings in the Krachtvoer and ProChildren projects (Martens, van Assema, Paulussen, van Breukelen, \& Brug, 2008; te Velde et al., 2008). One way to promote more healthful eating is through product innovation, i.e. by introducing equally palatable new foods that contain less saturated fat or by creating more convenient $F \& V$ products. A recent modelling study suggested that if Dutch young adults were successfully encouraged to replace three high-saturated fat products in their diet for readily available low-fat alternatives, compliance to the recommendation for saturated fat intake would increase from 23\% (Hulshof et al., 2004) to $86 \%$ (Schickenberg et al., 2009).

Because 'health' is an important selling point for the food industry, the availability in Dutch supermarkets of potentially healthful alternatives (low-fat products; convenient $\mathrm{F} \& \mathrm{~V}$ products) has steadily increased over the years. Although in some product groups shifts in product choice have taken place, such as the wide acceptance of semi-skimmed milk and low-fat margarine (Health Council of the Netherlands, 2002), many new, potentially healthful alternative products have not been accepted so easily. Reluctance to try new foods has been labelled as food neophobia, and people differ in this tendency (Pliner \& Hobden, 1992). Food neophobics, for example, are significantly less willing to try ethnic foods (Pliner, Pelchat, \& Grabski, 1993) but also potentially healthful low-fat and F\&V alternatives (Schickenberg, van Assema, Brug, \& de Vries, 2008). The effect of people's level of food neophobia on their willingness to approach unfamiliar foods has been found to be related to e.g. age, gender, mood state and appetite level (Pliner, Eng, \& Krishnan, 1995). 
Expected taste is also an important determinant of first time trial of a new product (Rozin, 1988) and it has been shown that provision of information on the taste of products can increase one's willingness to try unfamiliar food products. In earlier studies participants were informed on how others have liked the taste of an unfamiliar product ("9 out of ten say that this tastes great" (Pelchat \& Pliner, 1995), "We know from other subjects that these are foods that taste good" (Martins, Pelchat, \& Pliner, 1997)), and on the resemblance of the taste of an unfamiliar product to familiar flavours ("The flavour is traditionally birch, anise and clove"). It has been suggested that such information increases willingness to try the product by reducing uncertainty about the product (Tuorila, Meiselman, Bell, Cardello, \& Johnson, 1994).

The present study focused on unfamiliar healthful products available in Dutch supermarkets and explored the effects of information about the taste of such products on taste expectations and product choice, in a lunch buffet setting. We hypothesized that, while controlling for possible confounding factors such as mood and appetite, taste information would lead to more positive taste expectations, increase the chance that such an unfamiliar healthful food product was chosen at the buffet, and that these effects would be stronger among more neophobic respondents.

\section{Method}

\section{Design}

We used a 2 (condition) by 4 (products) between subjects design with a pre- and postexperimental questionnaire. The dependent variables were taste expectations and product choice (traditional product or healthful alternative) at a lunch buffet.

\section{Participants and setting}

The study was conducted at Maastricht University in a university buffet-style restaurant around lunch time (between 11:00 and 14:30 hours) on weekdays. Students approaching the lunch cafeteria were asked to participate in a study on food choice, and to complete a 5-minute recruitment questionnaire, which included written information on the study and an informed consent part. Participants who completed the recruitment questionnaire entered a lottery with an $\mathrm{mp} 3$ player as a prize. Participants who indicated in the recruitment questionnaire to have diabetes or other metabolic 
disorders, food-related allergies or food intolerances were excluded from further participation in the study. The other participants were informed that participation included filling out two additional questionnaires and that it would take about 30 minutes to complete. For participation in the second part of the study participants were promised a reward of $€ 5$ in cash, as well as a free lunch at a buffet.

\section{Procedures}

Participants were guided to a lunch buffet. As the Dutch usually consume a sandwichbased lunch, participants were presented a buffet consisting of products from the following five product groups (in sequence as encountered by participants): mineral water (sparkling and flat), bread rolls (a choice between brown and white), margarine bread spread, Gouda cheese, and F\&V's (tomato, apple, orange). In addition, for each participant one out of four target products was added to this line-up of the buffet. Two target products were unfamiliar healthful alternatives for frequently consumed products in the daily diet of the Dutch that are high in saturated fat, i.e. low-fat cheese and very low-fat margarine spread. The other two target products were convenient alternatives for fresh $\mathrm{F} \& \mathrm{~V}$ products, i.e. two juices that are available in portion sized, ready to use containers. Both products claim to cover a substantial percentage of the recommended dietary allowance (RDA) for fruit (fruit juice with pulp) or for fruit and vegetable (F\&V based juice). Target products were chosen based on their reduced saturated fat or high $\mathrm{F} \& \mathrm{~V}$ content and recent launch on the market. The target products were available in Dutch supermarkets at the time of the study. All products used in the buffet were presented to participants in neutral containers, thus without their usual packaging. Bogus product names were used to minimize the chance of recognition of the target products and to ensure that all offered products were perceived as new by the participants. Trustworthiness of the chosen product names was determined in a pretest. Target products were positioned immediately to the right of the corresponding product from the same product group. Colour cards (approx $15 * 5 \mathrm{~cm}$ ) were put in front of all products offered in the buffet. In the lower left corner of these cards the logo and name of Maastricht University were shown. In the upper left corner the name of the product group was stated, and in the centre of each card the product name. Per product group the cards had a different colour. 
Based on the information collected in the recruitment questionnaire participants were stratified by level of food neophobia (cut-off point 35 on the FNS) and assigned to one of the four healthful alternatives included in the study. Participants were only proposed a target product from a product group they had indicated to regularly consume products from. Within this constraint it was strived to assign equal numbers of male and female participants to all target products, based on sequence of arrival (alternating product groups over participants).

Random assignment of participants to either the experimental or control condition was done using two lists of randomly generated numbers, one for food neophobics, and the other for non food neophobics. The next number on the relevant list determined whether a participant was assigned to the control group (uneven number) or the experimental condition (even number).

While a participant filled out the pre-experimental questionnaire, which took about 3 minutes, the buffet was prepared according to the condition and target product to be used. In the experimental condition a poster was placed behind the target product on the buffet. The poster had a portrait A3 format $(29.7 \times 42 \mathrm{~cm})$ featuring a colour photograph of the target product in the lower third of the poster. In the top right corner of the poster the Dutch equivalent of the word 'new' was placed. Below that stood the question "How does < name target product> taste?". Below this question the sentence, "A new alternative for < name original product group $>$ " was placed. In the upper right corner of the name of the target product a symbol was placed implying that the name is copyrighted. In the middle of the poster specific information on the taste of the target product was provided (Figure 5.1). The taste information aimed to provide an appealing description of the products' taste and the resemblance of the target product in taste and texture with other, presumably familiar, flavours and products. Furthermore, the taste description aimed to appeal to the participants. The poster also explained to which product group the unfamiliar products belong, or where they would be available in supermarkets.

Participants were told that it was important to eat a lunch as the researchers wanted none of the participants to be hungry while participating in a final part of the study. Participants were guided to the buffet one by one by an assistant of the experimenter, and instructed to choose one product from all presented product groups. They were told that they were not obliged to consume all chosen products, but just as much to 
satisfy their appetite. Participants were instructed to sit and consume their chosen lunch at a group of tables after having made their choice at the buffet. They were asked to sit at an empty table and consume their lunch in silence. After instructions were completed the assistant left the participants at the buffet. The instruction and choice of products at the buffet took about three minutes on average.

After lunch consumption, participants completed the 15-minute post-experimental questionnaire, were thanked and rewarded and asked to keep silent about the study towards co-students. The study was approved by the ethical committee of Maastricht University.

\section{F\&V products}

Vita-leef ("vita-live") tastes overwhelmingly fresh and fruity. Vita-leef contains the best of 5 different fruits and vegetables, but its taste is particularly determined by the familiar taste of orange and banana. Vita-leef is thicker and less watery than usual juices, but it still tastes like juice.

All-in sap is a new drink in the F\&V shelf. The taste of All-in sap is determined by the familiar tastes of apple, orange and banana. The feeling of freshness comes from the pieces of fruit suspended in the juice that give you the feeling of eating real fresh fruit.
Products low in saturated fat products

Slankarine is a new lean bread spread in the margarine and butter shelf. Slankarine is extremely soft and easy to spread, even if taken directly out of the fridge. Still Slankarine tastes like the familiar lean margarine. The fresh taste of bread comes across well through the use of Slankarine.

Sun-cheese contains just as much fat as a $30+$ cheese, but part of the fat in Sun-cheese was replaced by vegetable fat instead of animalbased fat. The difference is tangible but not perceptible in taste. The cheese feels like a young cheese, but its taste is as rich as a matured cheese. Sun-cheese is the first delicious lean alternative for cheese that even tastes like cheese.

Figure 5.1: Target product specific informative text provided on the posters in the experimental condition

\section{Measures}

The recruitment questionnaire assessed participants' gender, age, length, weight, ethnicity (Dutch, one or both parents being born in a neighbouring country, or otherwise), and living situation (alone, with parents, in student dormitory, together with partner, or otherwise). Furthermore, questions on the participants' allergy status and the presence of diabetes, metabolic disorders, food allergies, and food related intolerances were included. Also, dietary regiments (to loose weight, special diet for medical reasons [low-fat, gluten-free, cholesterol-lowering], vegetarian, vegan, organic food) and whether participants were doing shopping for their household were questioned. With 
regard to bread, fresh fruit, fruit juice, vegetables, vegetable juice, cheese and bread spread, participants were asked to indicate whether they consume these food products regularly or not, and to specify which bread-spread they normally used (real-butter, regular margarine, low-fat margarine). Level of food neophobia was assessed with a Dutch translation of the food neophobia scale (FNS) (Pliner \& Hobden, 1992; Schickenberg, van Assema, Brug, \& de Vries, 2008) which comprises ten items measured on a seven-point Likert scale from completely disagree to completely agree. Respondents' food neophobia score was computed by summing the answers of the ten items (theoretical range 10-70), higher scores indicating higher reluctance to approach unfamiliar foods. The adapted Dutch version of the FNS was shown to be a reliable measure (Schickenberg, van Assema, Brug, \& de Vries, 2008). Usual intake of fruits in servings per day and intake of vegetables in grams a day were assessed with a validated 16-item food frequency questionnaire with a reference period of one month (Bogers, van Assema, Kester, Westerterp, \& Dagnelie, 2004).

The pre-experiment questionnaire assessed participants' current appetite on a fourpoint scale from 'none' to 'a lot'. Current mood state was measured using the shortened Dutch version of the Profile of Mood States Scale (POMS) (Wald \& Mellenbergh, 1990), a 32-item scale measuring the mood states of depression, tension, vigour, fatigue, and anger. Participants were asked to indicate the degree to which their mood corresponded to each of the 32 adjectives used in the list such as angry, helpless, or restless $(0=$ 'absolutely not', to $4=$ 'very much') at the moment of administration.

Post-experiment measures included registration of product choice by an assistant. The final questionnaire assessed product consumption, and included items about the taste of the target product and statements on the buffet situation, target product, and the information sign. All statements were measured on seven-point Likert scales from completely disagree to completely agree, unless otherwise indicated. Taste expectation of the target product was measured by one item, i.e., "When I saw < name target product $>$ being offered I thought I would like its taste". Among participants who chose the target product, perceived taste ("I liked the taste of < name target product>"), and resemblance between expected and perceived taste was assessed ("The taste of $<$ name target product> was as I expected"). To assess factors that might possibly confound our results eight items questioned trustworthiness of the experimental situation and resemblance with real restaurant situations, e.g., whether the restaurant 
looked clean and appealing, whether the buffet appeared to be a normal buffet. Participants' prior acquaintance with the target products was measured by two items asking whether they had heard of, or had consumed the product before (yes/no). Three more items also assessed prior acquaintance with the target products, thereby disclosing their original names. It was asked whether participants had heard of or had consumed the product before and whether they realized that the product offered at the buffet was identical to the product with the original name. As a manipulation check it was asked whether the participant noticed the poster providing information on the taste of the target product (yes/no). Furthermore, four statements assessed to what degree they trusted the information, whether the information convinced them that they would like the taste of the product, whether their product choice was based on the information, and whether they would not have chosen the product without the information. Finally, participants' usual fat intake was measured with a validated 35-item food frequency questionnaire covering 19 food products or groups of products that contribute most to the consumption of saturated fat (van Assema, Brug, Ronda, \& Steenhuis, 2001). Multiple versions of the final questionnaire were made to account for differences between conditions and target product used.

\section{Analyses}

Data input was conducted and double checked by two research assistants. Answers to questions included in all versions of the final questionnaire were grouped across target products. Participants' level of food neophobia, usual intake of fruit, vegetables and fat, and the five subscales of the POMS were calculated as indicated in the respective literature (Bogers, van Assema, Kester, Westerterp, \& Dagnelie, 2004; Pliner \& Hobden, 1992; van Assema, Brug, Kok, \& Brants, 1992; van Assema, Brug, Ronda, Steenhuis, \& Oenema, 2002; Wald \& Mellenbergh, 1990). Participants' body mass index (BMI) was calculated based on self-reported height and weight.

Missing values analysis regarding the outcome variables revealed two missing values on the variable of expected taste. Of the other variables, most had no missing values. Only three variables had more than three missing values: usual intake of vegetables (8), usual intake of fruit (9) and participants' age (15). Missing values were not replaced, except for age. As all participants were students, the missing values for age were replaced by the mean age of all participants. 
To assess possible selective drop-out after completion of the intake questionnaire, logistic regression analysis was conducted with dropout (yes/no) as dependent variable and gender, age, ethnicity, BMI, and level of food neophobia as independent variables. To assess possible differences in distribution of participants over the experimental conditions, logistic regression analysis was conducted with experimental condition as dependent variable and gender, age, ethnicity, BMI, level of food neophobia, appetite, mood states, and usual intakes of fruit, vegetables and fat as independent variables. A similar analysis was done to detect possible differences in distributions of participants exposed to either a low-fat or $\mathrm{F} \& \mathrm{~V}$ product.

To assess the effect of product information on taste expectation a multiple linear regression analysis was conducted with taste expectation as dependent variable and condition, level of food neophobia, age, sex, ethnicity, BMI, appetite, mood states, usual intake of fruit, vegetables, and fat, type of target product (low-fat versus F\&V) and the interaction term of condition by level of food neophobia as independent variables. To assess the effect of product information on product choice a multiple logistic regression analysis was done with participants' choice of the offered healthful alternative as dependent variable, and expected taste and the same variables as in the aforementioned analysis as independent variables. In both the analyses non-significant variables (except condition) were excluded from the model in a hierarchical and stepwise procedure. As secondary analyses, we repeated the analyses that did not reveal an effect of condition without the participants in the intervention group who reported to not have seen the taste information poster.

Data were analysed using the SPSS 15.0 statistical package (SPSS Inc., Chicago, IL, USA). A significance level of $\mathrm{p}<0.05$ was used.

\section{Results}

\section{Response and participant characteristics}

A total of 684 students $(73 \%$ women, $27 \%$ men) completed the recruitment questionnaire. Because it was not recorded how many students were approached no response rate could be determined. Forty students were excluded from further participation because they reported to have diabetes (7), other metabolic disorders (5), 
food-related allergies (17) or food intolerances (18). Seven students indicated to have more than one of the above.

Of the 644 students eligible for participation, 399 (62.0\%) participants agreed to participate in the second part of the study. Three participants dropped out after completion of the pre-experiment questionnaire. Their data were omitted from further analysis. No significant differences were found in sex, age, migrant status, BMI and level of food neophobia between participants who quit participation after the intake questionnaire and those who completed the study. The demographics and other key variables according to experimental group are reported in Table 5.1.

The 199 participants in the experimental group had a statistically significant higher BMI (22.2) than the 197 participants in the control group (21.5) (OR=1.1, 95\% CI 1.04- 1.22, $\mathrm{p}<0.05)$, but no other significant differences were found between the experimental groups, nor between participants that were offered a F\&V alternative and participants that were offered a low-fat alternative. In all further analyses participants' BMI was included as a covariate. 
Table 5.1: Means, range and percentages of participant demographics, FNS score, usual fruit, vegetable and fat intake, and mood states $(\mathrm{N}=396)$

Variable (reported values)

Gender, \% female

Mean age, years (SD)

Mean Body Mass Index (SD)

Ethnicity (\%)

Both parents born in the Netherlands

One or both parents born in the neighbouring nations of Germany or

Belgium

One or both parents born in a non-western country

10.2

Living situation (\%)

In a student house

47.2

With parents

33.6

On their own

9.8

With partner

6.3

Other (e.g. together with sibling(s))

Special dietary regimen $(\%)$

None

Vegetarian

4.5

Weight loss 4.3

Medical reasons

2.5

Biological diet 1.8

Vegan diet 1.0

Doing errands for the household, \% yes

Mean FNS score, points [range 10-57] (SD)

Mean fruit intake, servings a day (SD)

Mean vegetable intake, spoons a day (SD)

Mean fat intake, in points [range 3-38] (SD)

Mean appetite score [range 0-4] (SD)

Mean mood states scores (SD)

Anger [range 0-21] (SD)

Depression [range 0-20] (SD)

Vigour [range 0-19] (SD)

Tension [range 0-16] (SD) 


\section{Participants' perceptions of the experimental situation}

The first section of Table 5.2 shows that participants were slightly positive about the buffet, and did not report to behave very differently than during a normal restaurant lunch. On average the participants agreed nor disagreed that it was a normal buffet.

A minority of the participants reported to be familiar with the offered target products under the used mock names: $89.6 \%$ indicated to have never heard of the offered product before, and $92.9 \%$ indicated to have never consumed the product before. After the main data collection was completed the original product name was disclosed. Provided with the original product name $47.5 \%$ of the participants indicated to have heard of the target product under its original name before, and $19.7 \%$ indicated to have consumed the target product under its original name before. Ninety-two percent of the participants indicated not to have recognized the offered target product as a product being available in stores under its original product name.

Of the 199 participants assigned to the experimental condition, 57.3\% indicated to have seen the product information poster. Table 5.2 shows that on average the trustworthiness of the provided information was judged to be neutral. Furthermore, on average participants reported that their product choice and taste expectation was rather unrelated to the information provided on the information poster. 
Table 5.2: Mean (SD) agreement with statements concerning the experimental situation (range -3 (completely disagree) to 3 (completely agree) $(\mathrm{N}=396)$

Mean (SD)

The buffet $(\mathrm{N}=396)$

The products appeared to be fresh $(\mathrm{N}=395)$

The restaurant looked fine, concerning the hygiene $(\mathrm{N}=396)$

The lunch was nice $(\mathrm{N}=394)$

I did not feel at ease in the restaurant $(\mathrm{N}=395)$

I chose different products in the restaurant as compared to similar situations $(N=395)$

I ate more than planned $(\mathrm{N}=394)$

The instructions were trustworthy $(\mathrm{N}=394)$

The buffet appeared to me as a normal buffet $(\mathrm{N}=396)$

The information poster $(\mathrm{N}=199)$

The information was trustworthy $(\mathrm{N}=117)$

The information convinced me that I would like the taste of the target product $(\mathrm{N}=116)$

My product choice was based on the information $(\mathrm{N}=116)$

I would not have chosen the product if I had not been provided with the information

$-0.8(1.8)$ $(\mathrm{N}=115)$

Taste expectation, actual perceived taste, and agreement between expected and perceived taste

Table 5.3 shows that on average, participants had a neutral expectation of the taste of the offered target product. Those participants who had actually tasted the offered target product evaluated its taste slightly positive. The actually perceived taste after trying the product was to some extent in agreement with their pre-consumption expectations. 
Table 5.3: Mean scores (SD) on taste expectation, actual taste, and agreement between expected and actual taste $(-3$ to +3$)$

\begin{tabular}{llll}
\hline & $\begin{array}{l}\text { Experimental group } \\
(\mathrm{N}=199)\end{array}$ & $\begin{array}{l}\text { Control group } \\
\mathrm{N}=197)\end{array}$ & $\begin{array}{l}\text { Total group } \\
(\mathrm{N}=396)\end{array}$ \\
$\begin{array}{lll}\text { Taste expectation } \\
0.1(1.8)(\mathrm{N}=199)\end{array}$ & $0.1(1.8)(\mathrm{N}=195)$ & $0.01(1.8)(\mathrm{N}=394)$ \\
Actual taste & $0.7(1.6)(\mathrm{N}=86)$ & $1.1(1.7)(\mathrm{N}=66)$ & $0.9(1.8)(\mathrm{N}=152)$ \\
$\begin{array}{l}\text { Agreement between } \\
\text { expected and actual } \\
\text { taste }\end{array}$ & $0.7(1.6)(\mathrm{N}=86)$ & $0.6(1.7)(\mathrm{N}=65)$ & $0.7(1.7)(\mathrm{N}=151)$ \\
\hline
\end{tabular}

\section{Choice of the target product}

Table 5.4 shows that on average $39.4 \%$ of all participants chose the target product at the buffet. The prevalence of choosing the target product differed between the two offered product groups (juice compared to fat products) $(\mathrm{F}(1,394)=4.79, \mathrm{p}=0.03)$.

Table 5.4: Percentage of participants choosing the target product for the total group, according to condition (experimental (exp) and control (con)) and target product ( $\mathrm{N}=396)$

\begin{tabular}{lcccccccccccc}
\hline & $\begin{array}{l}\text { Total } \\
\text { group }\end{array}$ & Condition & Fruit drink & F\&V drink & Cheese & & Bread spread \\
& & exp & con & exp & con & exp & con & exp & on & exp & con \\
$\begin{array}{l}\text { Percentage } \\
\text { participants } \\
\text { choosing the } \\
\text { target product }\end{array}$ & 39.4 & 45.2 & 33.5 & 58.5 & 42.3 & 48.0 & 27.3 & 36.4 & 31.4 & 36.5 & 32.0 \\
\hline
\end{tabular}

\section{Effects of the information poster}

The regression analysis with participants' taste expectation towards the offered healthful alternative products as dependent variable revealed no significant main effect of condition and no significant interaction effect of condition by level of food neophobia. Significant main effects were found for type of target product, and the mood state of anger and those variables were included in the final model. Mean taste expectation was significantly higher for the F\&V drinks (0.6) than for healthful low-fat alternatives $(-0.4)(\beta=-0.25, \mathrm{p}<0.001)$. Higher scores on the anger subscale of the 
POMS questionnaire were related to higher expected taste of the target product $(\beta=$ $0.11, \mathrm{p}<0.05)$.

The logistic regression analysis with actual choice of the target product as the dependent variable showed a significant main effect for condition. Participants in the experimental condition had significantly higher odds for choosing the offered target product than participants in the control group (percentages indicated in Table 5.4) $(\mathrm{OR}=1.30,95 \%$ CI 1.05-1.61 $\mathrm{p}<0.05)$. No significant interaction effect of condition by level of food neophobia was found. Significant main effects were found for participant's migrant status, mood state of vigour, and type of target product. Participants whose parents were not born in the Netherlands or one of the neighbouring countries were more likely to choose the healthful alternative $(65.7 \%)$ than participants of Dutch ethnicity $(36.3 \%)$, or participants with one or two parents born in neighbouring countries of the Netherlands $(39.4 \%)(\mathrm{OR}=3.55,95 \%$ CI 1.66 $7.60, \mathrm{p}<0.001)$. Lower scores on the vigour subscale of the POMS questionnaire were related to choice of the target product $(\mathrm{OR}=0.93,95 \%$ CI 0.88-0.99, $\mathrm{p}<0.05)$. Participants were more likely to choose an offered healthful alternative for fresh $F \& V$ products $(44.7 \%)$ compared to healthful alternatives for products high in saturated fat content $(34.0 \%)(\mathrm{OR}=0.64,95 \% \mathrm{CI} 0.42-0.98, \mathrm{p}<0.05)$.

With regard to taste expectation, the secondary analyses with only those participants in the experimental condition who indicated to have seen the taste information poster also did not reveal a main effect of experimental condition.

\section{Discussion}

This study focused on the effect of taste information on the development of a more positive taste expectation towards unfamiliar low-fat or $F \& V$ products, and on the stimulation of the choice of these products. The results indicated that the information did not influence participants' taste expectation towards the target products as we had expected. However, in line with our hypothesis, the presence of taste information increased participants' likelihood to choose the offered healthful alternatives, although the effect size was small. Choice of the unfamiliar healthful food products offered at the experimental buffet was the study's main outcome variable as first time trial of such 
products is seen as a necessary step in the development of liking and eventually preference for healthful alternative products (Birch, 1999).

As the provision of taste information was not shown to affect participants' taste expectations, this indicates a more direct effect of the information than we initially thought. Possibly the provision of taste information reduced participants' safety concerns, being a variable that has been shown to affect willingness to try unfamiliar foods before (Bäckström, Pirttilä-Backman, \& Tuorila, 2003). Relatedly, the inclusion of concrete descriptions of the products' mouthfeel and other characteristics directly affecting the use of the product (e.g. degree of spreadability of the very-low-fat margarine spread, the fact that the fruit juice contains chunks of fruit giving the impression of consuming fresh fruit) might have led to a decrease in perceived novelty of the products. The fact that no effect of provision of taste information was found on participants' taste expectations might also be explained by the retrospective measure of expected taste. To better mimic a natural food choice situation at a buffet, we chose to not disturb the process of product choice of the participants by asking questions on their expected taste at that moment. Reported taste expectations may have changed towards consistency with their factual choice behaviour.

We expected that especially people with higher food neophobia would have a need for information on the target products' taste prior to deciding to try these products. The results, however, showed that the taste information was equally effective for participants with different levels of food neophobia. Level of food neophobia was also not associated with participants' expectation of the target products' taste, nor with their choice of the offered target products. In an earlier study we did find an association between level of food neophobia and willingness to try unfamiliar healthful alternatives, but in that study a measure of self-reported willingness was used in stead of actual product choice such as in the present study. Because there was an effect of level of food neophobia on participants' choice, one should note that taste information does not compensate for food neophobia.

On average the participants in the experimental condition reported to not have been influenced a lot by the taste information provided on the poster. This indicates that participants were not aware of the effect the poster had on their behaviour, as we did find a significant effect of the presence of the taste information on participants' choice of the healthful alternatives. Studies on the role of awareness in consumer 
behaviour identified that consumers might be unconsciously influenced by environmental features (Chartrand, 2005). The poster providing taste information might be seen as an example of such environmental feature that unconsciously affected participants' choice behaviour.

As recommended (Meiselman, 1992), we tried to conduct the study while optimally mimicking a context in which food is normally selected and consumed, and to give participants the impression that their choice of products at the buffet had nothing to do with the study they had agreed to take part. Participants' judgements of the experimental situation showed that we were reasonable successful in this effort, but the situation was of course not an entirely normal lunch choice situation. The total number of products that was offered at the buffet was quite small. By presenting the target products without their packaging, almost all participants perceived the products as unfamiliar (as intended), but this is not done in real-life restaurants. Furthermore, it is possible that some participants paid attention to the taste information poster because they were given instructions at the buffet. Without this delay at the buffet participants might have missed the poster. We conclude that our results might only to a limited extent be generalized to real-life food choice situations

Another possible threat to the external validity of this study is that only university students participated. We cannot generalize the results to people of other age groups or educational levels. Finally, our findings cannot be generalized beyond the products that were used in the present study. We, however, carefully selected two products representative for available low-fat healthful alternative products and two products representative for alternative $\mathrm{F} \& \mathrm{~V}$ products, and all four products were more often chosen by participants in the experimental group than by participants in the control group.

In conclusion: the "easy" strategy of providing taste information was shown to effectively influence participants' behaviour towards choice of unfamiliar food products. The effectiveness of this strategy in a non-experimental context, however, is yet to be shown. Now that we know that the strategy is promising, it is proposed to test the effectiveness of taste information in a field experiment in a real-life situation, i.e. in a public eating environment, such as a worksite restaurant. 


\section{Chapter 6:}

\section{Product samples stimulate choice of unfamiliar healthful food products}




\section{Abstract}

Purpose. The purpose of this study was to assess whether the availability of a product sample of an unfamiliar low-fat or fruit and vegetable products stimulates choice for this product among food neophobic young adults.

Design. The study had a 2 (condition) by 4 (product) between subjects design with a pre- and post-experiment questionnaire.

Setting. Restaurant rooms in several educational institutions in the Netherlands.

Subjects. The study was conducted among a convenience sample of 197 young adults aged 17-25 years.

Intervention. A small bite or sip-sized sample of the target product was provided.

Measures. The effect measure was choice of either an unfamiliar healthful food product or a traditional food product. Other measures included level of food neophobia, appetite level, mood states, usual intake of fruit, vegetables and fat, and demographics.

Analysis. Multiple binary logistic regression analyses.

Results. Offering a sample of an unfamiliar healthful food product resulted in a significantly higher proportion of food neophobic participants choosing this product.

Conclusion. Providing food product samples seems to be a promising strategy in healthy diet promotion programmes for food neophobic young adults to increase first time trial of unfamiliar low-fat and fruit and vegetable products. 


\section{Introduction}

High intakes of saturated fat and low intakes of fruits and vegetables $(F \& V)$ have been linked to increased risk for cardiovascular diseases, various forms of cancer, and obesity (World Cancer Research Fund, 2007). In promotion of more healthful diets, in many countries it is recommended to restrict saturated fat intake and to eat ample amounts of F\&V (Brug \& Oenema, 2006). The Dutch are recommended to reduce their intake of saturated fat intake to less than 10 percent of total energy intake (en\%) and to eat at least 2 pieces of fruit and 200 grams of vegetables each day (Health Council of the Netherlands, 2006).

Food industry has reacted to the growing interest in healthy diets, and "health" has become an important selling strategy for the food industry. The availability of potentially healthful alternatives (low-fat products, convenient $F \& V$ products) has steadily increased in Dutch supermarkets over the years. A recent modelling study indicated that if Dutch young adults were successfully encouraged to replace three highsaturated fat products (such as full-fat cheese or margarine) in their diet for readily available low-fat alternatives (such as low-fat cheese or margarine), compliance to the recommendation for saturated fat intake would increase from 23\% (Hulshof et al., 2004) to $86 \%$ (Schickenberg et al., 2009).

Although in some product groups shifts in product choice have taken place, such as the wide acceptance of semi-skimmed milk and low-fat margarine (Health Council of the Netherlands, 2002), many new, potentially healthful alternative products have not been accepted so easily. The first time trial of an unfamiliar healthful food product is seen as a crucial step in the development of liking and eventually preference for and acceptance of healthful alternative products (Birch, 1999). Food neophobia has been identified to influence first time trial of novel foods. Food neophobia is the reluctance to try new foods, and people differ in this tendency (Pliner \& Hobden, 1992). Food neophobics have been shown to be significantly less willing to try potentially healthful low-fat and F\&V alternatives (Schickenberg, van Assema, Brug, \& de Vries, 2008).

The method of providing product samples is widely used as a marketing tool by the food industry, e.g. in supermarkets (Arens, 2002). In a focus group study on factors associated with willingness to try unfamiliar food products, many participants indicated to be more willing to try an unfamiliar product when they could first try a small sample 
(Schickenberg, van Assema, Brug, \& de Vries, submitted). However, to our knowledge, there is no published evidence on the effectiveness of providing food samples to increase the choice of healthful alternative products. Although food exposure is a behavioural change method that has been used in healthy diet promotion interventions before, e.g. in the Krachtvoer and ProChildren projects (Martens, van Assema, Paulussen, van Breukelen, \& Brug, 2008; te Velde et al., 2008), the specific strategy of providing small samples seems not to have been widely used in programs and has not been tested as such.

The aim of the present study was to test the hypothesis that offering a sample of an unfamiliar healthful low-fat or $\mathrm{F} \& \mathrm{~V}$ product stimulates that such a food product is chosen by food neophobic young adults instead of comparable traditional products.

\section{Method}

\section{Design}

We used a 2 (condition) by 4 (products) between subjects design with a pre- and postexperimental questionnaire. The outcome measure was product choice of either a traditional product or a healthful alternative at a lunch buffet.

\section{Participants and setting}

The study was conducted in 5 different restaurants of educational institutions in the southern part of the Netherlands around lunch time (between 11:00 and 15:00 o'clock) on weekdays. Participants were 17-25 year old young adults. The age range of participants was chosen because many people of this age start living on their own and therefore need to take independent choices regarding what food to buy. Moving out of the parental home is a transition period when people may change dietary habits. Furthermore, different studies suggest that food preferences and choices adopted at a relatively early age may track into adulthood (Hill, Caswell, Maskill, Jones, \& Wyllie, 2008; te Velde et al., 2008). Participants were approached in educational institutes, sport-clubs, and musical societies. Young adults were asked to fill in a short paper and pencil recruitment questionnaire. The recruitment questionnaire included written information on the study and an informed consent form. At a later point in time we 
also offered the possibility to fill in the recruitment questionnaire online. For this approach posters and flyers advertising the website were published in supermarkets, pubs, snack-bars and other places where young adults come. Participants who completed the recruitment questionnaire entered a lottery with an mp3 player as a prize. The recruitment questionnaires were analyzed and participants with a food neophobia score of 35 points or more (see measures section) were invited to participate in the actual study either directly in the same location, or on appointment in a central location in town. They were informed that participation would take 30 minutes, and included filling out two questionnaires, a reward of $€ 5$ in cash, and a free lunch at a buffet. The food neophobia cut-off point was based on the mean score plus one half standard deviation in an earlier study (Schickenberg et al., 2008). Participants who indicated in the recruitment questionnaire to have food-related health problems were excluded from further participation in the study.

\section{Procedure}

As the Dutch usually consume a sandwich-based lunch, participants were presented a buffet consisting of products from five product groups, i.e., mineral water (with and without gas), bread rolls (brown and white), margarine bread spread, Gouda cheese, and F\&V's (tomato, apple and orange). For each participant one out of four target products was added to the buffet. Two target products were healthful alternatives for frequently consumed products in the daily diet of the Dutch that are high in saturated fat, i.e., a low-fat cheese and a very low-fat margarine spread. The other two target products were convenient alternatives for fresh $F \& V$ products, i.e. two juices that are available in portion sized ready to use containers. Target products were chosen based on their reduced saturated fat or high $F \& V$ content and recent launch on the market. The target products were available in Dutch supermarkets at the time of the study. Bogus product names were used to minimize the chance of recognition, and to ensure that all offered products were perceived as new by the participants. Trustworthiness of the chosen product names was determined in a pre-test. All products used in the buffet were presented to participants in neutral containers, thus without their usual packaging. Coloured name cards were put in front of all products. For each product group the cards had a different colour. 
Random assignment of participants to either the experimental or control condition was done using a list of randomly generated numbers. Additionally, participants were assigned to one of the four target products, based on which product groups they had indicated in the recruitment questionnaire to regularly consume. If participants indicated to regularly consume products from more than one product groups they were allocated to a healthful alternative from the product group to which the least number of participants was assigned at that moment. It was strived to assign equal numbers of male and female participants to all target products, based on sequence of arrival (alternating product groups over participants). While a participant filled out the 3minute pre-experimental questionnaire, the buffet was prepared according to the condition and target product to be used.

In the experimental condition a bite/sip sized sample of the target product was placed in front of the target product on the buffet. The cheese and margarine were presented on a piece of bread, and the two juices in a small plastic cup. In front of the sample a card was placed indicated that the sample was 'free of charge' to the participants.

Participants were told that it was important to have lunch as the researchers wanted none of the participants to be hungry while participating in a successive part of the study. Participants were guided to the buffet one by one, and instructed to choose one product from each product group. They were told that they were not obliged to consume all chosen products, but just as much to satisfy their appetite. After having made their choice at the buffet in privacy, participants were guided to a group of tables where they could sit and consume the lunch. They were asked to sit at an empty table and consume their lunch in silence. The instruction and choice of products at the buffet took about three minutes on average.

After lunch consumption, participants completed the 15-minute post-experimental questionnaire, were thanked and rewarded, and asked to keep silent about the study towards co-students. The study was approved by the ethical committee of Maastricht University.

\section{Measures}

The recruitment questionnaire assessed participant's gender, age, level of education, length, weight, ethnicity, living situation (e.g. living with parents or not), specific dietary 
regiments, household shopping responsibility, possible food-related health problems, and consumption frequency of food groups included in the study. Furthermore, level of food neophobia was measured with a Dutch translation of the 10-item food neophobia (Pliner \& Hobden, 1992; Schickenberg, van Assema, Brug, \& de Vries, 2008).

The pre-experiment questionnaire assessed participants' current appetite with 1 item on a four-point scale from 'none' to 'a lot', current mood states with the 32-item Dutch version of the Profile of Mood States Scale (Wald \& Mellenbergh, 1990) measuring the mood states of depression, tension, vigour, fatigue, and anger, and usual intake of F\&V's with a 16-item food frequency questionnaire (Bogers, van Assema, Kester, Westerterp, \& Dagnelie, 2004) as possible confounding factors.

Post-experiment measures included the registration of product choice by an assistant. The post-experiment questionnaire assessed usual fat intake with a 35-item validated food frequency questionnaire (van Assema, Brug, Ronda, Steenhuis, \& Oenema, 2002), and included statements on the buffet situation (see Table 6.2), prior acquaintance with the target products, and whether participants had noticed and tried the offered sample.

\section{Analyses}

Data input was conducted and double checked by two research assistants. The data were analysed using the SPSS 15.0 statistical package (SPSS Inc., Chicago, IL, USA). A significance level of $\mathrm{p}<0.05$ was used.

Participants' body mass index (BMI) was calculated based on self-reported height and weight. None of the variables had more than 3 missing values.

To assess possible selective drop-out after completion of the recruitment questionnaire, logistic regression analysis was conducted among all potential participants with dropout (yes/no) as dependent variable and gender, age, ethnicity, BMI, level of education and level of food neophobia as independent variables. To assess possible differences in distribution of participants over the experimental conditions or target products, logistic regression analyses were conducted with experimental condition as the dependent variable and gender, age, ethnicity, BMI, level of education, level of food neophobia, appetite, mood states, and usual intakes of $\mathrm{F} \& \mathrm{~V}$ 's and fat as independent variables. 
To assess the effect of providing a food sample on food choice, multiple binary logistic regression analysis was done with participants' choice of the offered healthful alternative as dependent variable, and experimental condition, gender, age, ethnicity, BMI, level of education, level of food neophobia, appetite, mood states, usual intake of $F \& V$ 's and fat, and type of target product (low-fat versus $F \& V$ ) as independent variables. Non-significant variables (except condition) were excluded from the model in a hierarchical and stepwise procedure.

\section{Results}

\section{Response and participant characteristics}

A total of 3431 participants $(60.5 \%$ women) completed the recruitment questionnaire. Because it was not recorded how many participants were approached no response rate could be determined. A total of 2602 participants were excluded from further participation due to (the combined) presence of diabetes (11), other metabolic disorders (34), food-related allergies (246), food intolerances (106) or a food neophobia score of less than 35 points (2410).

Of the 829 participants eligible for participation, 197 (23.7\%) participants agreed to participate in the study. Participants with a higher level of education were found to be significantly more willing to participate $(\mathrm{OR}=1.8,95 \% \mathrm{CI} 1.08-3.10, \mathrm{p}<0.05)$. The demographics and other key variables of the participants are reported in Table 6.1.

The participants in the experimental group had a statistically significantly higher usual fat intake than the participants in the control group (OR=1.05, 95\% CI 1.01$1.10, \mathrm{p}<0.05$. Therefore, in the key regression analyses participants' fat intake score was included in the final model.

Participants with one or both parents born in other countries than the Netherlands or its neighbouring countries were assigned significantly more often to one of the two juice based target products $(\beta=-1.67, \mathrm{p}<0.05)$. Furthermore, more participants with higher scores on consumption of vegetables were assigned to one of the two low-fat target products $(\beta=0.23, \mathrm{p}<0.05)$. 
Table 6.1: Means and percentages of participant characteristics $(\mathrm{N}=197)$

Variable (reported values)

Gender, \% female

Mean age, years [range 18-25] (SD)

Mean Body Mass Index (SD)

Ethnicity (\%)

Both parents born in the Netherlands

One or both parents born in neighbouring nations of Germany or Belgium

One or both parents born in other than neighbouring countries

Level of education (\%)

Low (primary or basic vocational school)

Medium (secondary vocational or high school)

High (college or university level)

Living situation (\%)

With parents

In a student house

On their own

With partner

Other (e.g. together with sibling(s))

Special dietary regimen $(\%)$

None

Weight loss

Vegetarian

4.1

Other

Doing errands for the household, \% yes

Mean FNS score, points [range 10-57] (SD)

Mean fruit intake, servings a day (SD)

Mean vegetable intake, spoons a day (SD)

Mean fat intake, in points [range 3-38] (SD)

Mean appetite score [range 0-4] (SD)

Mean mood states scores (SD)

Anger [range 0-21] (SD)

Depression [range 0-20] (SD)

Vigour [range 0-19] (SD)

Tension [range 0-16] (SD) 


\section{Participants' perceptions of the experimental situation}

Table 6.2 shows that participants were quite positive about the buffet, and did not behave very differently than during a normal lunch in such a restaurant. On average the participants agreed a bit that it was a normal buffet.

A minority of the participants reported to be familiar with the offered target products: $85.2 \%$ indicated to have never heard of the offered product before, and $91.9 \%$ indicated to have never consumed the product before. Provided with the original product name after the main data collection, $50.8 \%$ of the participants indicated to have heard of the target product under its original name before, and $14.7 \%$ indicated to have consumed the target product under its original name before. Ninety-one percent of the participants indicated not to have recognized the offered target product as a product being available in stores under its original product name.

Of the 98 participants assigned to the experimental condition, $97.9 \%$ indicated to have seen the offered sample of the target products and $30.6 \%$ of those participants $(\mathrm{N}=30)$ indicated to have taken the free sample.

Table 6.2: Means (SD) of participants' answers on statements concerning the experimental situation (range -3 (completely disagree) to +3 (completely agree)) $(\mathrm{N}=396)$

\begin{tabular}{ll}
\hline & Mean (SD) \\
The products appeared to be fresh $(\mathrm{N}=395)$ & $1.8(1.2)$ \\
The restaurant looked fine, concerning the hygiene $(\mathrm{N}=197)$ & $1.9(1.2)$ \\
The lunch was nice $(\mathrm{N}=195)$ & $1.7(1.0)$ \\
I did not feel at ease in the restaurant $(\mathrm{N}=197)$ & $-1.6(1.5)$ \\
I chose different products in the restaurant as compared to similar situations $(\mathrm{N}=195)$ & $-1.1(2.0)$ \\
I ate more than planned $(\mathrm{N}=197)$ & $-1.5(1.6)$ \\
The instructions were trustworthy $(\mathrm{N}=196)$ & $1.2(1.4)$ \\
The buffet appeared to me as a normal buffet $(\mathrm{N}=195)$ & $0.7(1.6)$
\end{tabular}

\section{Choice of the target product}

Table 6.3 shows that on average $43.7 \%$ of all participants chose the target product at the buffet. The prevalence of choosing the target product differed between the different target products that were offered to participants. Post hoc analysis using 
Tukey contrasts indicated that the offered fruit juice was chosen significantly more often than the low-fat margarine spread $(\mathrm{F}(3,193)=3.32, \mathrm{p}=0.02)$.

Table 6.3: Percentage participants choosing the target product for the total group, according to condition (experimental (exp) and control (con)) and target product $(\mathrm{N}=197)$

\begin{tabular}{|c|c|c|c|c|c|c|c|c|c|c|c|}
\hline & \multirow{2}{*}{$\begin{array}{l}\text { Total } \\
\text { group }\end{array}$} & \multicolumn{2}{|c|}{ Condition } & \multicolumn{2}{|c|}{ Fruit drink } & \multicolumn{2}{|c|}{ F\&V drink } & \multicolumn{2}{|c|}{ Cheese } & \multicolumn{2}{|c|}{$\begin{array}{l}\text { Bread } \\
\text { spread }\end{array}$} \\
\hline & & $\exp$ & con & $\exp$ & con & $\exp$ & con & $\exp$ & con & $\exp$ & con \\
\hline $\begin{array}{l}\text { Percentage } \\
\text { participants } \\
\text { choosing the target } \\
\text { product }\end{array}$ & 43.7 & 51.0 & 36.4 & 58.5 & 42.3 & 48.0 & 27.3 & 36.4 & 31.4 & 36.5 & 32.0 \\
\hline
\end{tabular}

\section{Effects of the free sample}

Based on the final logistic regression model, participants in the experimental condition had significantly higher odds for choosing the offered target product than participants in the control group (percentages indicated in Table 6.3) (OR=1.50, 95\% CI 1.11-2.05, $\mathrm{p}<0.01)$. 21 of the 30 participants within the experimental group who actually took the free sample did choose the offered healthful alternative as part of their lunch, in contrast to 29 of the 68 participants in the experimental condition who chose the healthful alternative product for their lunch without having taken the free sample. Posthoc analysis showed that there was no significant difference in the choice for the offered target product between participants from the experimental condition who had not tried the offered sample of the target product and participants of the control group.

Of the possible confounders, the depression subscale of the mood questionnaire was the only significant correlate of product choice in the final model. More depressed participants had higher odds for choosing the offered target product $(\mathrm{OR}=1.19,95 \%$ CI 1.03-1.37, $\mathrm{p}<0.05)$.

\section{Discussion}

In line with our hypothesis, the availability of a free sample of a healthful low-fat or $\mathrm{F} \& \mathrm{~V}$ product resulted in more people choosing this product for lunch. This result 
indicates that the food choice behaviour of higher than average food neophobic young adults was effectively influenced by a rather simple strategy. Based on the results of a focus group study conducted earlier we believe that a combination of factors might explain the effectiveness of the strategy, such as a reduction in uncertainty about the offered products' taste and a decrease in perceived risk of choosing the product (Schickenberg, van Assema, Brug, \& de Vries, submitted).

Only $30 \%$ of the participants in the experimental condition took the free sample. This group was, however, much more likely to also choose the healthful alternative as part of their lunch. Further analyses showed that participants in the experimental condition who had not tried the offered sample were not more likely to choose the offered target product for their lunch, as compared to participants in the control condition who had no chance of trying the sample. The finding that condition had a significant effect on participants' choice of the offered healthful alternatives therefore appears to result from the third of the participants in the experimental condition who actually tried the sample. Merely exposing participants to a possibility of trying a sample might therefore not be enough to reach an effect on product choice, but participants need to actually try the offered sample.

Study limitations include the low response rate, and therefore a possible selective sample. Our sample was more highly educated than the Dutch population in this age group at large, even though we did try to recruit participants in settings where also lower educated young adults could be recruited. Our findings can also not be generalized to other age groups. Furthermore, due to the limited sample size and the rather large number of estimated regression weights used in the regression models there is a chance of having made type I errors, so having erroneously rejected the null hypotheses. This limitation makes it even more urgent to replicate the study using a larger sample.

We tried to conduct the experiment while optimally mimicking a context in which food is normally selected and consumed (Meiselman, 1992). Participants were invited to a restaurant room in their own educational institution or at Maastricht University. In the setup of the buffet we used furniture, trays and other props from the local restaurants as much as possible. Furthermore, we tried to give participants the impression that their choice of products at the buffet had nothing to do with the study they had agreed to take part in. Participants' judgements on the experimental situation 
showed that we were reasonable successful in our effort to mimic a normal situation, but it was of course not an entirely normal lunch choice situation, especially with regard to the specific instructions that were given and the small total number of products that was offered at the buffet. For practical reasons it was not possible to conduct the study in one setting, but the different restaurant rooms were comparable and the setup of the buffets was the same in all locations where the study was conducted. We conclude that our results might only be generalized to some extent to comparable real-life food choice situations

Finally, our findings cannot be generalized beyond the products that were used in the present study. However, we carefully selected two products representative for available low-fat healthful alternative products and two products representative for alternative $\mathrm{F} \& \mathrm{~V}$ products, and all four products were more often chosen by participants in the experimental group than by participants in the control group.

It is encouraging that the strategy of free samples was shown to be effective in initiating first time trial of unfamiliar healthful food products. This first time trial is seen as an essential step in the process towards integration of such healthful foods in the dietary pattern.

This study provides evidence that a rather simple intervention can positively influence choice for a more healthful alternative food product among food neophobic young adults. Further research may explore if these results are valid for a wider range of product groups, and if similar effects apply to non experimental settings. 


\section{Chapter 7:}

General Discussion 
In this final chapter the main results of our studies will be discussed in relation to the projects' aims and the study limitations. Based on this discussion final conclusions will be provided. Furthermore, suggestions for incorporating the strategies developed during this project in local health promotion activities, and suggestions for future research will be made.

\section{Aims, studies, and main findings}

The research project had four aims. The first was to study what reduction in intake of saturated fat could theoretically be achieved by the replacement of a small amount of products in the daily diet by healthful alternative products. For this first aim a study was conducted in which the replacement of foods high in saturated fat by low saturated fat alternatives was simulated, using the data of the Dutch Food Consumption Survey in 2003. Results showed that in theory a vast majority of people would meet the recommended level of saturated fat intake after the replacement in their diet of only three 'regular' products for readily available lower fat alternatives.

The second aim was to explore what factors determine whether healthful alternatives will be tried for a first time. For this second aim focus group interviews were conducted. Multiple factors were identified that may influence first time choice of healthful alternatives. The importance of these factors may differ between products, persons, and situations. Product-related factors included the expected taste of the product, information about purpose of the product, product ingredients, and what product group it belongs to, perceived convenience and safety of the product, product price, and whether it is a light product. Person-related factors included participant's level of food neophobia, taste preferences, weight control behaviour, trust in own food preparation skills, and strength of habits. Situation-related factors included social influences, no choice social situations, shopping in a supermarket, eating in a restaurant), free promotion samples, weekends and holidays versus weekdays, appetite and mood. Of all product-, person- and situation-related factors identified, participants' expectations of the taste of the healthful alternatives and their level of food neophobia emerged as possible key factors.

The third aim was to gain better insight in the influence of the personality trait of food neophobia on the acquaintance with and willingness to try healthful alternatives. A related aim was to test the reliability of an adapted Dutch version of the food 
neophobia questionnaire as well as the assessment of possible sub-group differences in food neophobia score. For this third aim a study was conducted using a web-based questionnaire. The results showed that the adapted Dutch version of the food neophobia scale had sufficient internal consistency and test-retest reliability. Lower educated participants were found to have significantly higher levels of food neophobia than higher educated participants. Participants who scored high on the food neophobia questionnaire were significantly less familiar with healthful alternatives and were significantly less willing to try those healthful alternatives.

The fourth and final aim was to develop and test strategies for stimulating humans to try a healthful alternative for the first time. Two experimental studies were conducted, the first one on the effect of offering taste information on the choice of unfamiliar healthful products, and the second on the effect of offering product samples of healthful alternative products on the choice of the offered unfamiliar healthful products. Both strategies, providing taste information or offering a bite/sip-sized sample of healthful alternatives, effectively influenced participants' choice behaviour at the buffets in the direction of the healthful alternatives offered. The fourth aim of the study, has, however, only been achieved partially. Five strategies were developed, based on the results of the studies described in Chapters two to four. Healthful alternatives were identified and selected for use in the experimental phase. However, due to difficulties in the recruitment of participants it was not possible to experimentally test all developed strategies. At first it was tried to test the effect of all strategies in a sample of 18-25 year old participants representing all levels of education that had a higher than average level of food neophobia. We expected that relatively neophobic people really need to be encouraged and convinced to try the healthful alternatives. The experiment providing product samples was conducted with participants fulfilling the criteria described above. Once it turned out, however, that insufficient numbers of participants were recruited to be able to test all strategies, the inclusion criteria were amended. For the taste information experiment, participants were included who fulfilled all inclusion criteria, but regardless of their level of food neophobia; this to guarantee sufficient numbers of participants to enrol in the experiment. 


\section{Methodological considerations}

In interpreting the results of the studies several methodological issues have to be taken in account: the generalizability of the results to other populations and other products, the generalizability of the results beyond the experimental setting, the reliability and validity of the measures, the limitations of the qualitative data, and the problems that were faced in the recruitment of participants.

\section{Generalizability of the results to other populations}

The studies were conducted among participants of specific age groups, and educational background. The results may not be applicable to other groups than those tested. The strategies were tested among young adolescents only. This was also the study population in the simulation study. In the focus group study and the internet study the age range of participants was broader, and also included older participants. But also in these studies the results can not be generalized to younger or older age groups that were not represented in the study. For the taste information experiment a study population consisting solely of university students was used. This was due to major recruitment problems (see later section).

The choice of the study population for a first test of a newly developed strategy is debatable. In this project it was decided to test the strategies in the homogeneous study population of young adults first. We chose young adults because we expected to have easy access to this group. We chose a homogeneous group, because in a heterogeneous group effects might differ among subgroups and a much larger study population would have been needed to be able to find significant effects.

It cannot be ruled out that the studies were subject to selection biases. For all studies described in this thesis it is possible that predominantly individuals who were highly motivated to participate enrolled in the studies. Such an over-representation of participants interested in the topic of the study may lead to a distortion of the results of the study as such participants might e.g. discuss other topics (focus group study) or behave differently (experimental studies). In the focus group study some interviews were held with convenience groups, thus with participants that were used to assemble regularly in that constellation for other purposes as well. In these cases, overrepresentation of motivated people might not have been the case as participation 
of the group primarily depended on the motivation and helpfulness of the group leader. The participation of the group members was more or less imposed.

The results of the internet study may also have suffered from selection bias as participants were members of a consumer panel. In performing a study using an internet panel to recruit participants, of course only participants who have access to the internet can enrol. Internet penetration rate is high in the Netherlands (88\% in 2006). In the age group included in the internet study internet penetration is even higher, i.e. between 98\% (15-25 year olds) and 92\% (45-55 year olds) (CBS, 2006). The elderly and the lower educated have on average lower access to the internet at home than younger and higher educated groups. In the internet panel used for the study higher educated people are slightly over-represented, but this was corrected in the specific sampling for our study.

\section{Generalizability of the results to other food products}

For the generalizability of the findings to all available low-fat and $F \& V$ healthful alternatives it is important to include products in the studies that represent these foods. The choice of the products was limited to the products available in Dutch supermarkets at the time the studies were conducted. The process of the selection of healthful alternatives for the experimental studies already began in the focus group study. In the focus groups multiple products from a broad variety of product groups were discussed and this provided information both on the "unfamiliarity" as well as "potential acceptability" of the products. In the web-based study a selection was made of 15 products, being products that were unfamiliar to most people, yet potentially acceptable as an alternative food choice, with a reduced saturated fat or $F \& V$ content, and representing product groups that contribute highly to the consumption of saturated fat in the average Dutch diet or the consumption of F\&V.

For logistic reasons, it was not possible to include more than four healthful alternatives in the experimental studies. An additional selection criterion for these studies was the suitability of the product as a lunch product. To cover both aspects of the aim of the study - to eventually develop strategies to reduce the intake of saturated fat and to effectuate an increase the intake of $F \& V$ - it was decided to use two healthful alternatives from each product groups. It is possible that the results of the experiments 
might have turned out differently had other healthful alternatives been used in these studies. This also accounts for the results of the simulation study.

\section{Generalizability of the results beyond the experimental setting}

It has been shown that the environment in which food choices are made is an important factor influencing food choice behaviour (Meiselman, 2006). To allow generalizability of our findings to real-life situations, it was aimed to experimentally test the developed strategies in circumstances that were optimally similar to a real-life food choice environment. Both experiments were conducted in restaurants of educational institutions. However, there were notable differences between usual food choice situations and the food choice situation in our study. In our study the lunch was free of charge, and the participants were asked to choose one product from every product group offered as part of the buffet. The number of product groups and the overall number of products available was low, compared to the lunch offer in Dutch worksite restaurants. Most Dutch worksite restaurants offer a greater variety of product groups to choose from, e.g. soup, hot meals, sodas, snacks. Furthermore, the target products were offered without their packaging and placed right next to the traditionally often used products from the same product group. Especially in the case of the healthful alternatives for fresh fruit and vegetable $(\mathrm{F} \& \mathrm{~V})$ products this is likely to be different from a real restaurant setting, where the fruit and vegetable juices are predominantly positioned in the proximity of other drinks because those drinks need to be offered refrigerated. The most important difference between our experimental setup and a more realistic setting, however, is that participants were given instructions on the products to choose at the buffet. Participants' attention was actively directed to all products offered as part of the buffets, and they were all asked to choose one product from each product group. By instructing participants, regardless of their appetite state, to choose one product of each product group we tried to prevent participants only choosing a bread roll for lunch and thereby neglecting other product groups, possibly the one with the target product. Without the instructions, more participants might have overlooked the healthful alternative. Because their attention was drawn to the presence of the healthful alternative participants might have invested more time in actually reading the provided taste information or noticing the free sample than would have been the case in a real environment. 
A potential problem for the generalizability of the results of the simulation study, and for the ultimate impact of the effects of the strategies in the experimental studies, is that in real-life people may not maintain the use of the healthful alternative, and that compensatory behaviour may occur. Individuals might consume larger quantities of the healthful alternatives than of the original products or might start eating other products from the same or other product groups in addition to the alternatives. This might be due to a loss in taste and/or satiety. If a product contains a high percentage of saturated fat, the low-fat alternative may differ substantially in taste as well as mouthfeel from the original product, because fat content does strongly influence taste experience and mouthfeel (Stampanoni Koeferli, Piccinali, \& Sigrist, 1996). In real life this may lead to low acceptance of the low-fat alternative (Sampaio, Cláudia, Pinto e Silva, \& Torres, 2004). Effects of product replacement might therefore be much smaller in real-life. Relapse and compensatory behaviour is thought to be prevented by the selection of good alternative products. Healthful alternatives that share the taste and mouth feel of originally used products, and at the same time contain less saturated fat but an (almost) equal amount of total energy are expected to be suited best to prevent compensation or relapse behaviour.

\section{Reliability and validity of measures}

In the studies existing valid measures were used whenever possible. The reliability of the adapted Dutch version of the Food Neophobia was assessed as part of the study conducted online. No research was conducted on either the reliability or the validity of the measure of willingness to try healthful alternatives. In the internet study participants were asked to indicate their willingness to try the healthful alternatives displayed. The item used to measure willingness to try ("I would be willing to try the healthful alternative product", Agree-disagree) had a high face validity. The question, however, whether this item actually is a good predictor of participants' choice behaviour remains unanswered. In virtual space, where the internet study was conducted, it might be that participants' indication of their willingness to try the products must be interpreted as a more distal intention to try the products if that would actually be possible. Having a chance to actually try the products might make certain participants more considerate in indicating their willingness. Based on this thought the association between one's level of 
food neophobia and the willingness to try the healthful alternatives offered would be expected to be stronger if participants were given a chance to actually try the products.

\section{Limitations of the qualitative data}

As little knowledge was available on which factors determine first time trial of unfamiliar healthful food products it was decided to perform a series of focus groups. Focus groups are considered a useful means of exploratory data collection in studies where, as in our case, relatively little is known about the phenomenon of interest. In the focus group study multiple factors were reported to influence participants' choice of healthful alternatives. Due to the absence of quantitative data it is not possible to judge their respective importance or the impact of these factors on actual choice of healthful alternatives. Such quantitative research could yield additional input leading towards (priorities in) the development of additional strategies to promote first time trial of healthful alternatives.

\section{Problems in participant recruitment}

Initially it was tried to test the effectiveness of all five strategies that were developed based on the results of the focus group study with a population of 18-25 year old participants with relatively high scores on the food neophobia scale. Participants were recruited in the Maastricht region via different approaches. However, fewer participants than expected fulfilled the criterion of a food neophobia score higher than 35 , i.e. one half standard deviation above the mean food neophobia score measured during the internet study reported in Chapter 4. Of the more than 3431 participants who completed the recruitment questionnaire only $24 \%$ were suitable to take part in the experimental study. Of those participants, many were not interested to take part in the experimental part of the study at the restaurant of Maastricht University. In retrospect, the effort asked from participants in combination with the reimbursement offered withheld may participants from taking part in the experimental studies. This may have especially applied to the lower educated. It also appeared to be difficult to reach this group during the recruitment phase, foremost because this group, especially the older ones, are mostly out of school and thus were more difficult to recruit in large groups, e.g. via educational institutions. The original recruitment procedure did not result in 
enough participants to even test one of the strategies. Therefore, to be able to test at least one strategy, it was decided to additionally recruit participants outside the Maastricht region in educational institutions and to test the strategy in the restaurant of those educational institutions, which had to be located close to the daily whereabouts of the students.

To be able to test the remaining strategies as well, additional educational institutions, and various other event organisers in the Netherlands were contacted asking for permission to recruit participants and to stage experimental studies there. This effort, however, was futile, which was partly due to the conditions that had to be met by the experimental setting. For example, potential participants would at least need to have 30 minutes of spare time to be able to complete participation in the study. Furthermore, experimental settings were looked for which were located within a building, as it had to be assured that participants could participate in the experiment without disturbance. However, many large scale events, where sufficient numbers of possible participants were expected, were held outdoors; alternatively, the possible participants attending were not expected to have sufficient spare time to participate.

As it turned out that this was an inefficient way of recruiting participants and due to exhaustion of feasible contact possibilities with young, lower educated, adolescents it was decided to test the second strategy (taste information) at Maastricht University where it was possible to approach many students for participation. Besides the large number of available participants recruitment at the university had the advantage that the logistics were in place to directly recruit eligible participants for the experimental study. This resulted, however, in a population comprising solely of participants engaged in high education. Furthermore, it was decided to also include participants with lower scores on the food neophobia scale for logistical reasons.

\section{Implications for future work}

The most important recommendations for further work stem from the results, but also the limitations of the current studies. A general recommendation is to study whether the project's results also apply to people of different age and educational level groups, and different settings. More specifically, field studies are recommended to gain insight in the feasibility and effectiveness of the strategies of taste information and free sample in real life. Both tested strategies are promising enough to be now implemented and 
further tested in a real-life setting. They were both designed to be usable in settings where many people make food choices, either for direct consumption, such as worksite restaurants or schools, or in environments where consumers buy foods and ingredients for later consumption, such as supermarkets or other shops. Both strategies might also be integrated in the public health domain, such as in already existing healthy diet promotion courses as 'Goede voeding hoeft niet veel te kosten' [healthy nutrition does not need to be expensive; (van Assema, Steenbakkers, Rademakers, \& Brug, 2005)] and other forms of group-wise healthy diet promotion. Several issues should be dealt with in such a real-life test, i.e., the applicability of the strategies to a general population, the possible effect of price on strategy effectiveness, keeping the effort for consumers to select the offered healthful alternative products as low as possible, direct the publics' attention towards the presence of the offered healthful alternatives and the strategies.

A real-life study should also shed light on the issues regarding acceptability of the proposed replacement of traditional foods by healthful alternative foods by consumers, maintenance of the food replacement behaviour, and compensatory behaviour. A comparable simulation study as has been done for products low in saturated fat needs to be conducted using $\mathrm{F} \& \mathrm{~V}$ products. A quantitative study is needed to assess the importance and interrelatedness of the different factors that emerged from the explorative, qualitative focus group study. Conducting such a study could yield additional information about possible strategies to stimulate first time trial of healthful alternative foods. For such studies further research is needed of the reliability and validity of measuring participant's willingness to try healthful alternative products.

In view of the effectiveness of the first two tested strategies, it is recommended to experimentally test the effectiveness of the remaining three strategies developed in the course of this project. Therein, the experiences made in recruitment of participants in the present study should be considered.

This project's main focus was on stimulating first time trail of healthful alternative products, based on the assumption that participants would develop liking and eventually a preference for the taste of a previously unfamiliar food product if the participants would try the product repetitively. Taste is considered to be the most important determinant of food choice. Therefore, the first time trial of unfamiliar healthful foods, via the expected increase of liking through the repetitive intake of the food product in question can increase the likelihood of integrating healthful alternative 
food products in the daily diet. The studies conducted in the current project gave insight in the factors that are involved in the first time trial of healthful alternative products, and strategies that can stimulate that first time trial. It is recommended to conduct research on the consecutive steps in the process of integrating healthful alternative food products in the daily diet that were outlined above, e.g. in which circumstances the healthful alternative food product will be consumed for a second time, and whether the repetitive consumption of the product indeed leads to an increase in perceived liking.

The fact that purely offering the possibility to try a sample of an unfamiliar healthful food product (sample experiment) affected participants' choice behaviour indicates that food choice behaviour can be effectively influenced by a small change in the environment. Future research and future development of behavioural change interventions should incorporate such findings more and not only focus on rational decision processes, and motivational changes as means of persuasion.

Finally, it is recommended to further explore the role of food neophobia in healthy diet promotion. Food neophobia has been described as a personality trait (Pliner \& Hobden, 1992). Personality traits have been defined as relatively stable and therefore predictable over time and across diverse situations (Carver \& Scheier, 2000). According to Bernstein et al. personality traits are what make people act predictably (Bernstein, Clarke-Steward, Roy, \& Wickens, 1997). However, several studies, including our experimental studies, have shown that the willingness to try new foods of food neophobics can be improved, at least momentarily. In our experimental studies it was shown that even participants who scored relatively high on the food neophobia scale were persuaded rather easily to try an unfamiliar healthful food product, e.g. by providing taste information. Offering taste information was equally effective for participants with different levels of food neophobia. Of course, these effects could be explained by lack of validity: a high score on the scale might not indicate real reluctance to try novel foods. This seems unlikely in view of the validation studies that have been done with the scale we used. Alternatively, food neophobia might be much more situational than assumed, i.e. not represent a real personality trait. This would offer possibilities for intervention targeted at the group of persons with a high score: simple situational cues might overcome their original negative reactions. This, however, needs to be explored. 


\section{Final conclusions}

Replacement of only a small number of high saturated fat products in the diet by (unfamiliar) healthful alternatives low in saturated fat significantly reduces saturated fat intake. This replacement strategy is as yet not widely used in practice. Recommendation of this strategy can theoretically significantly increase the number of people complying with recommended saturated fat intake and therefore contribute to the prevention of chronic diseases. However, the feasibility and effectiveness of this strategy in real life needs further investigation.

This project has identified multiple factors that may determine first time trial of unfamiliar healthful alternatives in people, and perceived taste and level of food neophobia as possible key factors. Higher levels of food neophobia were found to be associated with less acquaintance with and willingness to try healthful alternatives. These findings provided a good point of departure for the development of strategies to stimulate first time trial of unfamiliar healthful alternatives as an important first step towards integration of such products in the daily diet.

Two 'simple' strategies, i.e. providing taste information and offering a free sample of healthful alternatives were shown to stimulate the choice of these products, across the neophobia scale. Based on these promising results it is recommended to implement and further test these strategies in the field.

This project was one of the first to explore the possible value and implementation possibilities of the replacement strategy for healthy diet promotion, and the role of food neophobia. Many questions still need to be answered, but the project resulted in promising approaches in the promotion of healthy diets. 


\section{References}

Addessi, E., Galloway, A. T., Visalberghi, E., \& Birch, L. L. (2005). Specific social influences on the acceptance of novel foods in 2-5 year old children. Appetite, 45, 264-271.

Alavanja, M. C. R., Brown, C. C., Swanson, C., \& Brownson, R. C. (1993). Saturated fat intake and lung cancer risk among nonsmoking women in Missouri. Journal of the National Cancer Institute, 85, 1906-1916.

Ammerman, A. S., Lindquist, C. H., Lohr, K. N., \& Hersey, J. (2002). The efficacy of behavioral interventions to modify dietary fat and fruit and vegetable intake: A review of the evidence. Preventive Medicine, 35, 25-41

Arens, W. F. (2002). Contemporary advertising (8th ed.). Boston: McGraw-Hill.

Arvola, A., Lähteenmäki, L., \& Tuorila, H. (1999). Predicting the intent to purchase unfamiliar and familiar cheeses: The effects of attitudes, expected liking and food neophobia Appetite, 32, 113-126.

Bäckström, A., Pirttilä-Backman, A.-M., \& Tuorila, H. (2003). Dimensions of novelty: a social representation approach to new foods. Appetite, 40, 299-307.

Bere, E., \& Brug, J. (2009). Towards health-promoting and environmentally friendly regional diets - a Nordic example. Public Health Nutrition, 12, 91-96.

Birch, L. L. (1999). Development of food preferences. Annual Review of Nutrition, 19, 41-62.

Birch, L. L., \& Fisher, J. A. (1996). The role of experience in the development of children's eating behavior. In E. D. Capaldi (Ed.), Why we eat what we eat, the psychology of eating (pp. 113-141). Washington, D.C.: American Psychological Association.

Birch, L. L., \& Marlin, D. W. (1982). I don't like it; I never tried it: effects of exposure to food on two-yearold children's food preferences. Appetite, 4, 353-360.

Birch, L. L., McPhee, L., Shoba, B. C., Pirok, E., \& Steinberg, L. (1987). What kind of exposure reduces children's food neophobia? Appetite, 9, 171-178.

Bogers, R. P., van Assema, P., Kester, A. D. M., Westerterp, K. R., \& Dagnelie, P. C. (2004). Reproducibility, validity, and responsiveness to change of a short questionnaire for measuring fruit and vegetable intake. American Journal of Epidemiology, 159, 900-909.

Brug, J., Lechner, L., \& de Vries, H. (1995). Psychosocial determinants of fruit and vegetable consumption. Appetite, 25, 285-296.

Brug, J., \& Oenema, A. (2006). Healthful nutrition promotion in Europe: goals, target populations, and strategies. Patient Education and Counseling 63 255-257.

Capaldi, E. D. (1996). Conditioned food preferences. In E. D. Capaldi (Ed.), Why we eat what we eat, the psychology of eating (pp. 53-80). Washington, D.C.: American Psychological Association.

Cardello, A. V., Maller, O., Bloom Masor, H., Dubose, C., \& Edelman, B. (1985). Role of consumer expectancies in the acceptance of novel foods. Journal of Food Science, 50, 1707-1718. 


\section{REFERENCES}

CBS. (2006). Onderzoek ICT gebruik bij personen [Survey ICT use by persons]. Heerlen: Centraal Bureau voor de Statistiek [Statistics Netherlands].

Chartrand, T. L. (2005). The role of conscious awareness in consumer behavior. Journal of Consumer Psychology, $15,203-210$.

Clarke, R., Frost, C., Collins, R., Appleby, P., \& Peto, R. (1997). Dietary lipids and blood cholesterol: quantitative meta-analysis of metabolic ward studies. British Medical Journal, 314, 112-117.

Contento, I. R. (2007). An overview of food choice and dietary change: Implications for nutrition education. In I. R. Contento (Ed.), Nutrition education linking research, theory, and practice (pp. 28-49). Sudbury: Jones and Bartlett Publishers.

Contento, I. R., Michela, J. L., \& Williams, S. S. (1995). Adolescent food choice criteria: role of weight and dieting status. Appetite, 25, 51-76.

Cooke, L., Wardle, J., \& Gibson, E. L. (2003). Relationship between parental report of food neophobia and everyday food consumption in 2-6-year-old children. Appetite, 41, 205-206.

Eertmans, A., Victoir, A., Vansant, G., \& van den Bergh, O. (2005). Food-related personality traits, food choice motives and food intake: Mediator and moderator relationships. Food Quality and Preference, 16, 714-726.

Falciglia, G. A., Couch, S. C., Gribble, L. S., Pabst, S. M., \& Frank, R. (2000). Food neophobia in childhood affects dietary variety. Journal of the American Dietetic Association, 100, 1474-1481.

Feunekes, G. I. J., de Graaf, C., Meyboom, S., \& van Staveren, W. A. (1998). Food choice and fat Intake of adolescents and adults: Associations of intakes within social networks. Preventive Medicine, 27, 645-656.

Flight, I., Leppard, P., \& Cox, D. N. (2003). Food neophobia and associations with cultural diversity and socio-economic status amongst rural and urban Australian adolescents. Appetite, 41, 51-59.

Fung, T. T., Willett, W. C., Stampfer, M. J., Manson, J. E., \& Hu, F. B. (2001). Dietary patterns and the risk of coronary heart disease in women. Archives of Internal Medicine, 161, 1857-1862.

Furst, T., Connors, M., Bisgogni, C. A., Sobal, J., \& Winter Falk, L. (1996). Food Choice: A conceptual model of the process. Appetite, 26, 247-266

Gatenby, S. J., Aaron, J. I., Jack, V. A., \& Mela, D. J. (1997). Extended use of foods modified in fat and sugar content: nutritional implications in a free-living female population. American Journal of Clinical Nutrition, 65, 1867-1873.

Gatenby, S. J., Aaron, J. I., Morton, G. M., \& Mela, D. J. (1995). Nutritional implications of reduced-fat food use by free-living consumers. Appetite, 25, 241-252. 
Glanz, K., Basil, M., Maibach, E., Goldberg, J., \& Snyder, D. (1998). Why Americans eat what they do: Taste, nutrition, cost, convenience, and weight control concerns as influences on food consumption. Journal of the American Dietetic Association, 98, 1118-1126.

Gordon, T., Castelli, W. P., Hjortland, M. C., Kannel, W. B., \& Dawber, T. R. (1977). High density lipoprotein as a protective factor against coronary heart disease. The Framingham Study. American Journal of Medicine, 62, 707-714.

Grunert, K. G. (2006). Marketing parameters and their influence on consumer food choice. In R. Shepherd \& M. Raats (Eds.), The psychology of food choice (pp. 161-178). Wallingford: Cabi.

Haslam, D. W., \& James, W. P. T. (2005). Obesity. Lancet, 366, 1197-1209.

Health Council of the Netherlands. (2001). Dietary reference intakes: energy, proteins, fats and digestible carbohydrates (No. 2001/19ER (corrected edition: June 2002)). The Hague: Health Council of the Netherlands.

Health Council of the Netherlands. (2002). Significant trends in food consumption in the Netherlands (No. 2002/12). The Hague: Health Council of the Netherlands.

Health Council of the Netherlands. (2006). Guidelines for a bealthy diet 2006 (No. publication no. 2006/21). The Hague: Health Council of the Netherlands.

Hill, D. S., Knox, B., Hamilton, J., Parr, H., \& Stringer, M. (2002). Reduced-fat foods: the shoppers viewpoint. International Journal of Consumer Studies, 26, 44-57.

Hill, L., Caswell, S., Maskill, C., Jones, S., \& Wyllie, A. (2008). Fruit and vegetables as adolescent food choices in New Zealand. Health Promotion International, 13, 55-65.

Hobden, K., \& Pliner, P. (1995). Effects of a model on food neophobia in humans. Appetite, 25, 101-113.

Hooper, L., Summerbell, C. D., Higgins, J. P. T., Thompson, R. L., Capps, N. E., Smith, G. D., et al. (2001). Dietary fat intake and prevention of cardiovascular disease: systematic review. British Medical Journal, 322, 757-768.

Howell, D. H., McNamara, D. J., Tosca, M. A., Smith, B. T., \& Gaines, J. A. (1997). Plasma, lipid and lipoprotein responses to dietary fat and cholesterol: a meta analysis. American Journal of Clinical Nutrition, 65, 1747-1764.

Hu, F. B., Rimm, E. B., Stampfer, M. J., Ascherio, A., Spiegelman, D., \& Willett, W. C. (2000). Prospective study of major dietary patterns and risk of coronary heart disease in men. American Journal of Clinical Nutrition, 72, 912-921.

Hulshof, K. F. A. M., Ocké, M. C., Van Rossum, C. T. M., Buurma-Rethans, E. J. M., Brants, H. A. M., Drijvers, J. J. M. M., et al. (2004). Resultaten van de voedselconsumptiepeiling 2003 Results of the national food consumption survey 2003] (No. RIVM report 350030002/2004). Bilthoven, The Netherlands: RIVM. 


\section{REFERENCES}

Hursti, U. K., \& Sjödén, P. (1997). Food and general neophobia and their relationship with self-reported food choice: familial resemblance in Swedish families with children of ages 7-17 years. Appetite, 29, 89-103.

Kistemaker, C. (1991). Simulatiestudie aangaande de invloed op de vetconsumptie van vervanging van vetrijke produkten door magere alternatieven, bij 22-49 jarige mannen. Voedselconsumptiepeiling 1987/1988. Zeist: TNO-Voeding.

Kistemaker, C., Löwik, M. R. H., Wedel, M., \& Hulshof, K. F. A. M. (1991). Compensatiemechanismen met betrekking tot de consumptie van vetarme produkten bij 22-49 jarige mannen. Voedselconsumptiepeiling 1987-1988 (No. V91.093). Zeist: TNO-Voeding.

Koivisto, U., \& Sjödén, P. (1996). Food and general neophobia in Swedish families: parent-child comparisons and relationships with serving specific foods. Appetite, 26, 107-118.

Koivisto, U., \& Sjödén, P. (1997). Food and general neophobia and their relationship with self-reported food choice: familial resemblance in Swedish families with children of ages 7-17 years. Appetite, 29, 89-103.

Kristensen, K., Ostergaard, P., \& Juhl, H. J. (1998). Success and failure of product development in the Danish food sector. Food Quality and Preference, 9, 333-342.

Krueger, R. A., \& Casey, M. A. (2000). Focus groups: A practical guide for applied research. (3rd Edition ed.). Thousand Oaks, CA: Sage Publishing.

Lewis, N. M., \& Hollingsworth, B. A. (1992). Food choices of young college women consuming low- or moderate calcium diets. Nutrition Research 12, 943-948.

Martens, M. K., van Assema, P., Paulussen, T. G. W. M., van Breukelen, G., \& Brug, J. (2008). Krachtvoer-: effect evaluation of a Dutch healthful diet promotion curriculum for lower vocational schools. Public Health Nutrition, 11, 271-278.

Martins, Y., Pelchat, M. L., \& Pliner, P. (1997). "Try it; it's good and it's good for you": effects of taste and nutrition information on willingness to try new foods. Appetite, 28, 89-102.

Martins, Y., \& Pliner, P. (1998). The development of the food motivation scale. Appetite, 30, 94.

Martins, Y., \& Pliner, P. (2005). Human food choices: An examination of the factors underlying acceptance/rejection of novel and familiar animal and nonanimal foods. Appetite, 45, 214-224.

McFarlane, T., \& Pliner, P. (1997). Increasing willingness to taste novel foods: effects of nutrition and taste information. Appetite, 28, 227-238.

Meiselman, H. L. (1992). Methodology and theory in human eating research. Appetite, 19, 49-55.

Meiselman, H. L. (2006). The role of context in food choice, food acceptance, and food consumption. In R. Shepherd \& M. Raats (Eds.), The psychology of food choice (pp. 179-199). Wallingford: Cabi.

Meiselman, H. L., Johnson, J. L., Reeve, W., \& Crouch, J. E. (2000). Demonstrations of the influence of the eating environment on food acceptance. Appetite, 35, 231-237. 
Meiselman, H. L., \& Schutz, H. G. (2003). History of food acceptance research in the US Army. Appetite, 40, 199-216.

Mela, D. J. (1999). Symposium on 'functionality of nutrients and behaviour' Food choice and intake: the human factor. Proceedings of the Nutrition Society, 58, 513-521.

Mela, D. J. (2001). Determinants of food choice: Relationships with obesity and weight control. Obesity Research, 9, 249S-255S.

Mensink, R. P., \& Katan, M. B. (1992). Effect of dietary fatty acids on serum lipids and lipoproteins - A meta analysis of 27 trials. Arteriosclerosis, Thrombosis and V ascular Biology, 12, 911-919.

Ministerie van Volksgezondheid Welzijn en Sport. (2006). Kiezen voor gezond leven. Den Haag.

Ministerie van Welzijn Volksgezondheid en Cultuur en het Ministerie van Landbouw en Visserij. (1988). Wat eet Nederland: Resultaten van de Voedselconsumptiepeiling 1987/1988 Rijswijk.

Mokdad, A. H., Bowman, B. A., Ford, E. S., Vinicor, F., Marks, J. S., \& Koplan, J. P. (2001). The continuing epidemics of obesity and diabetes in the United States. Journal of the American Medical Association, 286, 1195-1200.

Morgan, R., Sigman-Grant, M., Taylor, D. S., Moriarty, K., Fishell, V., \& Kris-Etherton, P. M. (1997). Impact of macronutrient substitutes on the composition of the diet and the U.S. food supply. Annals of the New York. Academy of Sciences, 819, 70-95.

NEVO-Table. (2001). Dutch food composition table 2001. The Hague: NEVO Foundation.

NEVO-Table. (2006). Dutch food composition table 2006. The Hague: NEVO Foundation.

Nicklaus, S., Boggio, V., Chabanet, C., \& Issanchou, S. (2005). A prospective study of food variety seeking in childhood, adolescence and early adult life. Appetite, 44, 289-297

Nunnally, J. C., \& Bernstein, I. H. (1994). Psychometric theory, 2nd ed. New York: McGraw-Hill.

Ocké, M. C., van Rossum, C. T. M., Fransen, H. P., Buurma-Rethans, E. J. M., de Boer, E. J., Brants, H. A. M., et al. (2008). Dutch national food consumption survey - Young children 2005/2006 (No. RIVM-rapport 350030002). Bilthoven: RIVM.

Pelchat, M. L., \& Pliner, P. (1995). "Try it. You'll like it." Effects of information on willingness to try novel foods. Appetite, 24, 153-165.

Pliner, P. (1994). Development of measures of food neophobia in children. Appetite, 23, 147-163.

Pliner, P. (2002). Consumer responses to novel and "functional foods". Abstract of an oral presentation to $\mathrm{X}^{\text {th }}$ Food Choice Conference. Paper presented at the Food Choice Conference, Wageningen, The Netherlands.

Pliner, P., Eng, A., \& Krishnan, K. (1995). The effects of fear and hunger on food neophobia in humans. Appetite, 25, 77-87. 


\section{REFERENCES}

Pliner, P., \& Hobden, K. (1992). Development of a scale to measure the trait of food neophobia in humans. Appetite, 19, 105-120.

Pliner, P., Lähteenmaki, L., \& Tuorila, H. (1998). Correlates of human food neophobia. Appetite, 30, 93.

Pliner, P., \& Loewen, E. R. (1997). Temperament and food neophobia in children and their mothers. Appetite, 28, 239-254.

Pliner, P., \& Martins, Y. (2002). The effects of meal cues and amount consumed on predictions of future eating in others. Personality and Social Psychology Bulletin, 28, 1354-1365.

Pliner, P., \& Melo, N. (1996). Food neophobia in humans: effects of manipulated arousal and individual differences in sensation seeking. Physiology \& Behavior, 61, 331-335.

Pliner, P., Pelchat, M., \& Grabski, M. (1993). Reduction of neophobia in humans by exposure to novel foods. Appetite, 20, 111-123.

Pliner, P., \& Pelchat, M. L. (1991). Neophobia in humans and the special status of foods of animal origin. Appetite, 16, 205-218.

Pollard, J., Kirk, S. F. L., \& Cade, J. E. (2002). Factors affecting food choice in relation to fruit and vegetable intake: a review. Nutrition Research Reviews, 15, 373-387.

Potts, H. W. W., \& Wardle, J. (1998). The list heuristic for studying personality correlates of food choice behaviour: A review and results from two samples. Appetite, 30, 79-92.

Raudenbush, B., \& Frank, R. A. (1999). Assessing food neophobia: The role of stimulus familiarity. Appetite, $32,261-271$.

Raudenbush, B., Schroth, F., Reilley, S., \& Frank, R. A. (1998). Food neophobia, odor evaluation and exploratory sniffing behavior Appetite, 31, 171-183.

Riboli, E., \& Norat, T. (2003). Epidemiologic evidence of the protective effect of fruit and vegetables on cancer risk. American Journal of Clinical Nutrition, 78, 559S-569S.

Rigal, N., Frelut, M.-L., Monneuse, M.-O., Hladik, C.-M., Simmen, B., \& Pasquet, P. (2006). Food neophobia in the context of a varied diet induced by a weight reduction program in massively obese adolescents. Appetite, 46, 207-214.

Ritchey, P. N., Frank, R. A., Koivisto Hursti, U.-K., \& Tuorila, H. (2003). Validation and cross-national comparison of the food neophobia scale (FNS) using confirmatory factor analysis. Appetite, 40, 163-173.

RIVM. (2004). Ons eten gemeten. Gezonde voeding en veilig voedsel in Nederland. Houten: RIVM [National Institute for Public Health and the Environment].

RIVM. (2006). Our food, our health. Healthy diet and safe food in the Netherlands. Bohn Stafleu Van Loghum, Houten: National Institute for Public Health and the Environment (RIVM). 
Rozin, P. (1984). The acquisition of food habits and preferences. In J. D. Matarazzo, S. M. Weiss \& J. A. Herd (Eds.), Behavioral health: a handbook of health enhancement and disease. Hoboken, NJ: Wiley-Interscience.

Rozin, P. (1988). Cultural approaches to human food preferences. In J. E. Moreley, M. B. Sterman \& J. H. Walsh (Eds.), Nutritional modulation of neural function. New York: Academic Press.

Rozin, P. (2006). The integration of biological, social, cultural and psychological influences on food choice. In R. Shepherd \& M. Raats (Eds.), The psychology of food choice (pp. 19-40). Oxfordshire: Cabi.

Sampaio, G. R., Cláudia, M. N., Pinto e Silva, M. E. M., \& Torres, E. A. F. S. (2004). Effect of fat replacers on the nutritive value and acceptability of beef frankfurters. Journal of Food Composition and Analysis, 17, 469-474.

Schickenberg, B., van Assema, P., Brug, J., \& de Vries, N. K. (2008). Are the Dutch acquainted with and willing to try healthful food products? The role of food neophobia. Public Health Nutrition, 11, 493-500.

Schickenberg, B., van Assema, P., Brug, J., \& de Vries, N. K. (submitted). A qualitative study into factors associated with first time trial of unfamiliar healthful foods.

Schickenberg, B., van Assema, P., Verkaik-Kloosterman, J., Ocké, M. C., Brug, J., \& de Vries, N. K. (2009). Replacing foods high in saturated fat by low saturated fat alternatives - A computer simulation of the potential effects on reduction of saturated fat consumption. British Journal of Nutrition, 102, 478-483.

Shepherd, R., \& Raats, M. (Eds.). (2006). The psychology of food choice. Oxfordshire: Cabi.

Slimani, N., Deharveng, G., Charrondie `re, R. U., van Kappel, A. L., Ocké, M. C., Welch, A., et al. (1999). Structure of the standardized computerized 24-h diet recall interview used as reference method in the 22 centers participating in the EPIC project. European prospective investigation into cancer and nutrition. Computer Methods and Programs in Biomedicine, 58 251-266.

Spector, P. E. (1992). Summated rating scale construction: An introduction Newbury Park, CA SAGE Publications.

Stampanoni Koeferli, C. R., Piccinali, P., \& Sigrist, S. (1996). The influence of fat, sugar and non-fat milk solids on selected taste, flavor and texture parameters of a vanilla ice-cream Food Quality and Preference, 7, 69-79.

Steinmetz, K. A., \& Potter, J. D. (1996). Vegetables, fruit, and cancer prevention: A review Journal of the American Dietetic Association 96, 1027-1039.

Steptoe, A., Pollard, T. M., \& Wardle, J. (1995). Development of a measure of the motives underlying the selection of food: the food choice questionnaire. Appetite, 25, 267-284.

Story, M., Neumark-Sztainer, D., \& French, S. (2002). Individual and environmental influences on adolescent eating behaviors. Journal of the American Dietetic Association, 102, S40-S51. 


\section{REFERENCES}

te Velde, S. J., Brug, J., Wind, M., Hildonen, C., Bjelland, M., Perez-Rodrigo, C., et al. (2008). Effects of a comprehensive fruit and vegetable promoting school-based intervention in three European countries: the Pro Children Study. British Journal of Nutrition, 99, 893-903.

Tuorila, H. (2001). Keeping up with the change: Consumer responses to new and modified foods. Paper presented at the Food Chain 2001, Uppsala.

Tuorila, H., Lähteenmäki, L., Pohjalainen, L., \& Lotti, L. (2001). Food neophobia among the Finns and related responses to familiar and unfamiliar foods. Food Quality and Preference, 12, 29-37.

Tuorila, H., Meiselman, H. L., Bell, R., Cardello, A. V., \& Johnson, W. (1994). Role of sensory and cognitive information in the enhancement of certainty and liking for novel and familiar foods. Appetite, 23, 231 246.

van Assema, P., Brug, J., Kok, G. J., \& Brants, H. (1992). The reliability and validity of a Dutch questionnaire on fat consumption as a means to rank subjects according to individual fat intake. European Journal of Cancer Prevention, 1, 375-380.

van Assema, P., Brug, J., Ronda, G., \& Steenhuis, I. (2001). The relative validity of a short Dutch questionnaire as a means to categorise adults and adolescents to total and saturated fat intake. Journal of Human Nutrition and Dietetics, 14, 377-390.

van Assema, P., Brug, J., Ronda, G., Steenhuis, I., \& Oenema, A. (2002). A short Dutch questionnaire to measure fruit and vegetable intake: relative validity among adults and adolescents. Nutrition and Health, 16, 85-106.

van Assema, P., Steenbakkers, M., Rademakers, C., \& Brug, J. (2005). The impact of a nutrition education intervention on main meal quality and fruit intake in people with financial problems. Journal of Human Nutrition \& Dietetics, 18, 205-212.

van den Brandt, P. A., van de Crommert, S., \& Mordant, A. (1990). De bijdrage van voedingsmiddelen aan de consumptie van macro- en micronutrienten door de Nederlandse bevolking. Maastricht: Maastricht University.

van der Lucht, F., \& Picavet, H. S. J. (2006). Sociaal-economische verschillen in leefstijl. Bilthoven: RIVM.

Voedingscentrum. (1998). Zo eet Nederland: resultaten van de Voedselconsumptiepeiling 1997-1998. Den Haag: Voedingscentrum.

Voorlichtingsbureau voor de Voeding. (1993). Zo eet Nederland, 1992: resultaten van de Voedselconsumptiepeiling 1992. . Den Haag.

Wald, F. D. M., \& Mellenbergh, G. J. (1990). De verkorte versie van de Nederlandse vertaling van de profile of mood states (POMS). Nederlands Tijdschrift voor de Psychologie, 45, 86-90. 
Wardle, J., Carnell, S., \& Cooke, L. (2005). Parental control over feeding and children's fruit and vegetable intake: How are they related? Journal of the American Dietetic Association, 105, 227-232.

Weststrate, J. A., van het Hof, K. H., van den Berg, H., Velthuis-te-Wierik, E. J. M., de Graaf, C., Zimmermanns, N. J. H., et al. (1998). A comparison of the effect of free access to reduced fat products or their full fat equivalents on food intake, body weight, blood lipids and fat-soluble antioxidants levels and haemostasis variables European Journal of Clinical Nutrition, 52, 389-395.

Willett, W. C. (1995). Diet, nutrition, and avoidable cancer. Environmental Health Perspectives, 103, 165-170.

Woodward, D. R., Boon, J. A., Cumming, F. J., Ball, P. J., Williams, H. M., \& Hornsby, H. (1996). Adolescents' reported usage of selected foods in relation to their perceptions and social norms for those foods. Appetite, 27, 109-117.

Wootan, M. G., Reger-Nash, B., Booth-Butterfield, S., \& Cooper, L. (2005). The cost-effectiveness of 1\% or less media campaigns promoting low-fat milk consumption [Electronic Version]. Preventing Chronic Disease, 2. Retrieved 16 March 2010 from www.cdc.gov/PCD/issues/2005/oct/pdf/05_0019.pdf.

World Cancer Research Fund. (1997). Food, nutrition and the prevention of cancer: A global perspective. Washington, DC: World Cancer Research Fund / American Institute for Cancer Research

World Cancer Research Fund. (2007). Food, nutrition, physical activity, and the prevention of cancer: a global perspective. Washington DC: World Cancer Research Fund / American Institute for Cancer Research

World Health Organization. (2003). Diet, nutrition and the prevention of chronic diseases. Report of a joint WHO/FAO expert consultation (Technical report series No. 916). Geneva: WHO. 


\section{Summary}

The diet of most of the Dutch is not in accordance with current recommendations of an intake of energy from fat of not more than 10 percent and consuming 200 grams of vegetables and two pieces of fruit daily. General health of the Dutch would improve if the diet of the Dutch was in accordance with these recommendations. Consuming less fat is, among other things, to be reached by replacing traditionally frequently consumed products in one's diet which are high in saturated fat content by healthful alternatives. Consumption of fruit and vegetables $(\mathrm{F} \& \mathrm{~V})$ could be increased by adding more convenient $\mathrm{F} \& \mathrm{~V}$ products to the diet.

In the research project described in this thesis it was assumed that replacement of a small number of traditional products by healthful alternatives could result in a large reduction in intake of saturated fat and an increase in the consumption of F\&V. For the reduction of intake of saturated fat this was studied in a simulation study for which food consumption data of 750 adolescents from a recent food consumption survey were used. For each participant those three products that contributed the most to the consumption of saturated fat for that person were replaced by three lower fat alternatives. The percentage of participants that would meet the recommendation regarding consumption of saturated fat rose from $23.3 \%$ to $86.0 \%$. It was concluded that the replacement of a small number of food products by healthful alternative products could significantly decrease the intake of saturated fat and thereby be of great influence on the proportion of participants that meet the recommendations regarding consumption of saturated fat (Chapter 2).

As little was known on which factors determine one's willingness to try a healthful alternative a focus group study was conducted among 66 adults. Trial of unfamiliar products is an important first step in the integration of such products in the daily diet. A large number of relevant factors was identified and those factors were sub-divided into three groups of factors, namely: product-, person- and situation-related factors. Product-related factors included the expected taste of the to be tried product, information on what product group it belonged to and the price of the product. Person-related factors included the participants' level of food neophobia, their taste preferences, and the degree of trust in their own food preparation skills. Examples of situation-related factors that were mentioned are social influences and being offered a free promotion sample (Chapter 3). 
In a study in which 326 adults completed a questionnaire via the Internet it was assessed to what degree participants were acquainted with healthful food alternatives and whether they were willing to try these products. For this the psychometric properties of an adapted Dutch version of a Food Neophobia Scale (FNS) was assessed. Internal consistency and test-retest reliability of the used FNS version were sufficient. On average participants knew 7.9 of the offered 15 healthful alternatives products from sight and participants indicated to be modestly willing to try these products. Lower educated participants had significantly higher FNS scores than higher educated participants (Chapter 4).

Based on the results of the first three studies five strategies were developed to stimulate the first time trial of healthful alternative food products. Two strategies were evaluated in randomized control trials with pre- and post tests in restaurant settings. Participants were asked to choose products from a lunch buffet consisting of mineral waters, bread rolls margarine bread spread, Gouda cheese, and a piece of fresh fruit or vegetables. Per participant one of four possible healthful alternatives was added to the buffet, namely: a very low-fat alternative for margarine or cheese and either a fruit juice or a fruit and vegetables juice as alternatives for the pieces of fresh fruit or vegetables. Participants were instructed to choose one product from every product group offered.

The first tested strategy was providing information on the taste and mouthfeel of the healthful alternative and a comparison with supposedly liked products. This strategy was tested among 396 university students. It was expected that offering taste information would lead to a more positive expectation of the products' taste and that more participants would chose the healthful alternative product as part of their lunch. The expected effect on the expected taste was not found, but offering a sample of an unfamiliar healthful food product resulted in a significant higher proportion of participants choosing this product in the experimental condition than in the control condition. Participants' level van food neophobia had no influence on the effect of the strategy (Chapter 5).

The second tested strategy comprised of offering participants the possibility of trying a bite or sip-sized sample of the offered healthful alternative product. This strategy was tested among 197 young adults. Offering samples of a healthful alternative was also shown to be an effective strategy to stimulate trying a more healthful product (Chapter 6). 
In the last chapter the most important results of the studies presented in this thesis are summarized. The methodological aspects, such as the choice of study populations and the quality of the measures used are discussed. Based on this discussion recommendations are provided for future steps, including the implementation and further research of the tested strategies in praxis and further exploration of the role of food neophobia in promoting healthy nutrition behaviour. This project was the first project that chose to explore the possible value and implementation possibilities of the replacement strategy for healthy diet promotion, and the role of food neophobia. Many questions still need to be answered, but the project resulted in promising approaches in the promotion of healthy diets (Chapter 7). 


\section{Samenvatting}

De voeding van de gemiddelde Nederlander is niet conform de aanbevelingen om minder dan 10 procent van de geconsumeerde energie uit verzadigde vetten te halen en dagelijks 200 gram groente en minimaal twee stuks fruit te eten. De volksgezondheid in Nederland zou sterk verbeteren als de voedselinname wel conform deze aanbevelingen zou zijn. Minder vet eten is ondermeer mogelijk door 'traditionele' producten in het dagelijkse eetpatroon te vervangen door voedingsmiddelen met minder verzadigd vet (gezonde alternatieven). De groente en fruitconsumptie zou verhoogd kunnen worden door de consumptie van kant en klare groente en fruit sappen met een hoger gebruiksgemak vergeleken met verse groente en vers fruit.

In het in dit proefschrift beschreven onderzoeksproject werd verondersteld dat het vervangen van een beperkt aantal traditionele producten door gezonde alternatieven al kan leiden tot een grote afname in de consumptie van verzadigd vet en een grote toename in de consumptie van groente en fruit. Voor verzadigd vet werd dit onderzocht in een simulatiestudie waarvoor voedselconsumptiegegevens van 750 jong volwassen aan een recente voedselconsumptiepeiling werden gebruikt. Voor iedere deelnemer werden de drie producten die de grootste bijdrage leverden aan de verzadigd vetconsumptie van die persoon vervangen door drie gezonde alternatieven. Het percentage deelnemers dat na de simulatie aan de aanbeveling met betrekking tot de inname van verzadigd vet voldeed, steeg van $23.3 \%$ tot $86.0 \%$. Geconcludeerd werd dat het vervangen van een beperkt aantal voedingsmiddelen door gezonde alternatieven de inname van verzadigd vet significant kan doen afnemen en van grote invloed kan zijn op het aantal mensen dat aan de aanbeveling voor verzadigd vetinname voldoet (hoofdstuk 2).

Omdat er weinig bekend was over de factoren die bepalen of iemand bereid is om een gezond alternatief uit te proberen, werd er een focusgroepstudie uitgevoerd onder 66 volwassenen. Het uitproberen van een nieuw product is een belangrijke eerste stap naar integratie van zo'n product in het dagelijkse eetpatroon. Een groot aantal factoren werd door de deelnemers als invloedrijk geïdentificeerd. Binnen de genoemde factoren is een onderverdeling aangebracht in product-, persoon-, en situatiegerelateerde factoren. Productgerelateerde factoren omvatten onder andere de verwachte smaak van het te proberen product, informatie over tot welke productgroep het product te rekenen is en de prijs van het product. Tot de persoonsgerelateerde factoren hoorden 
ondermeer de mate van voedselneofobie van deelnemers, smaakvoorkeuren en vertrouwen in de eigen kookkunst. Voorbeelden van situatiegerelateerde factoren die genoemd werden zijn sociale invloeden en het krijgen van een gratis proefmonster (hoofdstuk 3).

In een studie waarbij 326 volwassenen een vragenlijst op het internet invulden, werd vervolgens nader onderzocht in hoeverre mensen bekend zijn met gezonde alternatieven en bereid zijn om deze uit te proberen. Specifiek werd gekeken naar de rol van voedselneofobie daarbij. Daartoe werd ook de betrouwbaarheid van de in de studie gebruikte Nederlandse versie van een Engelstalige voedselneofobievragenlijst bepaald. De interne consistentie en test-hertest betrouwbaarheid van de voedselneofobievragenlijst bleken voldoende. Gemiddeld kenden deelnemers 7.9 van de aangeboden 15 gezonde alternatieven van zien, en gaven zij aan enigszins bereid te zijn om deze producten eens te proberen. Deelnemers die hoger scoorden op de voedselneofobievragenlijst kenden minder gezonde alternatieven en waren minder bereid om deze uit te proberen. Deelnemers met een laag opleidingsniveau hadden significant hogere waarden op de voedselneofobievragenlijst, vergeleken met hoog opgeleidde deelnemers (hoofdstuk 4).

Gebaseerd op de resultaten van de eerste drie studies werden vijf strategieën ontwikkeld om het een eerste keer uitproberen van gezonde alternatieven te stimuleren. Twee strategieën werden geëvalueerd in een gerandomiseerde gecontroleerde studie met een voor- en nameting in restaurants. Aan deelnemers werd gevraagd producten te kiezen uit een lunchbuffet bestaande uit mineraalwaters, broodjes, halvarine, Goudse kaas en een stuk verse groente en vers fruit. Per deelnemer werd één van vier mogelijke gezonde alternatieven aan het buffet toegevoegd, te weten: een vetarm alternatief voor halvarine of kaas en een fruitsap of een groente- en fruitsap als alternatief voor de verse groente/het verse fruit. Deelnemers werden geïnstrueerd om uit elk van de aangeboden productgroepen één product te kiezen.

De eerste geteste strategie was het plaatsen van een informatiebord waarop informatie werd gegeven over de smaak en het mondgevoel van het gezonde alternatief en een smaakvergelijking werd gemaakt met producten waarvan verondersteld werd dat mensen deze over het algemeen lekker vinden. Deze strategie werd getest onder 396 universiteitsstudenten. Verwacht werd dat het aanbieden van de smaakinformatie zou leiden tot een positievere verwachting van de smaak van het gezonde alternatief en dat 
meer deelnemers het gezonde alternatieve product zouden kiezen. Het verwachte effect op de smaakverwachting werd niet gevonden, maar wel werd wel aangetoond dat het aanbieden van de smaakinformatie ertoe leidde dat meer deelnemers in de experimentele conditie voor het gezonde alternatief kozen dan deelnemers in de controleconditie. De mate van voedselneofobie had geen invloed op de effectiviteit van de strategie (hoofdstuk 5).

De tweede strategie was het bieden van de mogelijkheid om een hapje/slokje (proefmonster) van het gezonde alternatief te proeven. Deze strategie werd getest onder 197 jong volwassenen. Ook het aanbieden van een proefmonster bleek een effectieve strategie om het uitproberen van gezonde alternatieven te stimuleren (hoofdstuk 6).

In het laatste hoofdstuk worden de belangrijkste resultaten van de uitgevoerde studies samengevat. De methodologische aspecten van de studies, zoals de keuzes voor de onderzoekspopulaties en de kwaliteit van de gebruikte metingen worden nader belicht. Op basis hiervan worden aanbevelingen gedaan voor vervolgstappen, waaronder implementatie en verder onderzoek van de geteste strategieën in het praktijkveld en verdere exploratie van de rol van voedselneofobie bij het bevorderen van gezond voedinggedrag. Dit project was het eerste project waarbij gekeken werd naar de mogelijke waarde en toepassingsmogelijkheden van het vervangen van producten in het eetpatroon en de rol van voedselneofobie. Veel vragen blijven onbeantwoord, maar de vernieuwende aanpak lijkt een vruchtbare en praktisch toepasbare weg voor het verbeteren van het voedingspatroon van de Nederlanders (hoofdstuk 7). 


\section{Zusammenfassung}

Die durchschnittliche Ernährung der Niederländer liegt bezüglich der täglich konsumierten Energie aus gesättigten Fettsäuren über dem empfohlenen Wert von 10 Prozent und bezüglich Obst und Gemüse unter der empfolenen Menge von 200 Gramm. Daher könnte die niederländische Volksgesundheit allein schon dadurch verbessert werden, dass sich die Verbraucher an den Lebensmittelempfehlungen orientieren würden. Beispielsweise könnte die Fettbilanz bei ,traditionellen’ Produkten in der täglichen Ernährung verbessert werden durch ein Umsteigen auf Lebensmittel, die weniger gesättigte Fettsäuren enthalten (gesunde Alternativen). Die Obst- und Gemüsemenge könnte durch den Verzehr von einfacher zu konsumierenden Obst- und Gemüsesäften erhöht werden.

In dem in dieser Doktorarbeit beschriebenen Untersuchungsprojekt wurde davon ausgegangen, dass schon das Ersetzen einer geringen Zahl traditioneller Produkte durch gesunde Alternativen zu einem deutlichen Rückgang im Konsum gesättigter Fettsäuren und einer großen Zunahme des Konsums von Obst und Gemüse führen würde. Bezüglich gesättigter Fettsäuren wurde dies in einer Simulationsstudie untersucht. Hierzu wurden die Daten von 750 Teilnehmern einer niederländischen Ernährungsstudie genutzt. Bei jedem Teilnehmer wurden die drei Lebensmittel ermittelt, die den größten Beitrag zum Konsum gesättigter Fettsäuren lieferten und in der Simulation ersetzt durch die korrespondierende Menge dreier gesunder Alternativen. Basierend auf der Simulation steigt der Prozentsatz der Teilnehmer, die weniger als 10 Prozent der konsumierten Energie aus gesättigten Fettsäuren zu sich nahmen, von 23.3\% auf 86\%. Schlussfolgerung: Das Ersetzen einer kleinen Anzahl von Lebensmitteln durch gesunde alternative Produkte kann ein Weg sein, die Einnahme gesättigter Fettsäuren signifikant zu verringern und großen Einfluss haben auf die Zah derer, die sich an den Ernährungsempfehlungen orientieren (Kapitel 2).

Weil diejenigen Faktoren wenig bekannt waren, die den Ausschlag dafür geben, dass jemand bereit ist, eine gesunde Alternative zu probieren, wurde eine Studie in acht Fokusgruppen mit insgesamt 66 Teilnehmern durchgeführt. Das ,zum ersten Mal Ausprobieren eines alternativen Produktes' wird als erster notwendiger Schritt angesehen im Prozess der Integration dieses Lebensmittels in den täglichen Gebrauch. Die Teilnehmer erörterten eine große Zahl einflussreicher Faktoren. Um alle genannten Faktoren zu kategorisieren, wurde eine Einteilung in produkt-, personen-, und 
situationsgebundene Faktoren vorgenommen. Produktgebundene Faktoren sind u.a. der erwartete Geschmack des Produktes, seine Produktgruppenzugehörigkeit und sein Preis. Personengebundene Faktoren, die erörtert wurden, sind z.B. die Stärke der Lebensmittel-Neophobie der Teilnehmer, deren Geschmacksvorlieben und ihr Vertrauen in die eigenen Kochkünste. Beispiele für die situationsgebundenen Faktoren sind soziale Einflüsse und die Möglichkeit, das Lebensmittel überhaupt probieren zu können (Kapitel 3).

In einer Studie mit 326 Erwachsenen, die im Internet einen Fragebogen ausgefüllt haben, wurde erforscht, inwieweit die Teilnehmer gesunde alternative Produkte kannten und ob sie bereit waren, diese Produkte auszuprobieren. Insbesondere wurde dabei die Bedeutung der Lebensmittel-Neophobie untersucht. Zu diesem Zweck wurde auch die Zuverlässigkeit der in dieser Studie eingesetzten niederländischen Version eines im Original englischsprachigen Lebensmittel-Neophobie Fragebogens ermittelt. Die Interne Konsistenz des Fragebogens und die Test-Retest Zuverlässigkeit waren ausreichend. Im Durchschnitt kannten die Teilnehmer 7.9 der 15 Produkte, die in der Studie gebraucht wurden, und sie gaben an, einigermaßen bereit zu sein, diese Produkte einmal zu probieren. Die Teilnehmer, die auf dem Lebensmittel-Neophobie Fragebogen höhere Werte erzielten, kannten auch nur eine geringere Zahl der angebotenen gesunden Alternativen und waren zudem weniger bereit, diese einmal zu probieren. Verglichen mit hoch gebildeten Teilnehmern erzielten weniger gebildete Teilnehmer signifikant höhere Werte auf dem Lebensmittel-Neophobie Fragebogen (Kapitel 4).

Aufgrund der Resultate der ersten drei Studien wurden fünf Strategien entwickelt, ,das zum ersten Mal Ausprobieren eines gesunden alternativen Produktes' zu stimulieren. Zwei von diesen fünf Strategien wurden in randomisierten kontrollierten Studien mit einer Vor- und Nachmessung in Restaurants bewertet. Teilnehmer an diesen Studien wurden aufgefordert, an einem Mittagsbuffet Produkte zu wählen. Zur Wahl standen Sprudel, Brötchen, fettarme Margarine, Holländer Käse und wahlweise ein Stück Obst oder Gemüse. Außerdem wurde bei jedem Teilnehmer das Angebot am Buffet erweitert um eine von vier möglichen gesunden Alternativen, die da waren: eine sehr fettarme Margarine, eine fettarme Variante vom Holländer Käse und einem Obstoder Obst- und Gemüsesaft als Alternative zum Obst- oder Gemüsestück. 
Die erste Strategie, die getestet wurde, war der Einsatz eines Schildes mit Informationen zum Geschmack und Mundgefühl des jeweilig angebotenen alternativen Produkts. Im Informationstext wurde der Geschmack des alternativen Produktes verglichen mit dem Geschmack von Produkten, die hinlänglich als gemocht gelten. Diese Strategie wurde bei 396 Studenten getestet. Die Frage war, ob der Informationstext bei den Teilnehmern eine positivere Erwartung bezüglich des Geschmacks bewirken würde und ob mehr Teilnehmer die angebotene gesunde Alternative auswählen würden. Die erwartete Steigerung des Geschmacks konnte bei den Teilnehmern zwar nicht beobachtet werden, wohl aber hatte die experimentelle Gruppe die gesunde Alternative öfter gewählt als die Kontrollgruppe, die keine Geschmacksinformation sehen konnten (Kapitel 5).

Die zweite Strategie, die getestet wurde, war, den Teilnehmern in der experimentellen Gruppe die Möglichkeit zu geben, eine kleine Probe von der gesunden Alternative zu nehmen, bevor sie die Auswahl von Produkten am Buffet machen mussten. Diese Strategie wurde bei 197 Jugendlichen getestet. Die Ergebnisse zeigen, dass das Anbieten von kleinen Proben eine effektive Strategie ist, das Ausprobieren gesunder Alternativen zu stimulieren (Kapitel 6).

Im letzten Kapitel werden die wichtigsten Ergebnisse der durchgeführten Studien zusammengefasst. Die methodologischen Aspekte dieser Untersuchungen, etwa die Wahl von Studienpopulationen und die Qualität der verwendeten Messungen werden besprochen. Darauf aufbauend werden Empfehlungen für anschließende Schritte ausgesprochen, zum Beispiel die Implementierung der Strategien in Programme der gesundheitlichen Aufklärung und weitere Studien zur Rolle der LebensmittelNeophobie bei der Förderung gesunden Ernährungsverhaltens. Dieses Projekt war das erste, in dem die Anwendung und Bewertung des Ersetzens einzelner Lebensmittel im täglichem Essverhalten und die Rolle der Lebensmittel-Neophobie im Zentrum standen. Hierbei ergaben sich naturgemäß viele neue Fragen, aber die dargelegte neue Herangehensweise erscheint als fruchtbarer und in der Praxis brauchbarer Weg, die Essgewohnheiten der Niederländer zu verbessern (Kapitel 7). 